Aus der Abteilung Anaesthesiologie (Prof. Dr. med. M. Quintel)

im Zentrum Anaesthesiologie, Rettungs- und Intensivmedizin

der Medizinischen Fakultät der Universität Göttingen

\title{
QUANTIFIZIERUNG VON PROPOFOL IN DER ATEMLUFT MITTELS ENDTIDALER IONENMOBILITÄTSSPEKTROMETRIE
}

\author{
INAUGURAL - DISSERTATION \\ zur Erlangung des Doktorgrades \\ der Medizinischen Fakultät der \\ Georg-August-Universität zu Göttingen
}

vorgelegt von

Eike T. H. Carstens

aus

Braunschweig

Göttingen 2010 
Dekan: Prof. Dr. med. C. Frömmel

I. Berichterstatter: Prof. Dr. med. M. Quintel

II. Berichterstatter: Prof. Dr. med. von Ahsen

III. Berichterstatter: Priv.-Doz. Dr. rer. Nat. Dihazi

Tag der mündlichen Prüfung: 27. Juni 2011 


\section{INHALTSVERZEICHNIS}

\section{Abbildungsverzeichnis}

\section{Tabellenverzeichnis}

1 Einleitung 1

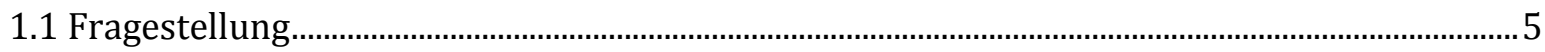

2 Theoretischer Hintergrund $\quad 6$

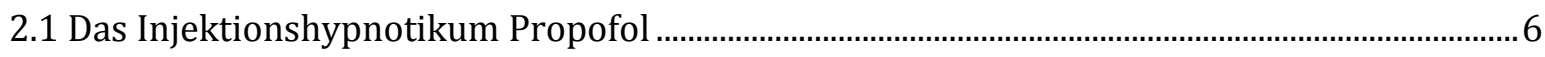

2.2 Allgemeine Anforderungen an Techniken der Atemgasanalyse................................................. 10

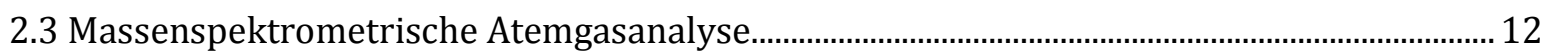

2.3.1 Exspiratorische Propofoldetektion mittels massenspektrometrischer Verfahren......... 16

2.4 Grundlagen der Ionenmobilitätsspektrometrie ……............................................................. 17

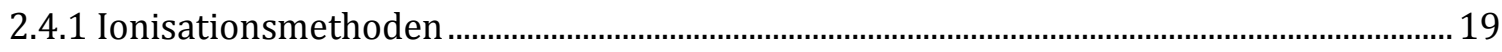

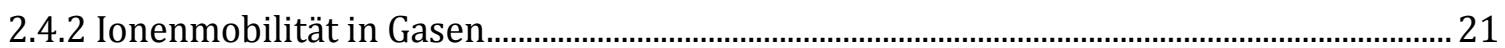

2.4.3 Kopplung der Ionenmobilitätsspektrometrie mit gaschromatographischen

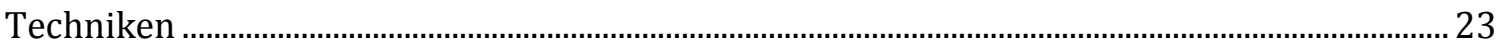

3 Material und Methoden $\quad 25$

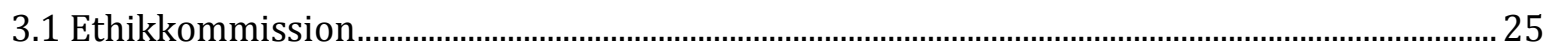

3.2 Verwendetes Ionenmobilitätsspektrometer................................................................................ 25

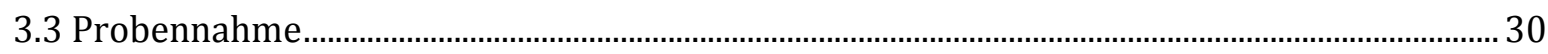

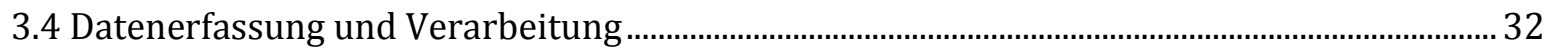

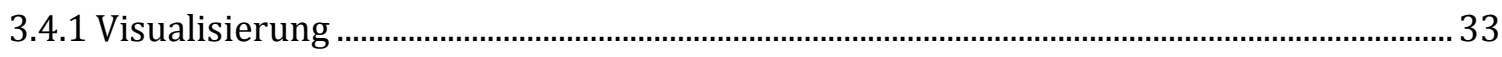

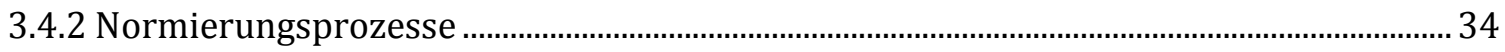

3.4.3 Auswertung 


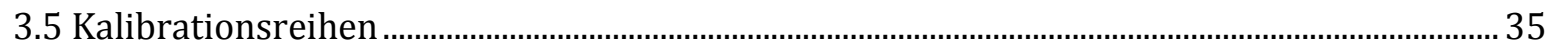

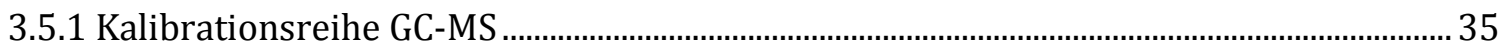

3.5.2 Kalibrationsreihe BR-MCC-IMS ………….............................................................................. 36

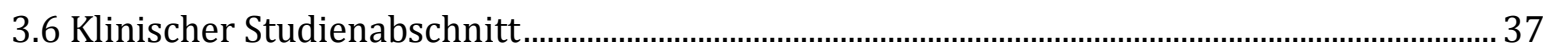

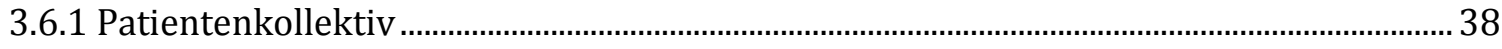

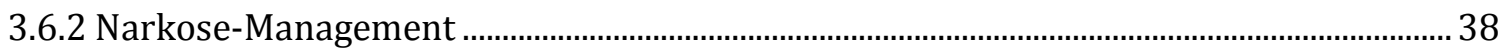

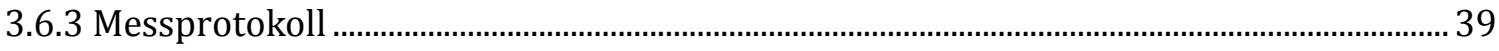

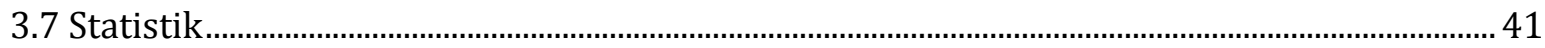

$\begin{array}{ll}4 \text { Ergebnisse } & 43\end{array}$

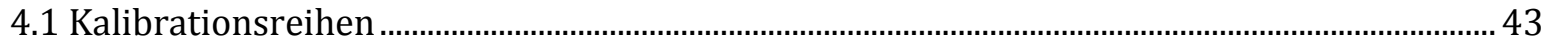

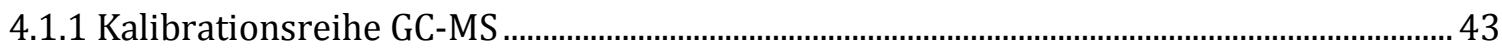

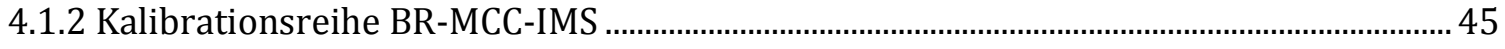

4.2 Klinische Untersuchung der plasmatischen und exspiratorischen Propofol-Konzentration

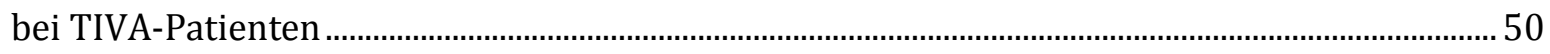

5 Diskussion $\quad 57$

5.1 Identifizierung von Propofol in der Exspirationsluft .......................................................................... 58

5.2 Quantifizierung von Propofol in der Exspirationsluft.....................................................................59

5.3 Erfassung von Fragmenten und Metaboliten des Propofols ......................................................... 61

5.4 Korrelation zwischen exspiratorischer und intravasaler Propofol-Konzentration ............... 63

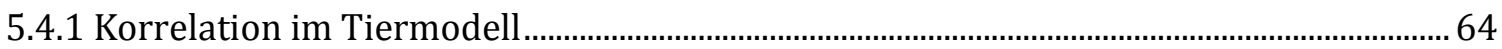

5.4.2 Korrelation in humanen Patientenkollektiven......................................................................... 64

5.5 Der Aspekt Zeit in der Atemgasanalyse ............................................................................................. 67

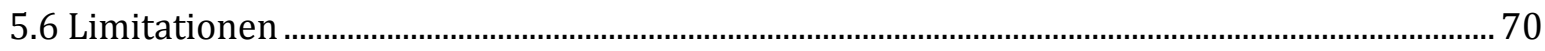

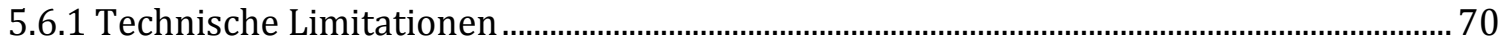


5.6.2 Pharmakokinetische Limitationen .............................................................................................. 73

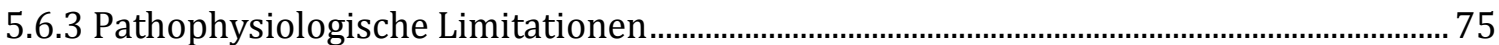

6 Zusammenfassung $\quad 76$

$\begin{array}{ll}7 \text { Abkürzungsverzeichnis } & 79\end{array}$

8 Literaturverzeichnis $\quad 83$ 


\section{ABBILDUNGSVERZEICHNIS}

Abbildung 1. Strukturformel Propofol (2,6 Di-isopropyl-phenol) ……………........................................6

Abbildung 2. Mamilläres 3-Kompartiment-Modell für i.v. Anästhetika ..................................................8

Abbildung 3. Übersicht direkte und indirekte Massenspektrometrie ................................................. 15

Abbildung 4. Schematische Darstellung eines Ionenmobilitätsspektrometers ...................................19

Abbildung 5. Schema eines Ionenmobilitätsspektrums des verwendeten Nickel-Ionenmobilitäts-

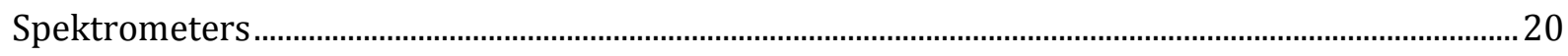

Abbildung 6. Querschnitt durch eine Multikapillarsäule ............................................................................ 24

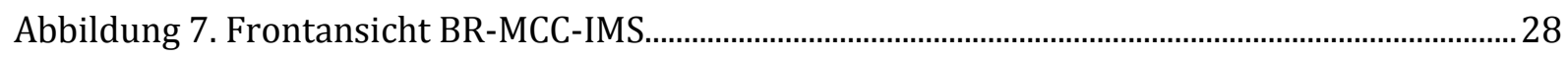

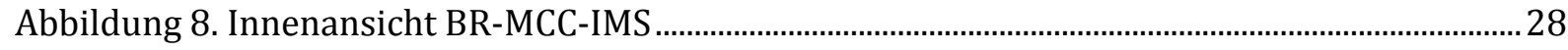

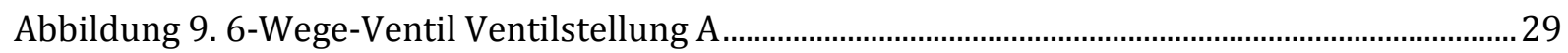

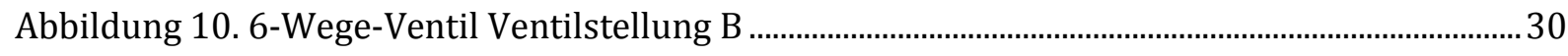

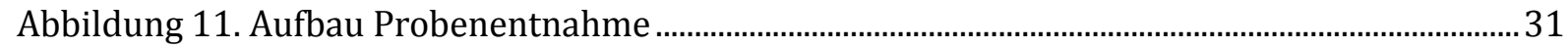

Abbildung 12. Schematische Darstellung der $\mathrm{CO}_{2}$-gesteuerten Probennahme................................... 32

Abbildung 13. Zweidimensionale Darstellung der Messergebnisse mittels

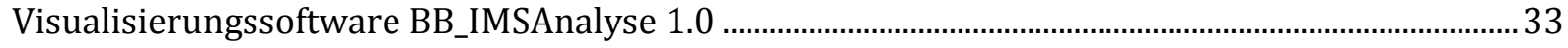

Abbildung 14. Schematische Darstellung Messablauf ............................................................................ 40

Abbildung 15. Gaschromatogramm der Kalibrationsreihe GC-MS........................................................ 43

Abbildung 16. Regressionsanalyse 1. Art der Kalibrationsreihe GC-MS ............................................ 44

Abbildung 17. Regressionsanalyse 1. Art der Kalibrationsreihe BR-MCC-IMS .................................... 46

Abbildung 18. BR-MCC-IMS Spektrum Propofol-Area........................................................................ 49

Abbildung 19. Regressionsanalyse 2. Art Patientenkollektiv .................................................................... 54

Abbildung 20. Passing-Bablok-Regression der nach Mayevsky et al. (2004) normierten

Messwerte. 
Abbildung 21. Bland-Altman-Diagramm Patientenkollektiv, modifiziert nach Mayevsky et al. (2004) .56

Abbildung 22. Logarithmische Darstellung des Einflusses der Säulentemperatur auf die Retentionszeit von Propofol 68

Abbildung 23. Schematische Darstellung eines in der Anästhesiologie gebräuchlichen Kreissystems für Respiratoren.. .73 


\section{TABELLENVERZEICHNIS}

Tabelle 1. Chemische Eigenschaften von Propofol........................................................................................

Tabelle 2. Erwünschte Wirkungen Propofol.............................................................................................

Tabelle 3. Ionisationsmethoden in der Massenspektrometrie ............................................................16

Tabelle 4. Übersicht Einstellungen Versorgungseinheit und Säulenheizung des verwendeten BR-

MCC-IMS . .26

Tabelle 5. Hauptparameter des verwendeten BR-MCC-IMS .27

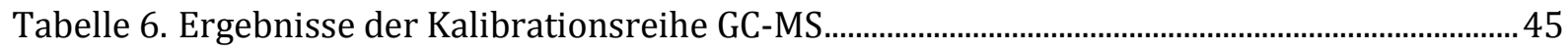

Tabelle 7. Ergebnisse der Kalibrationsreihe BR-MCC-IMS . .47

Tabelle 8. Signalvisualisierung Kalibrationsreihe BR-MCC-IMS. Dargestellt sind in aufsteigender Konzentration die gemessenen Signale 48

Tabelle 9. Zusammensetzung des Patientenkollektivs. .50

Tabelle 10. Übersicht Patientenkollektiv mit Alter, Geschlecht, Diagnose und Operation .51

Tabelle 11. Ergebnisse der Patientenmessungen . .53

Tabelle 12. Zusammenfassung der statistischen Verfahren .56 


\section{EINLEITUNG}

Der Begriff „Anästhesie“ leitet sich vom altgriechischen „ $\alpha v \alpha \iota \sigma \theta \eta \sigma \iota \alpha$ " ab, was so viel wie NichtEmpfindung bedeutet. Ziel der Anästhesie ist es, Eingriffe in die Körperintegrität (Operationen, invasive Diagnostik) zu ermöglichen, was allgemein als Narkose bezeichnet wird. Grundlage hierfür ist die Ausschaltung sowohl der Schmerzwahrnehmung (Analgesie) als auch des Bewusstseins (Hypnose) der Patienten. Heutzutage wird eine Narkose üblicherweise durch die Kombination mehrerer Substanzen erzeugt. Durch die Kombination der Medikamente kann dank eines additiven Effektes eine ausreichende Wirkung bei vertretbarem Nebenwirkungsprofil erzielt werden. Zur Analgesie wird in der Regel ein Opioidanalgetikum eingesetzt. Für die Ausschaltung des Bewusstseins stehen dem Anästhesisten verschiedene Pharmaka aus der Gruppe der Hypnotika zur Verfügung.

Hypnotika werden in der Anästhesie zumeist auf zwei Wegen appliziert, inhalativ und intravenös (i.v.). Als Inhalationshypnotika sind heute Stickoxydul $\left(\mathrm{N}_{2} 0\right)$ sowie halogenierte Kohlenwasserstoffe (Halothan) und vor allem halogenierte Äther (Gruppe der Flurane) gebräuchlich. Wird auf inhalative Substanzen verzichtet und die Narkose ausschließlich durch i.v.-Medikamente erreicht, spricht man von einer total intravenösen Anästhesie (TIVA). Als Injektionshypnotika können Barbiturate (Thiopental, Methohexital), Etomidat, Ketamin oder Propofol eingesetzt werden. Welche Substanz, inhalativ oder intravenös, verwendet wird, obliegt der Entscheidung des Anästhesisten. Patientenindividuell erfolgt die Substanzauswahl nach bestehenden Vorerkrankungen und Kontraindikationen sowie orientiert an den Anforderungen des Eingriffs. Darüber hinaus sind ökologische (Wirkung der Inhalationshypnotika auf den Treibhauseffekt) und wirtschaftliche Faktoren zu beachten. Neben einem Hypnotikum wird weiterhin ein Analgetikum und bei Bedarf ein Muskelrelaxans verwendet.

Die Qualität einer Narkose hängt von der Dosierung der verwendeten Substanzen ab. Hierbei ist zu beachten, dass sich während eines invasiven Eingriffs unterschiedliche Stimulationsphasen abwechseln, die eine dynamische Adaptierung der Narkose erfordern. Eine Narkose sollte desweiteren orientiert an dem Grundsatz „so viel wie nötig, so wenig wie möglich“ gesteuert werden. Dies hilft dosisabhängige Nebenwirkungen der verwendeten Medikamente zu 
minimieren und ein rasches Aufwachen aus der Narkose nach Beendigung des invasiven Eingriffs zu ermöglichen. Die Steuerung der Narkosetiefe stellt somit eine der zentralen Aufgaben der perioperativen Anästhesie dar und erfordert insbesondere eine exakte Dosierung des Hypnotikums.

Da bis zum heutigen Zeitpunkt zuverlässige Verfahren für die Bestimmung der Narkosetiefe fehlen, erfolgt die Dosierung des Hypnotikums auf der Basis von hämodynamischen und klinischen Parametern.

Methoden, die Narkosetiefe durch eine Erfolgskontrolle am zentralen Nervensystem (ZNS) als Zielorgan zu beurteilen, konnten sich bisher nicht als Standard durchsetzen. Im Bereich dieses neurophysiologischen Monitorings ist derzeit die Bispektralanalyse führend. Hierfür werden mittels Elektroenzephalografie die Hirnaktivitäten gemessen und über einen mathematischen Algorithmus der Bispektral-Index mit Werten zwischen 0 und 100 ermittelt. Aus dem Jahresbericht 2008 der vertreibenden Firma (Aspect Medical Systems, Inc., Norwood, Massachusetts, USA) geht zwar hervor, dass bereits 19\% aller in den Vereinigten Staaten durchgeführten Narkosen mittels Bispektral-Index überwacht wurden (Chamoun 2009). Dem gegenüber stehen jedoch kritische Publikationen, welche sich mit fehlerhaften Bestimmungen des Bispektral-Index (Duarte und Saraiva 2009) beziehungsweise dessen Aussagekraft bezüglich der intraoperativen Wahrnehmung des Patienten (Avidan et al. 2008) auseinandersetzen.

Einen Parameter für die Steuerung der Narkosetiefe könnte die Konzentrationsbestimmung des jeweiligen Medikamentes darstellen. Ein solches Drug-Monitoring würde dem Anästhesisten zeigen, ob sich die Konzentration des Hypnotikums innerhalb des therapeutischen Bereichs befindet. Über die Position innerhalb dieses Bereiches könnte die Konzentration den variablen Reizen des Eingriffes angepasst werden.

Lediglich für die Inhalationsanästhetika existiert bisher ein Goldstandard zur Konzentrationsbestimmung. Hier dient die alveoläre Konzentration als indirektes Maß für die Konzentration im Blut und am zentralen Nervensystem als Zielorgan. Dies ist möglich, da sich nach dem Henry-Gesetz die Partialdrücke im Blut, dem Gehirn und den Alveolen unter 
konstanten Bedingungen angleichen. Die Messung erfolgt durch in Beatmungsgeräte integrierte Infrarot-Sensoren. Diese bestimmen kontinuierlich den Partialdruck des Inhalationsanästhetikums im Atemgas. Für die verschiedenen Substanzen wurden unterschiedliche minimale alveoläre Konzentrationen (minimal alveolar concentration, MAC) ermittelt, die eine ausreichende Anästhesie bei definiertem Reiz (Hautschnitt) ergeben. Die MAC-Werte dienen dem Anästhesisten als Richtwerte für die Steuerung der Narkose.

Für das häufig verwendete Injektionshypnotikum Propofol besteht gegenwärtig keine Möglichkeit, die Konzentration während der Narkose routinemäßig zu bestimmen. Eine Konzentrationsbestimmung aus dem Medium Blut ist zwar technisch möglich, wäre jedoch zeitintensiv und ohne unmittelbaren Nutzen für die Narkosesteuerung.

Kommerziell erhältlich sind derzeit lediglich computergesteuerte Perfusoren (target-controlled infusion, TCI), die auf den Grundlagen der pharmakokinetischen und pharmakodynamischen Eigenschaften von Propofol patientenindividuell den Zielbereich und die hierfür erforderliche Dosierung errechnen. Diese Kalkulation basiert auf Alter, Größe und Gewicht des Patienten. Für die Berechnung sind gegenwärtig verschiedene Modelle (Marsh- (Marsh et al. 1991), modifiziertes Marsh- (Struys et al. 2000) und Schnider-Modell (Schnider et al. 1999)) gebräuchlich. Diese unterscheiden sich zum Teil erheblich, was sich beispielsweise in ungleichen Bolus-Gaben zur Narkoseeinleitung zeigt (Enlund 2008). In einem Review über 20 Studien mit insgesamt 1759 Patienten konnte kein Vorteil der TCI-Technologie gegenüber klinisch gesteuerten Narkosen festgestellt werden (Leslie et al. 2008).

Eine mögliche Alternative zur Propofol-Konzentrationskontrolle mittels TCI-Perfusoren beziehungsweise Blutuntersuchungen stellt die Atemgasanalytik dar. Harrison et al. gelang 2003 die massenspektrometrische Identifizierung von intravenös appliziertem Propofol in der Exspirationsluft.

Auf den Ergebnissen von Harrison et al. (2003) aufbauende Studien (Grossherr et al. 2006, Hornuss et al. 2007, Takita et al. 2007, Miekisch et al. 2008) befassten sich mit der massenspektrometrischen Quantifizierung von Propofol in der Exspirationsluft. Hierdurch sollte 
die Möglichkeit einer Korrelation zur Plasma-Konzentration ermittelt werden, welche ein exspiratorisches Drug-Monitoring des Injektionshypnotikums ermöglichen würde. Die Ergebnisse sind insgesamt vielversprechend, allerdings konnte bis heute keines der verwendeten massenspektrometrischen Verfahren in Gänze überzeugen.

Eine Alternative $\mathrm{zu}$ den massenspektrometrischen Verfahren stellt die Ionenmobilitätsspektrometrie dar. Die Ionenmobilitätsspektrometrie basiert auf Arbeiten aus dem späten 19. und frühen 20. Jahrhundert. Röntgen, Townsend und Philos, Langevin sowie Thomsen und Rutherford erforschten die Bildung von Ionen in Luft und deren Beweglichkeit in elektrischen Feldern. Durch die intensive Arbeit von Karasek fanden in den siebziger Jahren die theoretischen Erkenntnisse praktischen Einzug in die analytische Chemie (Stach und Baumbach 2002). Revercomb und Mason fassten erstmals 1975 den Forschungsstand der noch als GasElektrophorese bzw. Plasmachromatographie bezeichneten Methode in einem Review zusammen (Revercomb und Mason 1975). Neben der zunächst fast ausschließlich militärischen Nutzung zur Detektion von chemischen Kampfstoffen und Sprengstoffen weitete sich das Anwendungsspektrum zunehmend auf die Drogenerkennung und die Prozesskontrolle aus (Hill et al. 1990, Roehl 1991, Baumbach und Eiceman 1999, Eiceman und Karpas 2005). Ein Einsatz zur medizinischen Atemgasanalytik, mit dem Ziel der Diagnostik sowohl pulmonaler als auch extrapulmonaler pathologischer Prozesse, ist seit den 1990er Jahren Gegenstand verschiedener Forschungsarbeiten (Baumbach und Eiceman 1999, Ruzsanyi et al. 2005, Westhoff et al. 2007, Baumbach 2008, Vautz und Baumbach 2008). 


\subsection{FRAGESTELLUNG}

Die vorliegende Arbeit befasst sich mit einer nicht-massenspektrometrischen Technik der Atemgasanalyse. Mittels Ionenmobilitätsspektrometrie wurde die Möglichkeit der qualitativen und quantitativen Bestimmung des Injektionshypnotikums Propofol in der humanen Exspirationsluft unter totaler intravenöser Anästhesie untersucht.

Das Ziel der Studie ist die Evaluierung des Einsatzes der Ionenmobilitätsspektrometrie zum Zweck des exspiratorischen Drug-Monitorings von Propofol-Serumkonzentrationen. Hierfür sind folgende Fragen zu beantworten:

1. Ist eine Detektion des Injektionshypnotikums Propofol in der Exspirationsluft mittels Ionenmobilitätsspektrometrie möglich?

2. Ist eine Quantifizierung des detektierten Propofols mittels Ionenmobilitätsspektrometrie möglich?

3. Ist eine Bestimmung der intravasalen Propofol-Konzentration auf Grundlage der Atemgasanalyse mittels Ionenmobilitätsspektrometrie möglich?

Die Studie ist in zwei Abschnitte unterteilt. Präklinisch wurden zunächst Kalibrationsreihen zur Bestimmung der Propofol-Konzentration in Serum und Gasgemisch durchgeführt. Die Analyse der Serumproben erfolgte mittels Gaschromatographie-Massenspektrometrie. Für die Untersuchung der gasförmigen Proben wurde ein Ionenmobilitätsspektrometer eingesetzt. Im klinischen Abschnitt der Studie erfolgte die Bestimmung der intravasalen Serum-PropofolKonzentration und endexspiratorischen Propofol-Konzentrationen unter TIVA in einem chirurgischen Patientenkollektiv ( $\mathrm{n}=13$ ). Die Erhebung der Daten erfolgte prospektiv. 


\section{THEORETISCHER HINTERGRUND}

In diesem Kapitel wird zunächst das Injektionshypnotikum Propofol hinsichtlich chemischer und pharmakologischer Eigenschaften besprochen. Im Folgenden werden die allgemeinen Anforderungen an die Atemgasanalytik dargestellt. Die Massenspektrometrie, als eines der gebräuchlichsten Verfahren zur Atemgasanalytik, wird in einem eigenen Unterkapitel vorgestellt. Abschließend folgt ein Grundlagenkapitel über die Ionenmobilitätsspektrometrie als alternatives Verfahren zur Atemgasanalytik.

\subsection{DAS INJEKTIONSHYPNOTIKUM PROPOFOL}

Das Hypnotikum Propofol (2,6-Di-isopropyl-phenol) konnte erstmals 1977 durch Kay und Rolly synthetisiert werden. Seit der europäischen Marktzulassung 1988 stellt Propofol eine Alternative zu den Inhalationsnarkotika dar. Bei der Substanz handelt es sich um ein Phenolderivat mit der hierfür charakteristischen Ringstruktur (siehe Abbildung 1).<smiles>CC(C)c1cccc(C(C)C)c1O</smiles>

Abbildung 1. Strukturformel Propofol (2,6 Di-isopropyl-phenol). (Quelle: Datenbank der United States National Library of Medicine; http://chem.sis.nlm.nih.gov/chemidplus/chemidlite.jsp; Downloaddatum 17.11.2009) 
Die chemischen Eigenschaften von Propofol sind in Tabelle 1 zusammengefasst.

\begin{tabular}{c|c} 
Summenformel & $\mathrm{C}_{12} \mathrm{H}_{18} \mathrm{O}$ \\
CAS-Nummer & $2078-54-8$ \\
Molare Masse & $178,28 \mathrm{~g}^{*} \mathrm{~mol}^{-1}$ \\
Schmelzpunkt & $18^{\circ} \mathrm{C}$ \\
Siedepunkt & $256^{\circ} \mathrm{C}$ \\
Dissoziationskonstante $\left(\mathrm{pK}_{\mathrm{s}} 20^{\circ} \mathrm{C}\right)$ & 11,1 \\
Löslichkeit (Wasser $\left.25^{\circ} \mathrm{C}\right)$ & $124 \mathrm{mg} / \mathrm{L}$ \\
Dampfdruck $\left(25^{\circ} \mathrm{C}\right)$ & $0,00305 \mathrm{mmHg}$ \\
Henry-Konstante $\left(25^{\circ} \mathrm{C}\right)$ & $2,12 * 10^{-06} \mathrm{~m}^{3 * \mathrm{~Pa} / \mathrm{mol}}$ \\
\hline
\end{tabular}

Tabelle 1. Chemische Eigenschaften von Propofol. (Quelle: Datenbank der United States National Library of Medicine; http://chem.sis.nlm.nih.gov/chemidplus/chemidlite.jsp; Downloaddatum 17.11.2009)

Das Phenolderivat Propofol ist wasserunlöslich und wird daher in einer Lipidemulsion gelöst. Erhältlich sind sowohl einprozentige wie auch zweiprozentige Emulsionen. Nach intravenöser Applikation geht Propofol zu 98 \% eine Proteinbindung ein. Propofol wird überwiegend in der Leber durch Sulfatkonjugation und Glukuronidierung metabolisiert (Ostwald 2004). Neben dem hepatischen Metabolismus konnte auch die Lunge als Ort der Transformation identifiziert werden (Dawidowicz et al. 2000). Die Elimination der inaktiven Metabolite erfolgt über die Niere (Ostwald 2004). Zu einem nicht genau bekannten Anteil wird intaktes Propofol und auch die inaktiven Metabolite über die Lunge eliminiert (Harrison et al. 2003).

Für das Verständnis der Pharmakokinetik von Propofol wird das für i.v.-Anästhetika gebräuchliche 3-Kompartiment-Modell herangezogen (Abbildung 2). 


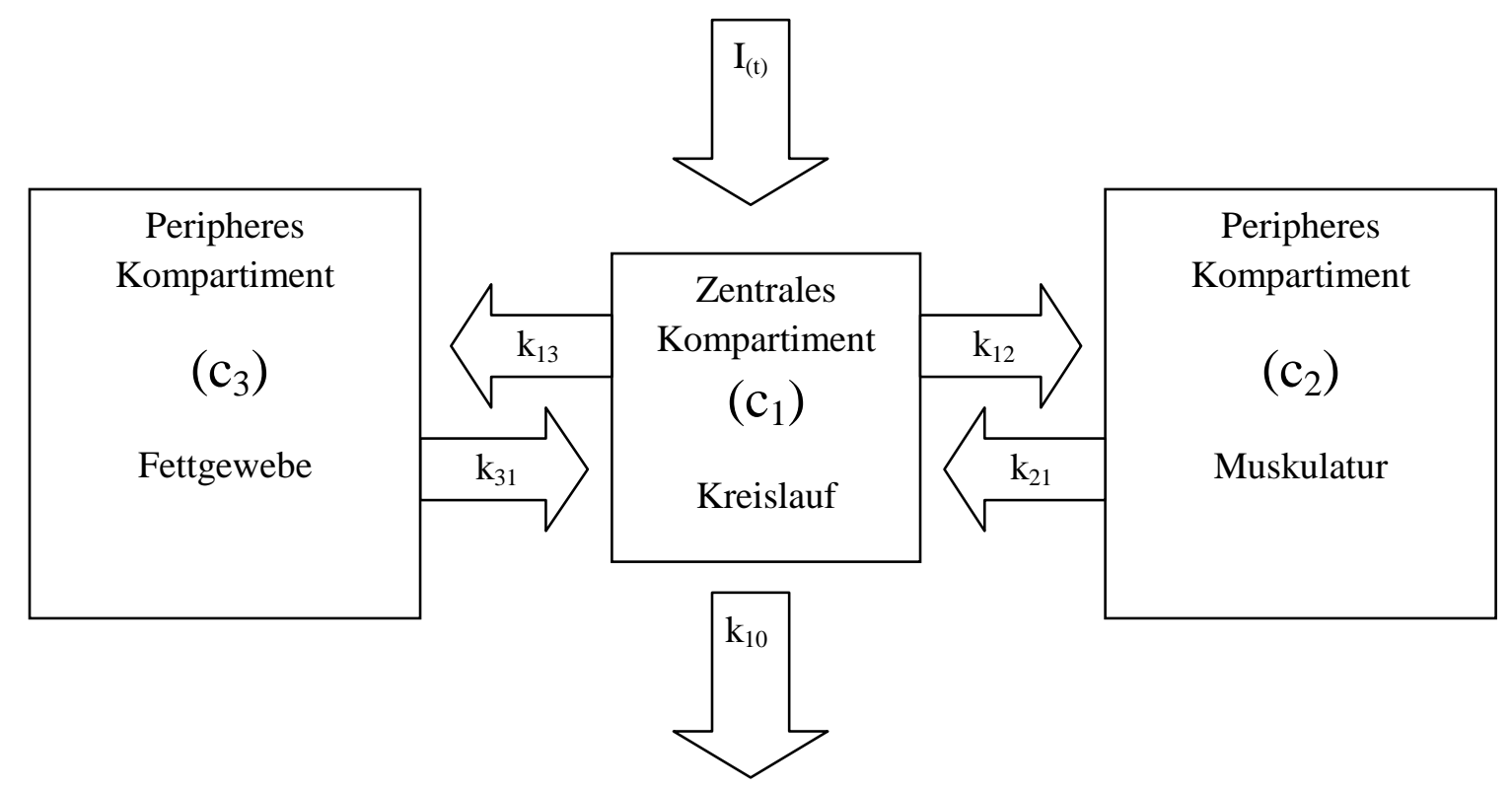

Elimination

Abbildung 2. Mamilläres 3-Kompartiment-Modell für i.v. Anästhetika. $I(t)=$ Medikamentenzufuhr pro Zeit, $c_{x}=$ Kompartiment X, $\mathrm{k}_{\mathrm{xy}}=$ Transferkonstante zwischen den Kompartimenten X und Y (modifiziert nach Schüttler und Schwilden 2004 S. 197)

Das 3-Kompartiment-Modell besagt, dass ein Pharmakon sich zwischen Applikation und Elimination charakteristisch und ohne Änderung der Gesamtmenge in ein zentrales ( $\left.c_{1}\right)$ und zwei periphere Kompartimente verteilt. Bei den peripheren Kompartimenten wird zwischen einem „flachen“, schnell äquilibrierenden ( $c_{2}$, Muskulatur) und einem „tiefen“, langsam äquilibrierenden ( $\mathrm{c}_{3}$, Fettgewebe $)$ Kompartiment unterschieden. Für die peripheren Kompartimente sind pharmakonabhängige Konstanten definiert, mit denen der Transfer zwischen dem jeweiligen peripheren und zentralen Kompartiment beschrieben wird. Es erfolgt kein direkter Transfer zwischen den peripheren Kompartimenten. Die Elimination erfolgt ausschließlich aus dem zentralen Kompartiment. Ausschließlich die freie Substanzmenge im zentralen Kompartiment ist an der Wirkung eines Pharmakons beteiligt (Schüttler und Schwilden 2004).

Die Wirkung von Propofol ist in hohem Maße auf eine direkte Aktivierung von $\gamma$ Aminobuttersäure-Rezeptoren Typ A und einer damit verbundenen Erhöhung der Leitfähigkeit von Chloridionen-Kanälen zurückzuführen. Das Hypnotikum besitzt keinen analgetischen Effekt und muss daher zur TIVA in Kombination mit einem Analgetikum eingesetzt werden. Neben der hypnotischen Wirkung scheint Propofol einen psychotropen Effekt zu vermitteln, der sich 
positiv auf das Einschlaf- und Aufwachverhalten der Patienten auswirkt. Weitere erwünschte Wirkungen für den anästhesiologischen Einsatz (Ostwald 2004) sind in Tabelle 2 zusammengefasst.

\begin{tabular}{c|c}
\hline Organsystem & Wirkung \\
\hline Zentrales Nervensystem & Senkung des zerebralen Sauerstoffbedarfs \\
Respiratorisches System & Senkung des intrakraniellen Drucks \\
& Atemdepression (Apnoe) \\
Gastrointestinaltrakt & Bntiemetisch \\
\hline
\end{tabular}

Tabelle 2. Erwünschte Wirkungen Propofol.

Neben diesen erwünschten Effekten kann es bei der Verwendung von Propofol auch zu unerwünschten Arzneimittelwirkungen (UAW) kommen. Propofol verfügt dosisabhängig über einen ausgeprägt kardiovaskulären Effekt. Die Senkung des peripheren Gefäßwiderstandes und die negativ inotrope Wirkung am Myokard sorgen für einen Abfall des mittleren arteriellen Drucks. Propofol senkt den Sympathikotonus und reduziert den Barorezeptorreflex. Folge dieser kardiovaskulären Effekte kann eine akut behandlungsbedürftige hämodynamische Instabilität sein (Ostwald 2004, Ebert 2005).

Eine weitere dosisabhängige Komplikation stellt die intraoperative Wahrnehmung (Anaesthesia awareness) der Patienten dar. Bei zu geringer Dosierung besteht die Möglichkeit, dass die Sinneswahrnehmung der Patienten während der Operation einsetzt. Studien ermittelten für die Anaesthesia awareness eine Inzidenz von 0,1 bis 0,2\% (Bruhn et al. 2006). Psychologisch relevante Folgen können auftreten, aus denen Regressansprüche gegenüber dem behandelnden Arzt hergeleitet werden können (Domino et al. 1999). 
Die Tatsache, dass relevante UAW sowohl bei einer zu geringen als auch einer zu hohen Konzentration von Propofol auftreten können, verdeutlicht die Notwendigkeit einer sorgfältigen Dosierung. Die Blutkonzentration sollte für chirurgische Eingriffe zwischen 2,5 und $8 \mu \mathrm{g} / \mathrm{mL}$ betragen. Dieser Zielbereich wird von der Analgetikakonzentration und dem Schmerzreiz beeinflusst (Ostwald 2004).

\subsection{AlLGEMeine ANForderungen AN TECHNiKen DER ATEMGASANALYSE}

Die Exspirationsluft des Menschen enthält neben den Hauptbestandteilen Kohlendioxid, Stickstoff, Sauerstoff, Wasser und diverser Edelgase individuell mehr als 500 unterschiedliche flüchtige organische Verbindungen (volatile organic compounds, VOC) (Miekisch et al. 2004). Die meisten VOC in der Atemluft sind Stoffwechselprodukte, welche sowohl vom Blut (und damit auch aus anderen Organen mit Blut als Transportmedium) mittels passiven Transports durch die alveolaren Membranen in die Exspirationsluft gelangen, als auch im Lungengewebe selbst entstehen. Die Lunge als Ausscheidungsorgan entfernt nicht nur endogene Stoffe über die Exspirationsluft aus dem Körper, sondern auch von außen zugeführte Substanzen. Dies gilt sowohl für pulmonal aufgenommene Stoffe (Inhalationsanästhetika) wie für oral zugeführte Substanzen (z.B. Ethanol).

Grundlage dieser Ausscheidung ist die Lösungseigenschaft der volatilen Substanzen in einer Flüssigkeit. Beschrieben wird das Lösungsverhalten durch das Henry-Gesetz:

$$
p_{\text {partial }}=k_{h} \times c_{l}
$$

Die Henry-Konstante $\left(\mathrm{k}_{\mathrm{h}}\right)$ ist substanzspezifisch. Die Konzentration in der Lösung $\left(\mathrm{c}_{\mathrm{l}}\right)$ der volatilen Substanz ist direkt proportional dem Partialdruck ( $\left.p_{\text {partial }}\right)$ in der angrenzenden Gasphase. 
Das Ziel der Atemgasanalytik zu diagnostischen Zwecken muss sowohl die qualitative wie auch quantitative Bestimmung der einzelnen VOC sein, um aus der komplexen Matrix, welche die Exspirationsluft darstellt, Schlüsse auf physiologische oder pathologische Prozesse zu ermöglichen.

Die Konzentrationen der VOC sind zum Teil so gering, dass eine Detektion in der totalen Exspirationsluft durch eine Verdünnung mit Totraumluft schwierig und möglicherweise fehlerbehaftet ist, weshalb gezielt Alveolarluft untersucht werden sollte (Schubert et al. 2001). Selbst in idealen Proben erfordert die geringe Konzentration der nachzuweisenden VOC, welche zum Teil nur in einer Größenordnung von wenigen ppt (parts per trillion) bis ppb (parts per billion) in einem komplexen Gasgemisch vorliegen, eine niedrige Nachweisgrenze der Messmethode. Des Weiteren muss ein Verfahren zur Atemgasanalyse möglichst unanfällig für äußere Störfaktoren (Druck, Temperatur, Feuchtegehalt, etc.) sein (Miekisch et al. 2004). Die idealerweise nicht-invasive Probengewinnung muss in einem geschlossen System erfolgen, um Beimengungen nicht humaner VOC aus der Umgebungsluft $\mathrm{zu}$ verhindern. Schnell durchführbare Untersuchungsmethoden, die zu reproduzierbaren Ergebnissen führen, können den Einsatz als point-of-care-Analyse ermöglichen. Hierfür sind transportable und patientennah einsetzbare, miniaturisierte Geräte notwendig.

Seit den 1970er Jahren gab es eine Vielzahl verschiedener methodischer Ansätze, die sich mit der Atemgasanalytik befassten (Buszewski et al. 2007, Amorim und Cardeal 2007, Di Francesco et al. 2005, Miekisch et al. 2004, Kharitonov und Barnes 2001). Die Mehrzahl der Techniken, die zur Atemgasanalyse im Allgemeinen und zur Propofoldetektion im Speziellen eingesetzt werden, basiert auf massenspektrometrischen Verfahren. Daher wird diese Grundtechnik mit ihren Modifikationen im folgenden Kapitel vorgestellt. 


\subsection{MASSENSPEKTROMETRISCHE ATEMGASANALYSE}

Durch die Verwendung eines Massenspektrometers (MS) ist der qualitative wie quantitative Nachweis sehr geringer Substanzmengen bis in den Femtogrammbereich möglich. In der Atemgasanalyse kommen verschiedene Techniken beziehungsweise Kopplungen der Massenspektrometrie zum Einsatz.

Grundsätzlich besteht ein Massenspektrometer aus Probeneinlass, Ionisationsraum, Massenfilter und Detektor. Die ionisierten Bestandteile einer Probe werden in dem Massenfilter nach ihrem Verhältnis von Masse zu Ladung aufgetrennt. Um eine Kollision der ionisierten Analyten zu vermeiden, wird innerhalb des Massenspektrometers ein Hochvakuum erzeugt (Gey 2008). Die Auftrennung geschieht je nach MS durch ein Hochfrequenz-, Magnet- oder elektrisches Feld. Im Anschluss an diese Trennung erfolgt die Detektion. Als Detektoren werden hauptsächlich Sekundärelektronenvervielfacher eingesetzt, aber auch Faraday-Auffänger oder Photomultiplier finden Verwendung (Budzikiewicz 1998). Die Detektoren registrieren das aus der Auftrennung resultierende Masse-Ladungs-Verhältnis $[\mathrm{m} / \mathrm{z}]$ der ionisierten Substanzen. Da die Ladung der Analytionen in der Regel gleich 1 ist, lässt sich aus dem Masse-LadungsVerhältnis die molare Masse ableiten. Diese ermöglicht Schlüsse auf die Summenformel des Moleküls. Massenspektren-Bibliotheken vereinfachen die Identifizierung der Substanzen (Gey 2008). In der Literatur hat sich die Verwendung der Atom- bzw. Molekülmasse [u] für mittels Massenspektrometrie identifizierte Substanzen durchgesetzt. Der Detektor registriert darüber hinaus noch die Quantität der eintreffenden Signale. Gemessen wird diese entweder als die Anzahl der auftreffenden Ionen pro Sekunde (counts per second, CPS) oder als Totalionenstrom (total ion current, TIC). Die unterschiedlichen Einheiten resultieren aus verschiedenen Aufnahmetechniken. Es werden zwei Modi unterschieden. Im SCAN-Modus werden innerhalb eines festgelegten Massebereichs alle Signale detektiert und durch Summieren der TIC gebildet (Gey 2008). Die Einheit CPS wird im sogenannten SIM-Modus (single/selected ion monitoring, SIM) ermittelt. Hierbei erfolgt eine quantitative Beurteilung eines einzelnen Ions bzw. ausgewählter Ionen, deren Häufigkeit pro Zeiteinheit detektiert wird.

Neben den eingesetzten Massenfiltern und Detektoren unterscheiden sich die verschiedenen Methoden der Massenspektrometrie vor allem nach der Art der Ionisation. Die gasförmige Probe wird hierfür über ein Einlasssystem in den Ionisationsraum eingebracht. Die Probenmoleküle 
werden dort durch Zufuhr von Energie ionisiert. Es stehen verschiedene Ionisationsmethoden zur Verfügung, die sich in harte und weiche Methoden unterteilen lassen (Gey 2008).

Bei den harten Ionisationsmethoden ist die zugeführte Energie so hoch, das es neben der Ionisation zu einer Fragmentierung der Probenmoleküle kommt. Diese Fragmentierungen sind von der chemischen Struktur des Moleküls abhängig. Die Fragmente können für die Auswertung des Massenspektrums weitere wichtige Informationen zur Identifizierung des Stoffes liefern. Ein Beispiel für die harten Ionisationsmethoden ist die Elektronenstoßionisation (Gey 2008). Die Probe wird bei dieser Methode durch einen Elektronenstrahl geleitet, durch den Energie auf die Moleküle übertragen wird.

Bei weichen Ionisationsmethoden wird auf Grund einer deutlich geringeren zugeführten Energie die Fragmentierung der Moleküle minimiert beziehungsweise vermieden. Die Moleküle werden somit überwiegend als Ganzes ionisiert. Eine weiche Ionisationsmethode ist beispielsweise die chemische Ionisation. Hierbei wird ein Gas zunächst mittels Elektronenstoßionisation ionisiert. Diesem ionisierten Gas wird dann die Probe zugeführt. Die entstandenen Primärionen übertragen ihre Ladung durch verschiedene chemische Reaktionen auf die gasförmigen Probenmoleküle (Gey 2008). Generell können MS, welche eine chemische Ionisation verwenden, unterschieden werden in solche, die ausschließlich Wasserdampf ionisieren, oder Geräte, die mit verschiedenen Gasen arbeiten. Als Protonentransferreaktions-Massenspektrometer (PTR-MS) werden Systeme bezeichnet, welche Wasserdampf ionisieren und Hydroniumionen $\left(\mathrm{H}_{3} \mathrm{O}^{+}\right)$als Primärionen verwenden (Hansel et al. 1995). Ionenmolekülreaktions-Massenspektrometer (IMR-MS) verwenden beispielsweise Krypton, Xenon oder Quecksilberdampf als Quelle für die Primärionen (Hornuss et al. 2007).

Für einen Einsatz in der Atemgasanalytik besteht der wichtigste Unterschied zwischen den weichen und harten Ionisationsmethoden in der Möglichkeit zur Gemischanalyse. Auf Grund der Fragmentierung im Rahmen der Elektronenstoßionisation ist die Analyse auf Einzelstoffe limitiert. Würden zwei fragmentierte Stoffe gleichzeitig in den Massenfilter gelangen, könnte aus dem gemischten Massenspektrum nicht mehr die Zuordnung der jeweiligen Fragmente zu den ursprünglichen Molekülen erfolgen. Eine Identifizierung wäre nicht mehr möglich. Da aber die humane Exspirationsluft, wie beschrieben, eine Vielzahl an Stoffen beinhaltet, ist eine 
Vortrennung bei Verwendung harter Ionisationsmethoden erforderlich. Im Gegensatz hierzu stellt die chemische Ionisation durch die Analyse ganzer Moleküle ein Verfahren dar, bei dem für die Gemischanalyse auf eine Vortrennung verzichtet werden kann.

Massenspektrometer, die mit Elektronenstoßionisation ausgestattet sind, werden in der Regel mit einem Gaschromatographen (GC) gekoppelt. Hierbei handelt es sich um eine Analysemethode zur Auftrennung einzelner verdampfbarer chemischer Verbindungen aus komplexen Gemischen. Die Probe wird durch ein inertes Trägergas (meist Helium) in eine Kapillare (Trennsäule) geleitet. Diese weist einen Innendurchmesser von $100-500 \mu \mathrm{m}$ und eine Länge von 10 - $100 \mathrm{~m}$ auf. Die Innenseite ist mit einem flüssigen, hochviskosen Material beschichtet, typischerweise Polyorganosiloxanen, das als stationäre Phase bezeichnet wird. Die mobile Phase ist das Trägergas. Das Prinzip eines GC besteht darin, dass die Probenmoleküle je nach chemischen Eigenschaften kurzzeitige Bindungen mit der stationären Phase eingehen, während das Trägergas ohne Verzögerung die Säule durchströmt. Hieraus resultiert für das Trägergas die so genannte Totzeit, die abhängig von der Flussrate und dem Säulenvolumen ist. Für die Analyten ergibt sich durch die Wechselwirkung mit der stationären Phase eine Verzögerung im Durchlaufen der Säule, die als Retentionszeit bezeichnet wird. Diese entspricht der Zeitdifferenz zwischen Injektion der Probe und Detektion. Sie ist spezifisch für den Analyten und hängt von der Molekülgröße, der Polarität und der chemischen Struktur ab. Des Weiteren ist die Retentionszeit abhängig von der Säulentemperatur. Die Trennsäule eines GC wird in einem so genannten Säulenofen aufgehängt, der für eine konstante Temperatur oder den Ablauf von Temperaturprogrammen sorgt. Die Temperaturprogramme ermöglichen durch Temperatursteigerung in definierten Zeitintervallen die Auftrennung komplexer Probengemische. Durch die unterschiedlichen Retentionszeiten der Moleküle in der Exspirationsluft können diese dann separiert in einen MS eingeleitet werden (Gey 2008).

Da die Auftrennung einer komplexen Probe mittels Gaschromatographie zeitintensiv ist, eignen sich die Gaschromatograph-Massenspektrometer (GC-MS) nicht zum direkten Einsatz am Patienten. Die Kombination GC-MS stellt viel mehr eine zeitversetzte Labormethode dar. Hierfür ist die Sammlung der Proben in speziellen inerten Transportbehältern notwendig. Im Labor wird aus dem Transportbehälter mittels Festphasenmikroextraktion (solid phase microextraction, SPME) adsorptiv eine Probe zur Verdampfung im GC entnommen. Dieser Schritt dient der Präkonzentration der Substanzen und ermöglicht eine gewisse Selektion aus 
komplexen Proben wie der humanen Atemluft (Buszewski et al. 2007). Ebenso ist eine direkte Sammlung einer Probe und deren Transport auf adsorbierenden Substanzen (z.B. TenaxRöhrchen) möglich.

Man kann demnach auf Grund der Ionisationsmethode, mit daraus resultierender Notwendigkeit einer Vortrennung, zwischen direkter und indirekter Massenspektrometrie unterscheiden. Abbildung 3 zeigt die verschiedenen Methoden der massenspektrometrischen Atemgasanalysen, Tabelle 3 die Vor- und Nachteile, die aus der jeweiligen Ionisationsmethode resultieren.

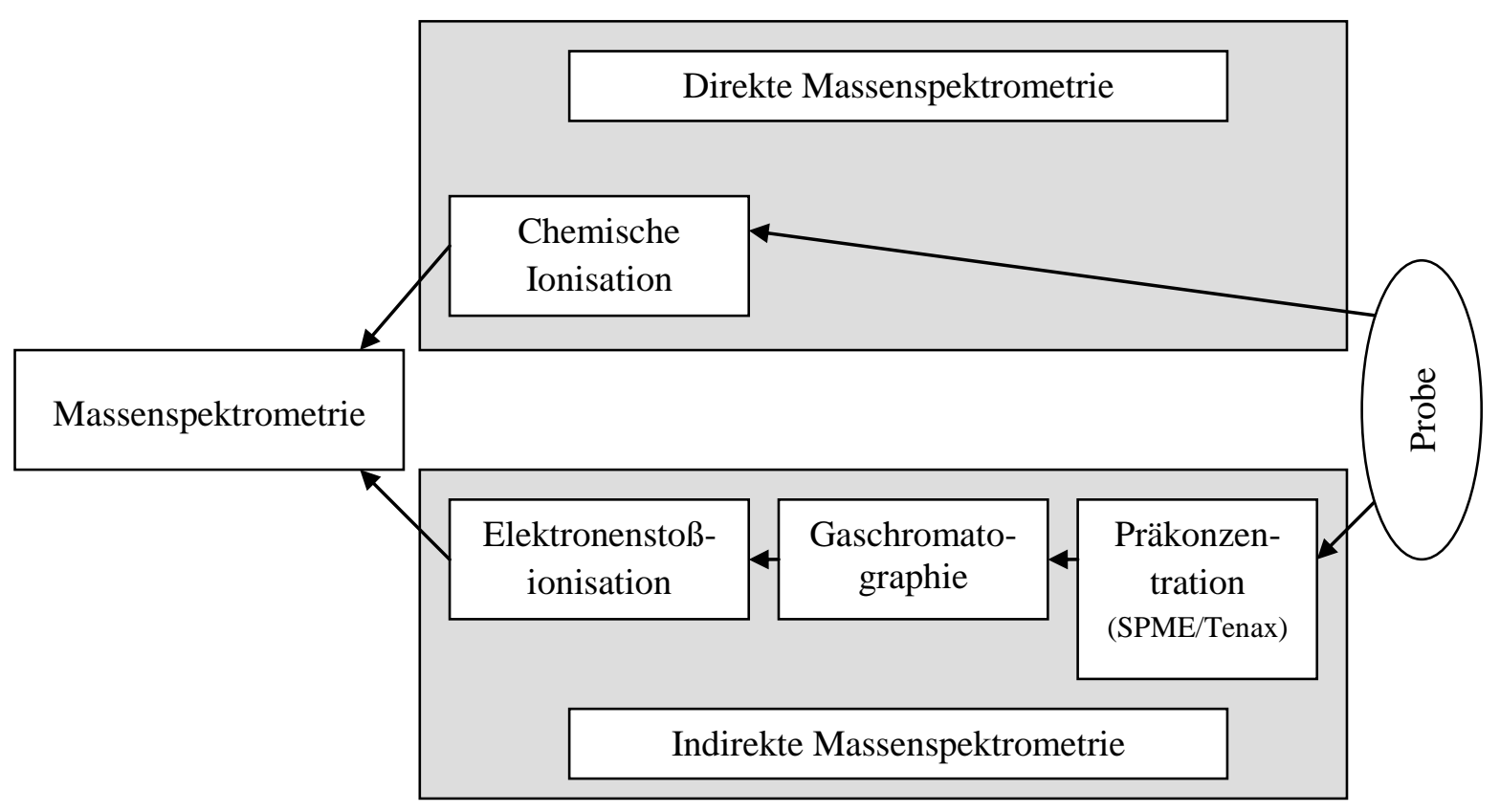

Abbildung 3. Übersicht direkte und indirekte Massenspektrometrie. 


\begin{tabular}{|c|c|c|}
\hline Ionisationsmethode & Vorteile & Nachteile \\
\hline Elektronenstoßionisation & $\begin{array}{l}\text { - } \text { Einfache Anwendung } \\
\text { - Umfangreiche } \\
\text { Spektrenbibliotheken } \\
\text { - Einfache Identifizierung der } \\
\text { Strukturformel des } \\
\text { Analyten }\end{array}$ & $\begin{array}{l}\text { Bei zu starker } \\
\text { Fragmentierung keine } \\
\text { Aussage über } \\
\text { Molekulargewicht des } \\
\text { Analyten möglich } \\
\text { - } \\
\text { Gemischanalysen benötigen } \\
\text { Vortrennung }\end{array}$ \\
\hline Chemische Ionisation & $\begin{array}{l}\text { - Sichere Bestimmung des } \\
\text { Molekulargewichts } \\
\text { - Selektive Ionisation } \\
\text { möglich } \\
\text { - Gemischanalysen möglich }\end{array}$ & $\begin{array}{l}\text { - Keine Information über die } \\
\text { Strukturformel des } \\
\text { Analyten } \\
\text { - Ausgehend vom } \\
\text { Molekulargewicht wird die } \\
\text { Substanz ermittelt, } \\
\text { Moleküle gleichen } \\
\text { Gewichts schwer zu } \\
\text { differenzieren }\end{array}$ \\
\hline
\end{tabular}

Tabelle 3. Ionisationsmethoden in der Massenspektrometrie. Vor- und Nachteile der Elektronenstoß- und der chemischen Ionisation.

\subsubsection{EXSPIRATORISCHE PROPOFOLDETEKTION MITTELS MASSENSPEKTROMETRISCHER VERFAHREN}

Harrison et al. gelang 2003 erstmals mittels PTR-MS der Nachweis von Propofol in gemischter Exspirationsluft einer TIVA-Patientin. Zuvor durchgeführte Laboruntersuchungen zeigten, dass es möglich ist, Propofol und dessen Metabolite mittels Dampfraumanalysen (headspace, HS) über propofolhaltigem Patientenserum zu detektieren (Harrison et al. 2003). Nachfolgende Studien bestätigten die Detektion von Propofol in HS-Analysen und konnten darüber hinaus eine Korrelation zwischen der Blut- und Gasphasenkonzentration nachweisen (Hornuss et al. 2007, Miekisch et al. 2008). 
Diese im HS-Modell nachgewiesene Korrelation bestätigte sich bei Vergleichsuntersuchungen der Propofol-Konzentrationen zwischen Blut und Exspirationsluft sowohl in humanen Kollektiven (Hornuss et al. 2007, Takita et al. 2007, Miekisch et al. 2008) als auch in Tiermodellen (Grossherr et al. 2006).

Der Nachweis einer solchen Korrelation zwischen den Propofol-Konzentrationen in Blut und Exspirationsluft beim Menschen konnte mit unterschiedlichen massenspektrometrischen Verfahren gezeigt werden. Die Ergebnisse einer IMR-MS Studie zeigten bei 11 Probanden eine enge individuelle Korrelation (Korrelationskoeffizient $r=0,784-0,985$ ) zwischen arterieller Propofol-Konzentration und endexspiratorischem Propofol-Signal gemessen in counts per second (Hornuss et al. 2007). Takita et al. ermittelten 2007 für die Analyse mittels PTR-MS eine mittlere systematische Messabweichung von 5,2\% ( $n=11)$. In einer weiteren Studie $(n=16)$ konnte mittels SPME-GC-MS eine Korrelation zwischen der arteriellen und exspiratorischen Propofol-Konzentration mit einem Bestimmtheitsmaß von $r^{2}=0,849$ bestimmt werden. In dieser Studie konnte keine Beziehung zwischen der venösen oder gemischtvenösen und der exspiratorischen Konzentration belegt werden (Miekisch et al. 2008).

Grossherr et al. ermittelten an zwei Tiermodellen (Schwein und Ziege) Korrelationen zwischen plasmatischer (arteriell und gemischtvenös) und exspiratorischer Propofol-Konzentration; hierbei wurden allerdings Differenzen sowohl innerhalb als auch zwischen den Spezies sowie den jeweiligen Kreislaufsegmenten festgestellt (Grossherr et al. 2006).

\subsection{GRUNDLAGEN DER IONENMOBILITÄTSSPEKTROMETRIE}

Das Grundlagenkapitel zur Ionenmobilitätsspektrometrie orientiert sich an der Monographie „Ion mobility spectrometry“ von Eiceman und Karpas 2005.

Ein Ionenmobilitätsspektrometer (IMS) besteht aus den Hauptkomponenten Ionisationsraum, Driftraum und Detektor (siehe Abbildung 4). Durch den Driftraum strömt ein als Driftgas bezeichnetes Gas in Richtung des Ionisationsraums. Bei der Verwendung von ß-Strahlern als Ionisationsquelle bilden sich dort über eine Reaktionskette die sogenannten Reaktionsionen 
(protonierte Wassercluster). Wird nun zusätzlich ein Analyt in den Ionisationsraum eingeleitet, werden dessen Moleküle mittels Protonentransfer ionisiert.

Der Ionisationsraum wird durch ein elektrisches Schaltgitter vom Driftraum getrennt, welches sich periodisch öffnet und dann jeweils einen Ionenschwarm in den Driftraum einlässt. Dort wird mittels einer Widerstandskette verbundener Ringe aus Metall und Isolationsmaterial ein homogenes elektrisches Feld erzeugt, in dem sich die Ionen entlang der Feldlinien in Richtung des Detektors bewegen. Während ihrer Drift zum Detektor kollidieren die Ionen abhängig von ihrer Form und Größe mit den Driftgasmolekülen. Dadurch stellt sich für jedes Molekül eine charakteristische Driftgeschwindigkeit ein. Die Zeit, welche die Ionen für den Durchlauf der Driftstrecke benötigen, ist das Maß für ihre Mobilität in dem verwendeten Gas. Diese Driftzeit wird in Millisekunden (ms) angegeben. Durch eine Normierung auf die Länge der Driftstrecke, das elektrische Feld sowie Druck und Temperatur erhält man die reduzierte Ionenmobilität $\left(\mathrm{K}_{0}\right)$.

Dem Detektor (i. A. Faraday-Platte) ist ein Aperturgitter vorgeschaltet, welches der kapazitiven Entkopplung der Ionen in der Driftstrecke und der Faraday-Platte dient. Das Auftreffen der Ionen auf die Faraday-Platte erzeugt ein Signal, welches durch einen Strom/Spannungswandler verstärkt wird. Die Darstellung der verstärkten Signale erfolgt computergestützt. Es resultiert ein Driftzeitspektrum, welches die Signalintensität in Abhängigkeit der Driftzeit wiedergibt. Abbildung 4 zeigt eine schematische Darstellung eines IMS. 


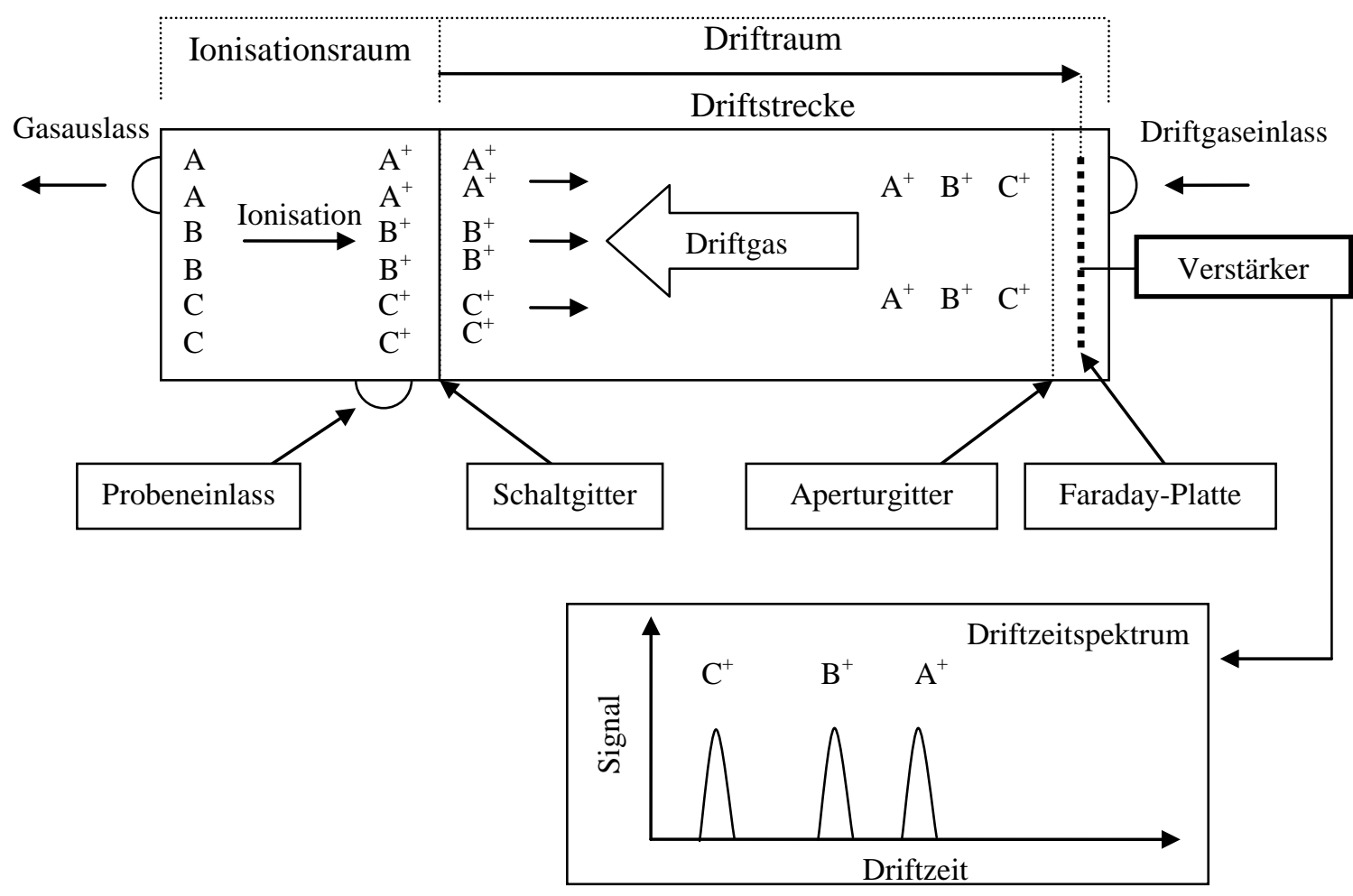

Abbildung 4. Schematische Darstellung eines Ionenmobilitätsspektrometers. (vgl. Sielemann 1999, S.6) A, B, C kennzeichnen Analytmoleküle, A+, B+, C+ kennzeichnen ionisierte Analytmoleküle.

\subsubsection{IONISATIONSMETHODEN}

In dem Ionisationsraum eines IMS können Gase auf verschiedene Weise ionisiert werden. In der vorliegenden Arbeit wurde ein IMS verwendet, welches mittels einer radioaktiven ${ }^{63}$ NickelStrahlungsquelle (550 MBq) $\beta$-Teilchen (maximale Energie von 67 Kiloelektronenvolt) emittiert, die bei einer Kollision mit Gasmolekülen $\mathrm{zu}$ deren Ionisation führen. Weitere Ionisationsmethoden beruhen auf UV-Strahlungsquellen, Elektrospray, Laser oder Teilentladung. Wird wie in der vorliegenden Arbeit synthetische Luft $\left(\mathrm{N}_{2}+\mathrm{O}_{2}\right.$ Synthetische Luft Scientific; Air Liquid, Düsseldorf, Deutschland) als Trägergas verwendet, ionisieren die $\beta$ Teilchen den molekularen Stickstoff $\left(\mathrm{N}_{2}\right)$ wie folgt:

$$
N_{2}+\beta \rightarrow N_{2}^{+}+\beta^{\prime}+e^{-}
$$

Hierbei entspricht $\beta$ `einem $\beta$ mit reduzierter Energie (Sielemann 1999). 
Der ionisierte Stickstoff reagiert anschließend mit in der synthetischen Luft enthaltenen Spuren von Wassermolekülen, Ammoniak oder Stickstoffmonoxid. Als Ladungsträger entstehen hierdurch neben $\left(\mathrm{H}_{2} \mathrm{O}\right)_{x} \mathrm{NO}^{+}$und $\left(\mathrm{H}_{2} \mathrm{O}\right)_{x} \mathrm{NH}_{4}{ }^{+}$vor allem $\left(\mathrm{H}_{2} \mathrm{O}\right)_{\mathrm{x}} \mathrm{H}^{+}$-Ionen, die als prozentual häufigste Ionen als Reaktionsionen bezeichnet werden. Bei Einbringen einer Probe in den Ionisationsraum fungieren sie als Reaktionspartner der Analytmoleküle. In einem IMS-Spektrum sind sie als Reaktionsionenpeak (RIP) sichtbar, ebenso wie die $\left(\mathrm{H}_{2} \mathrm{O}\right)_{\mathrm{x}} \mathrm{NH}_{4}{ }^{+}$als kleiner Peak links vom RIP. Die $\left(\mathrm{H}_{2} \mathrm{O}\right)_{x} \mathrm{NO}^{+}$sind nicht zu erkennen, da ihre Anzahl zu gering ist (siehe Abbildung 5).

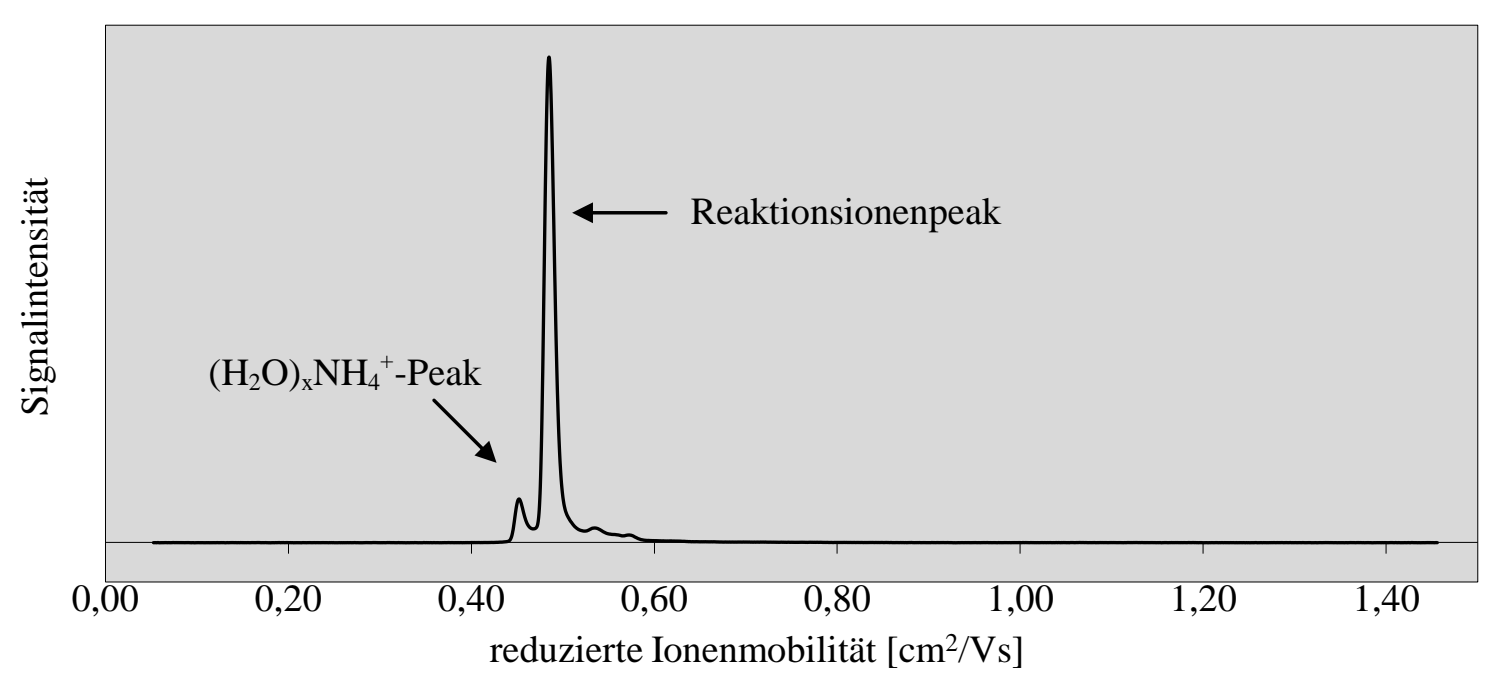

Abbildung 5. Schema eines Ionenmobilitätsspektrums des verwendeten Nickel-IonenmobilitätsSpektrometers.

Die Bildung der Analytionen $\left(\mathrm{AH}^{+}\right)$erfolgt bedingt durch die höhere Protonenaffinität der Analytmoleküle (A) verglichen mit den Reaktionsionen durch Protonentransfer:

$$
\left(\mathrm{H}_{2} \mathrm{O}\right)_{x} \mathrm{H}^{+}+\mathrm{A} \rightarrow \mathrm{AH}^{+}+x \mathrm{H}_{2} \mathrm{O}
$$

Die so gebildeten Analytionen sind in der Regel stabil, eine Dissoziation oder Fragmentierung tritt selten auf. Abhängig von der Protonenaffinität und der Konzentration der Substanz kann es auch zur Bildung von Dimeren kommen: 


$$
A+A H^{+} \rightarrow A_{2} H^{+}
$$

Auch die Bildung höherwertiger Polymere ist möglich.

\subsubsection{IONENMOBILITÄT IN GASEN}

Die Mobilität der Ionen in einem IMS führt auf Grund der Beschleunigung im elektrischen Feld und dem Abbremsen durch Kollisionen mit den neutralen Driftgasmolekülen zu einer resultierenden mittleren Geschwindigkeit innerhalb der Driftstrecke. Diese Driftgeschwindigkeit $\mathrm{V}_{\mathrm{d}}[\mathrm{cm} / \mathrm{s}]$ ist charakteristisch für das ionisierte Molekül (Masse, Form und Ladung). Bei einem homogenen elektrischen Feld innerhalb der Driftstrecke $E_{d}[V / c m]$ besteht direkte Proportionalität zwischen $\mathrm{v}_{\mathrm{d}}$ und $\mathrm{E}_{\mathrm{d}}$.

$$
v_{d}=K \times E_{d}
$$

Der Proportionalitätskoeffizient $\mathrm{K}\left[\mathrm{cm}^{2} / \mathrm{Vs}\right]$ bezeichnet die Mobilität der Ionen. Die Geschwindigkeit $v_{d}$ errechnet sich aus der Länge der Driftstrecke $l_{d}[\mathrm{~cm}]$ und der gemessenen Driftzeit $t_{d}[s]$ bis zur Detektion.

$$
v_{d}=\frac{l_{d}}{t_{d}}
$$

Unter Berücksichtigung von Gleichung (6) lässt sich Gleichung (5) umformen zur direkten Bestimmung der Ionenmobilität $\mathrm{K}$ aus der gemessenen Driftzeit:

$$
K=\frac{l_{d}}{t_{d} \times E_{d}}
$$


Nach dem idealen Gasgesetz führt eine Änderung des Druckes p beziehungsweise der Temperatur T zu einer Änderung der Moleküldichte eines Gases. Daher ist es bei der Beurteilung der Ionenmobilitätsspektrometrie wichtig die daraus resultierenden Veränderungen der Ionenmobilität K zu berücksichtigen. Eine bessere Vergleichbarkeit von Messergebnissen wird durch die reduzierte Ionenmobilität $\mathrm{K}_{0}\left[\mathrm{~cm}^{2} / \mathrm{Vs}\right]$ sichergestellt, welche die Einflüsse der Temperatur und des Druckes korrigiert (Standardbedingungen $\mathrm{p}_{0}=1013,2 \mathrm{hPa}$ und $\mathrm{T}_{0}=273,2$ $\mathrm{K})$.

$$
K_{0}=K\left(\frac{p}{p_{0}}\right)\left(\frac{t_{0}}{t}\right)
$$

Unter Einbeziehung der gaskinetischen Gesetze lässt sich die Mobilität der Ionen nach Revercomb und Mason über ihre 1975 postulierte Gleichung berechnen:

$$
K=\frac{3}{16} \frac{q}{N}\left(\frac{m+M_{m}}{m M_{m}}\right)^{1 / 2}\left(\frac{2 \pi}{k_{B} T_{e f f}}\right)^{1 / 2} \frac{(1+\gamma)}{\Omega_{d}\left(T_{e f f}\right)}
$$

Hierbei kennzeichnet $\mathrm{q}$ die Ladung des Ions, $\mathrm{N}$ die Molekülzahl des Driftgases, $\mathrm{m}$ die Ionenmasse, $\mathrm{M}_{\mathrm{m}}$ die Masse der neutralen Driftgasmoleküle, $\mathrm{k}_{\mathrm{B}}$ die Boltzmann-Konstante, $\mathrm{T}_{\text {eff }}$ die Temperatur des Driftgases, $\gamma$ einen Korrekturfaktor, welcher für $m>M_{m}$ kleiner 0,02 ist, und $\Omega_{\mathrm{d}}\left(\mathrm{T}_{\text {eff }}\right)$ den temperaturabhängigen Stoßquerschnitt zwischen den Ionen und Gasmolekülen. Nach Gleichung (9) ist die Mobilität von Ionen abhängig von ihrer Masse und umgekehrt proportional zu ihrer Größe. Für atomare Ionen ist die Größe konstant und ihre Mobilität somit durch ihre Masse bestimmt. Molekülionen, welche die häufigsten Analytionen sind, weisen einen größeren Stoßquerschnitt auf, woraus eine geringere Mobilität resultiert.

Die spezifische Driftzeit der (Molekül-)Ionen wird des Weiteren von Diffusion beeinflusst. Eine gaußförmige Verteilung eines Ionenschwarms innerhalb der Driftstrecke führt zu einem Peakmaximum, welches die durchschnittliche Mobilität identischer Ionen bezeichnet (Sielemann 1999). 


\subsubsection{KOPPLUNG DER IONENMOBILITÄTSSPEKTROMETRIE MIT GASCHROMATOGRAPHISCHEN TECHNIKEN}

Um mittels IMS Bestandteile komplexer Gasgemische wie beispielsweise der humanen Exspirationsluft zu analysieren, ist eine Vortrennung der Probe unerlässlich. Ohne diese könnte es zu chemischen Reaktionen und Clusterbildungen innerhalb der Ionisationskammer oder der Driftstrecke kommen. Die Auswertung selber würde durch mögliche Überlappung einzelner Peaks beeinträchtigt (Baumbach et al. 2000). Als weiteren Nutzen liefert die aus der gaschromatographischen Vortrennung gewonnene Retentionszeit zusätzliche Identifizierungsmerkmale der einzelnen Substanzen.

Bereits kurz nach der Einführung der Ionenmobilitätsspektrometrie in die analytische Praxis erfolgte eine Kopplung an einen Gaschromatographen (Karasek und Keller 1972). Dabei auftretende Probleme konnten zwar durch verschieden technische Modifikationen behoben werden, doch blieb die herkömmliche Gaschromatographie eine zeitintensive und nur bedingt miniaturisierbare Technik. Eine Alternative zur herkömmlichen Vortrennung stellt eine in der ehemaligen Sowjetunion entwickelte Multikapillarsäule (Multi-Capillary-Column, MCC) dar (Baumbach et al. 1997). Diese patentierte Technik besteht nach Herstellerangaben aus 9001200 gebündelten Kapillaren mit einem jeweiligen Durchmesser von $43 \mu \mathrm{m}$ und einer stationären Phase mit einer Filmdicke von 0,2 $\mu \mathrm{m}$. Die in der vorliegenden Studie verwendete $20 \mathrm{~cm}$ lange stabförmige Säule weist einen Durchmesser von $3 \mathrm{~mm}$ auf und lässt sich somit in einem transportablen IMS einsetzen. Der weite Betriebsbereich der MCC von 5-250 mL/min entspricht im Vergleich zur herkömmlichen GC (0,4-1,5 $\mathrm{mL} / \mathrm{min})$ den gebräuchlichen Probengasflüssen eines IMS, was eine Kopplung vereinfacht. Der Betrieb ist im Vergleich zur GC sowohl bei Raumtemperatur als auch bis $\mathrm{zu} 250^{\circ} \mathrm{C}$ möglich. Ebenso sind keine Temperaturprogramme notwendig. Die Auftrennung komplexer Gasgemische erfolgt bei einer konstanten Temperatur idealer Weise innerhalb von Sekunden und ist spätestens nach wenigen Minuten abgeschlossen (Baumbach et al. 2000, Ruzsanyi et al. 2005). Abbildung 6 zeigt einen Querschnitt durch eine in der Studie verwendete MCC. 


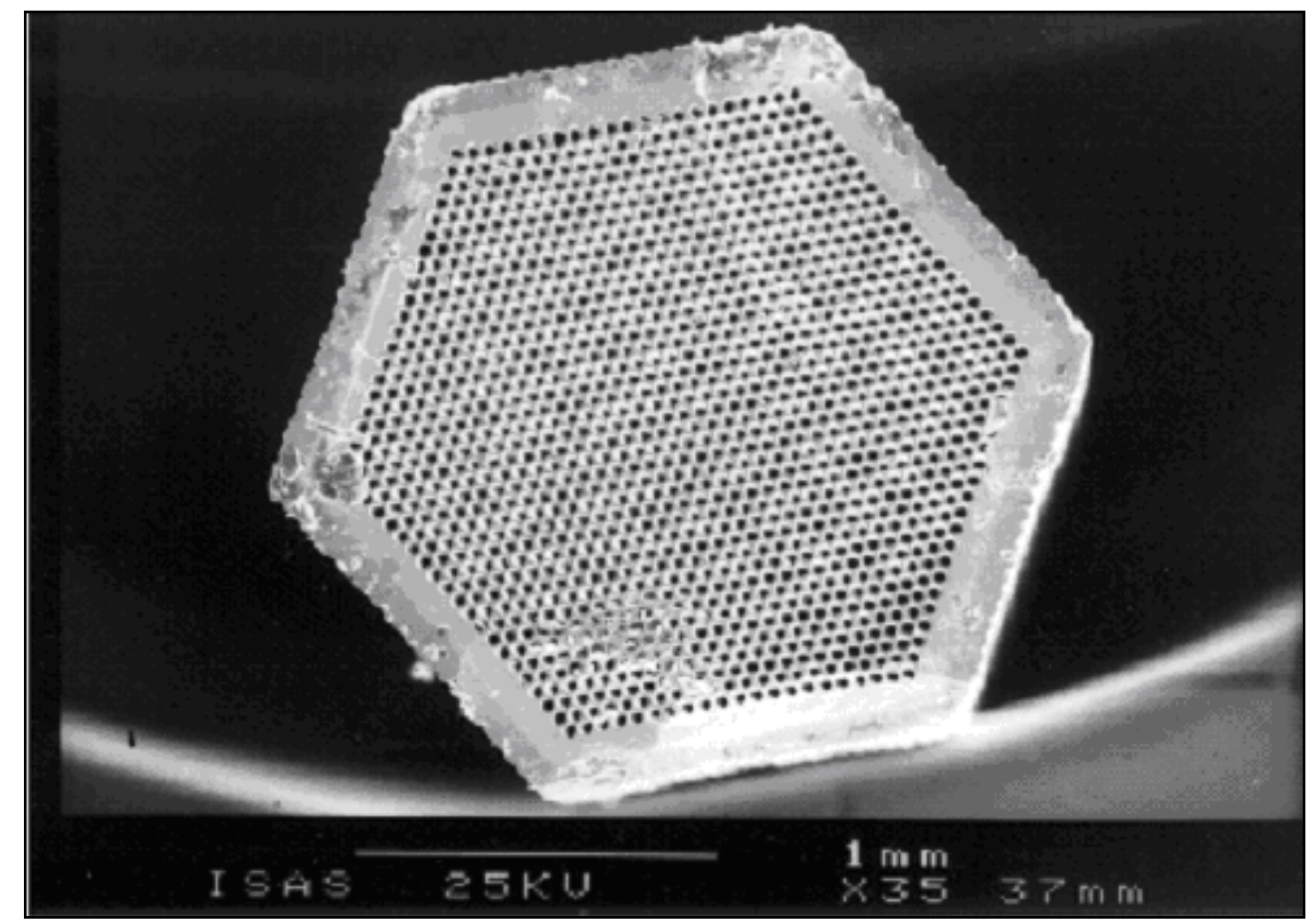

Abbildung 6. Querschnitt durch eine Multikapillarsäule. MCC OV-5 der Firma Sibertech Ltd., Novosibirsk, Russland. (Vgl. Sielemann 1999, Seite 18) 


\section{Material Und Methoden}

\subsection{ETHIKKOMMISSION}

Die Ethikkommission der Georg-August-Universität Göttingen prüfte den Antrag zu der Studie "Quantifizierung von Propofol in der Atemluft mittels endtidaler Ionenmobilitätsspektrometrie“ mit einem positiven Votum (lfd. Antragsummer 1/07/08).

\subsection{VERWENDETES IONENMOBILITÄTSSPEKTROMETER}

Bei dem in der vorliegenden Arbeit verwendeten IMS handelt es sich um einen im ISAS - Institute for Analytical Sciences in Dortmund entwickelten Prototypen zur Atemgasanalytik. Der Aufbau entspricht generell den in Kapitel 2 dargestellten Grundlagen eines MultikapillarsäulenIonenmobilitätsspektrometers (MCC-IMS) mit im Folgenden erläuterten Spezifikationen. Der Prototyp wird im Weiteren als Breath-MCC-IMS (BR-MCC-IMS) bezeichnet.

Das IMS (Ionisationsraum, Driftstrecke und Detektor) des Prototypen ist mit einer ${ }^{63}$ NickelStrahlungsquelle ausgestattet. Der aus Teflon gefertigte Driftraum hat eine Driftlänge von $12 \mathrm{~cm}$. Das homogene elektrische Feld (Driftspannung) in der Driftstrecke wird durch in gleichen Abständen angeordnete Messing-Ringe an der Außenseite der Driftröhre erzeugt.

Die Steuerung des IMS erfolgt durch eine im ISAS entwickelte Versorgungseinheit. Mit dieser können die Öffnungszeit und Impulsrate des Schaltgitters, die Driftspannung und die Polarität reguliert werden. Dem Probeneinlass in den Ionisationsraum ist eine wie unter 2.4.3 beschriebene Multikapillarsäule (MCC-OV-5, Sibertech Ltd., Novosibirsk, Russland) vorgeschaltet, über welche ein konstanter Gasfluss (Trägergas) in das IMS geleitet wird. Die apolare stationäre Phase der MCC setzt sich aus 95\% Dimethylsiloxan und 5\% Phenylsiloxan zusammen. Die Temperaturregulierung der MCC erfolgt zwischen $20^{\circ} \mathrm{C}$ und $70^{\circ} \mathrm{C}$ über eine externe, digitale Steuereinheit (Säulenheizung). Tabelle 4 gibt eine Übersicht über die Einstellungsmöglichkeiten der Versorgungseinheit. 


\begin{tabular}{l|cccc}
\hline & $\begin{array}{c}\text { Einstellung } \\
\text { Propofol-Studie }\end{array}$ & Minimum & Zwischenschritte & Maximum \\
\hline Gitter & Puls & Aus & Puls & Ein \\
Gitterimpulse & $100 \mathrm{~ms}$ & $25 \mathrm{~ms}$ & $50 \mathrm{~ms}$ & $100 \mathrm{~ms}$ \\
Gitteröffnungszeit & $300 \mu \mathrm{s}$ & $30 \mu \mathrm{s}$ & $100 \mu \mathrm{s}, 300 \mu \mathrm{s}$ & $1000 \mu \mathrm{s}$ \\
Driftspannung & $4,0 \mathrm{kV}$ & 0 & Stufenlos & $5,0 \mathrm{kV}$ \\
Polarität & + & - & & + \\
Säulenheizung & $40^{\circ} \mathrm{C}$ & $20^{\circ} \mathrm{C}$ & Stufenlos & $70^{\circ} \mathrm{C}$ \\
\hline
\end{tabular}

Tabelle 4. Übersicht Einstellungen Versorgungseinheit und Säulenheizung des verwendeten BR-MCC-IMS.

Als Drift- und Trägergas wird synthetische Luft der Firma AirLiquid Deutschland (Düsseldorf) verwendet. Die Flusssteuerung erfolgt extern über einen Mass-Flow-Controller. Durch diesen erfolgt die kontinuierliche Versorgung des BR-MCC-IMS mit synthetischer Luft über die Anschlüsse „Driftgas“ (100 mL/min) und „Trägergas“ (150 mL/min). Die Gasanschlüsse des BRMCC-IMS sind mit Swagelok ${ }^{\circledR}$-Fittings (Swagelok, Solon, Ohio, USA) versehen. Als Gasleitungen dienen Teflonschläuche mit einem Innendurchmesser von 1,6 mm der Firma Bohlender GmbH (Grünsfeld, Deutschland). Die geringe Oberflächenspannung der Teflonschläuche verhindert ein Anhaften von Probenbestandteilen. Tabelle 5 zeigt die verwendeten Einstellungen. 


\begin{tabular}{ll}
\hline Ionenquelle & ${ }^{63}$ Nickel $\beta$-Strahler, $550 \mathrm{MBq}$ \\
Länge der Driftstrecke & $12 \mathrm{~cm}$ \\
Elektrische Feldstärke & $303 \mathrm{~V} / \mathrm{cm}$ \\
Driftspannung & $4 \mathrm{kV}$ \\
Gitteröffnungszeit & $300 \mu \mathrm{s}$ \\
Drift- und Trägergas & Synthetische Luft \\
Driftgasfluss & $100 \mathrm{~mL} / \mathrm{min}$ \\
Trägergasfluss & $150 \mathrm{~mL} / \mathrm{min}$ \\
Säulentemperatur & $40^{\circ} \mathrm{C}$ \\
Temperatur & Umgebungstemperatur \\
Druck & Umgebungsdruck \\
\hline
\end{tabular}

Tabelle 5. Hauptparameter des verwendeten BR-MCC-IMS.

Die Abbildungen 7 und 8 zeigen den in der Studie verwendeten Prototyp BR-MCC-IMS. 


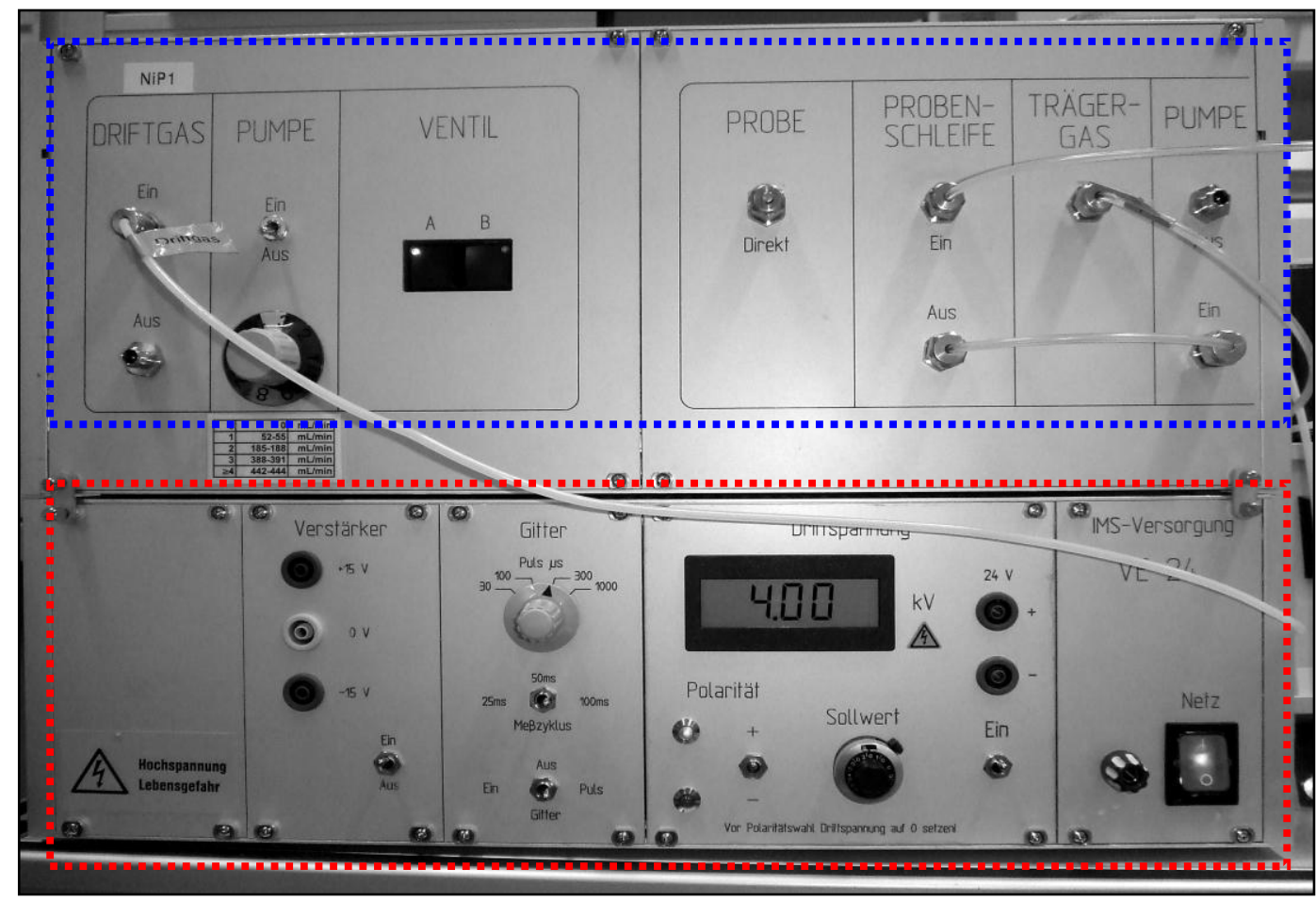

Abbildung 7. Frontansicht BR-MCC-IMS. Blau markiert: Außenanschlüsse Gasversorgung, Pumpe, manuelle

Ventilschaltung. Rot markiert: Versorgungseinheit mit den in Tabelle 5 dargestellten Einstelloptionen, nicht im Bild: Säulenheizung und Mass-Flow-Controller.

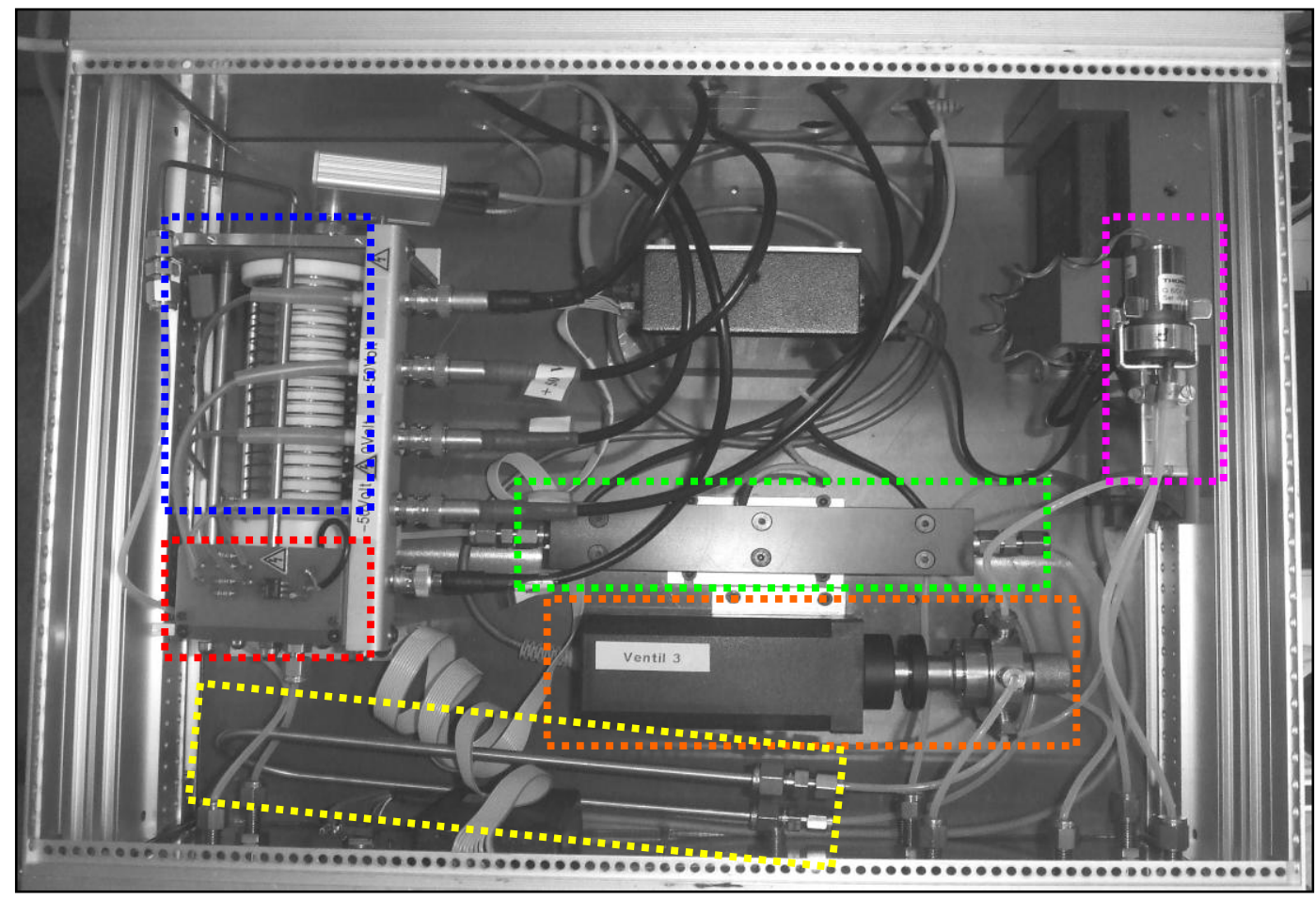

Abbildung 8. Innenansicht BR-MCC-IMS. Blau markiert: Driftraum, rot markiert: Ionisationsraum, gelb markiert: Probenschleife, orange markiert: 6-Wege-Ventil, grün markiert: Multikapillarsäule, violett markiert: Pumpe. 
Eine zu untersuchende Probe wird der MCC über eine so genannte Probenschleife (Volumen 8 $\mathrm{mL)}$ zu geführt. Das BR-MCC-IMS verfügt hierfür über eine 6-Wege-Ventilschaltung, die zwei unterschiedliche Gasflüsse für die Probenschleife ermöglicht (siehe Abbildungen 9 und 10).

Die Ventilstellung A dient als Grundstellung des Ventils, welche zwei unterschiedliche Aufgaben erfüllen kann. Zum einen ermöglicht diese einen kontinuierlichen Spülvorgang mit einem Gasfluss von $100 \mathrm{~mL} / \mathrm{min}$ synthetischer Luft, welche die Probenschleife durchläuft und über einen Ausgang als Abgas entweicht, ohne mit dem IMS in Kontakt zu treten. Das Spülgas dient der Reinhaltung der Probenschleife um Verschmutzungen der Proben durch das System zu minimieren. Des Weiteren kann in Ventilstellung A das Spülen der Probenschleife mit der zu untersuchenden gasförmigen Probe erfolgen. Hierfür wird anstelle der synthetischen Luft die zu untersuchende Probe eingeleitet oder durch eine Pumpe am Anschluss „Abgas“ angezogen. In Ventilstellung A gelangt neben dem Driftgas lediglich das Trägergas über die MCC in das IMS.

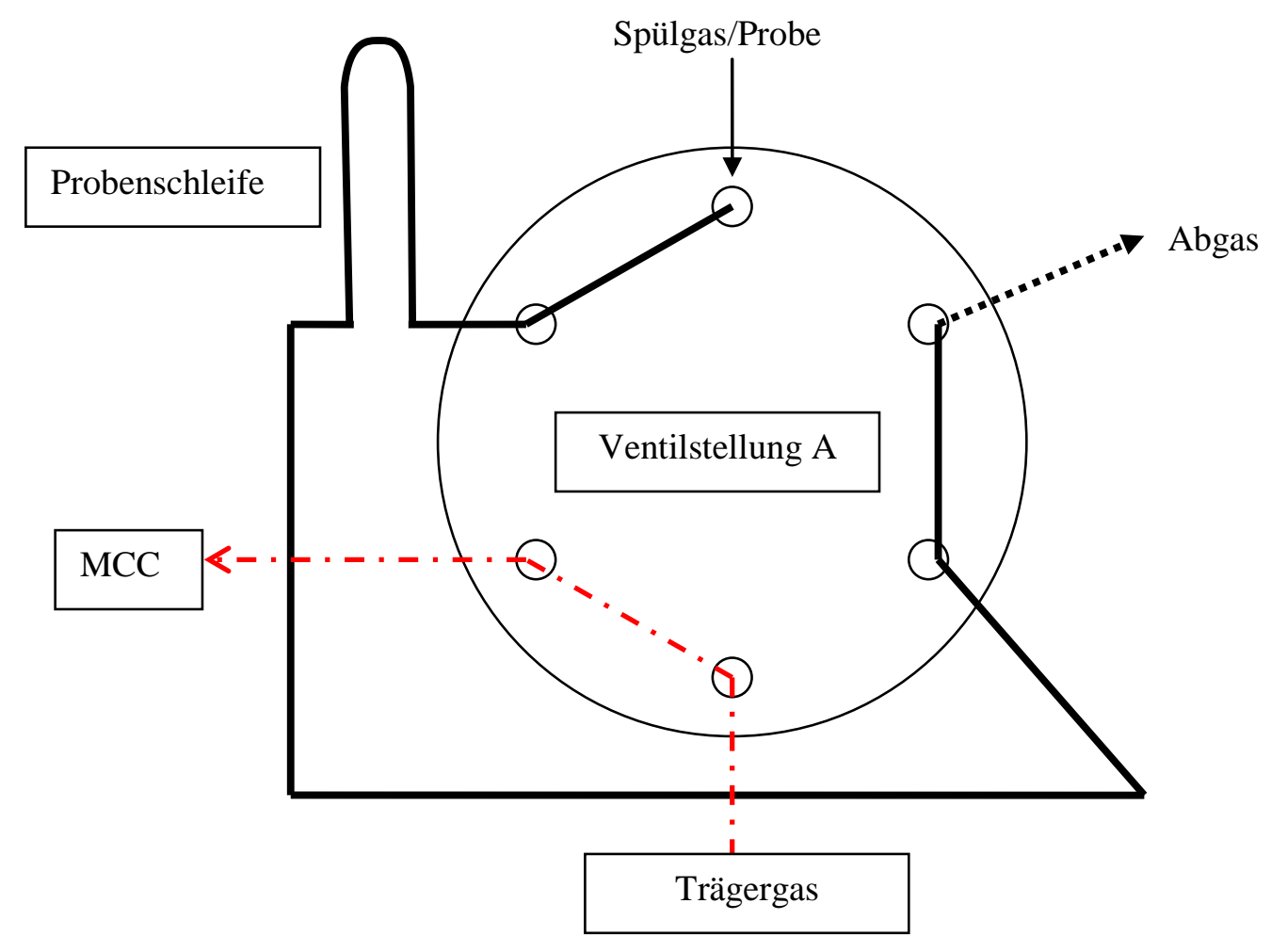

Abbildung 9. 6-Wege-Ventil Ventilstellung A. Spülen der Probenschleife mit Probengas oder Spülgas, Trägergasfluss über die MCC in den Ionisationsraum des IMS. 
Die Ventilstellung B dient der Injektion der Probe in die Multikapillarsäule mit anschließender Analyse im IMS. Das Umschalten auf Ventilstellung B verändert die Gasflüsse derart, dass das Volumen der Probenschleife durch das Einströmen von Trägergas in die MCC ausgespült wird. Das Spülgas wird in dieser Ventilstellung direkt in den Raum ausgeleitet. (Abbildung 10).

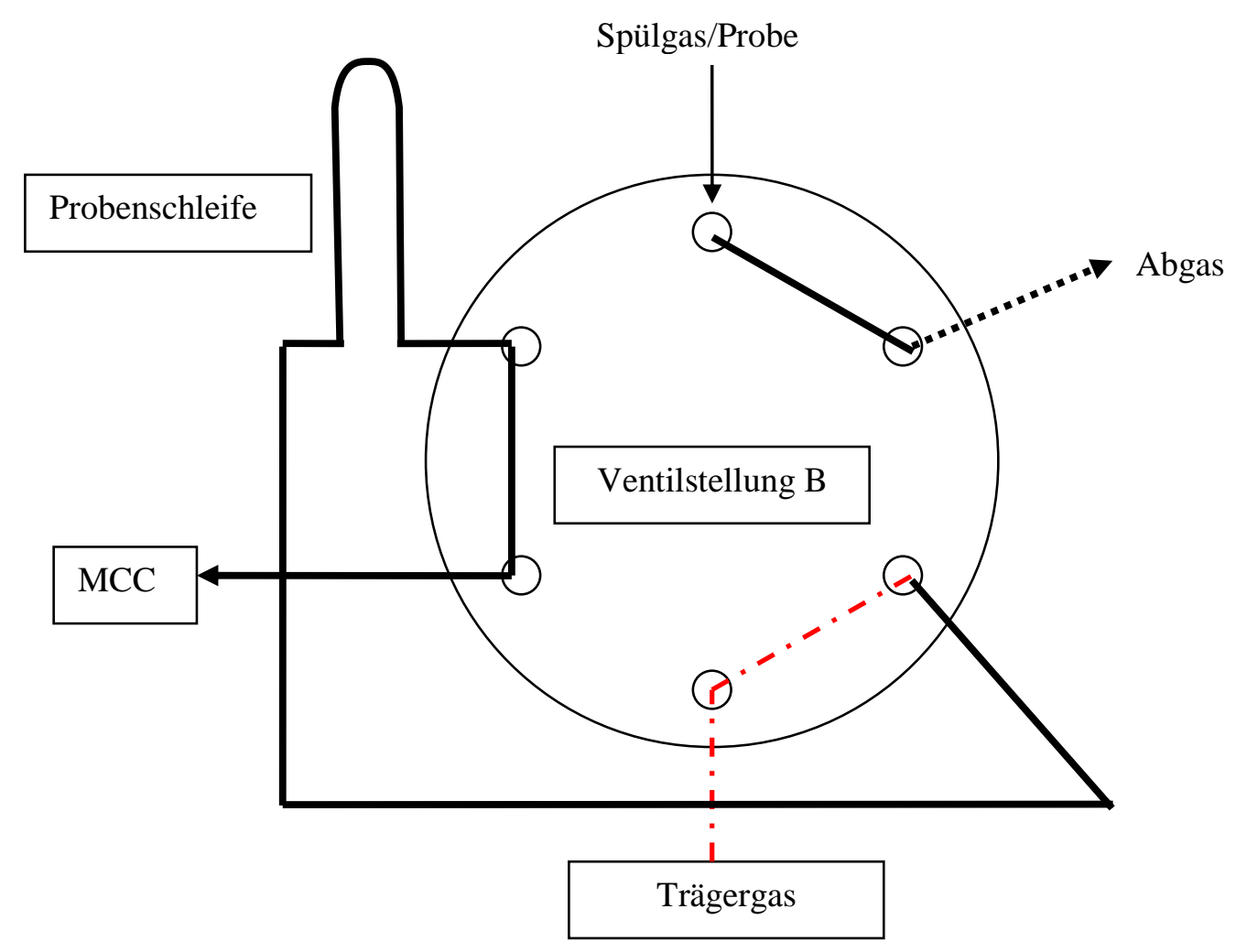

Abbildung 10. 6-Wege-Ventil Ventilstellung B. Spülgas entweicht als Abgas in die Umgebung, Trägergas spült das Volumen der Probenschleife in die MCC.

\subsection{Probennahme}

Zur Analyse der Exspirationsluft der Probanden wurde die Exspirationsluft über einen $220 \mathrm{~cm}$ langen Teflonschlauch (Probenschlauch, Durchmesser 1,6mm, Bohlender, Grünsfeld) tubusnah entnommen. Über einen Luerlock-Anschluss erfolgte durch ein auf $1 \mathrm{~cm}$ gekürztes Infusionssystem die Verbindung mit dem Probenschlauch, über welchen die Exspirationsluft der Probenschleife zugeführt wurde. Abbildung 11 zeigt den Aufbau der Probenentnahme. 


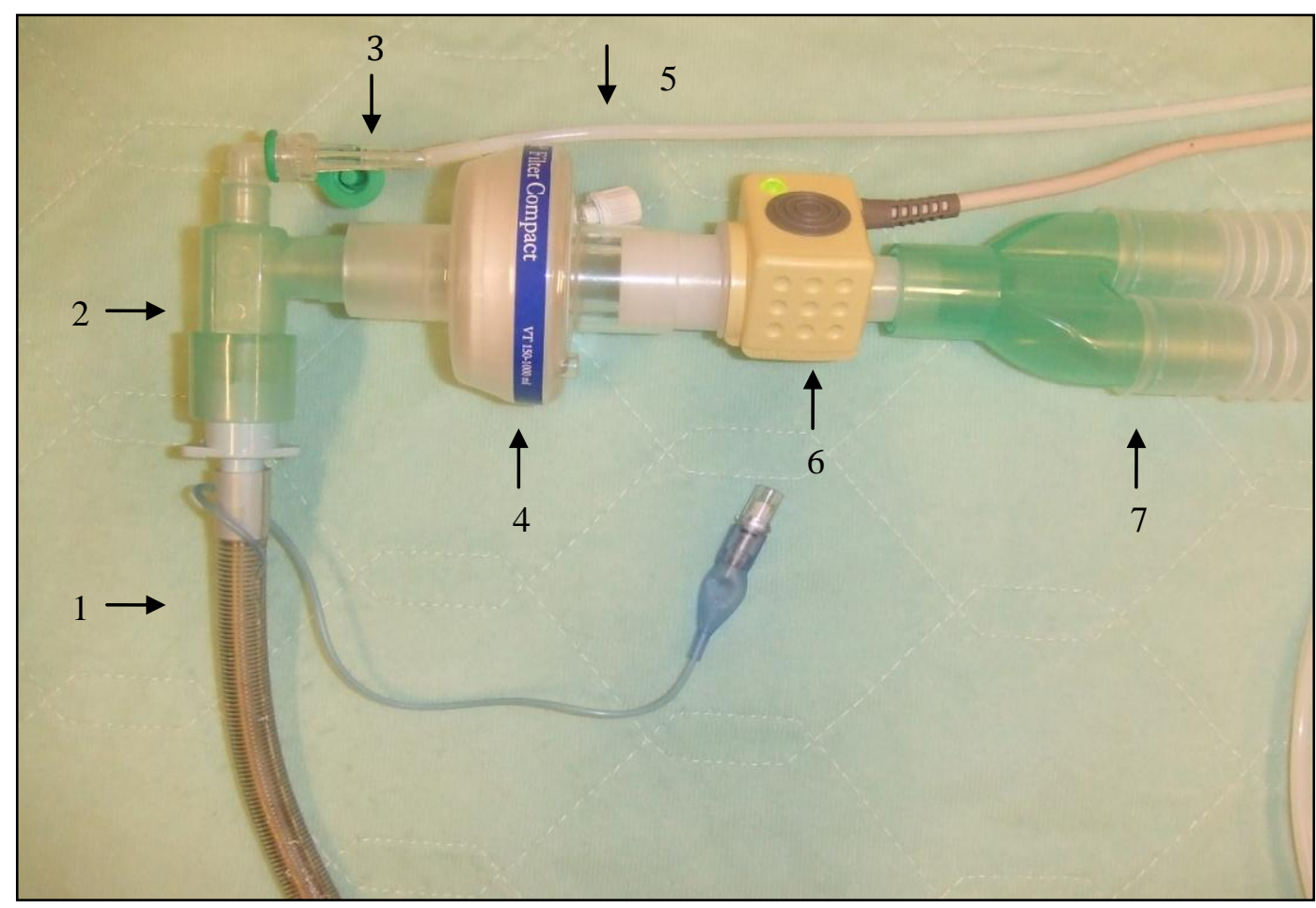

Abbildung 11. Aufbau Probenentnahme. 1=Tubus, 2=Winkelstück (Intersurgical, Elbow 22M/15F-15M, gas sampling port, REF 2714), 3=gekürztes Infusionssystem (Fresenius Kabi, Infudrop, Air 21 P, REF 2886532), 4=Beatmungsfilter (Teleflex Medical, Humid-Vent ${ }^{\circledR}$ Filter Compact S, REF 19401), 5=Probenschlauch (Bohlender, PTFE-Schlauch), 6=IRMATM-Hauptstrom-CO2-Sensor (PhaseIN, IRMA Airway Adapter, REF 106220),

7=Beatmungsschlauch (Intersurgical, Compact II Breathing System, 2M, REF 2151).

Um die Analyse alveolarer Exspirationsluft sicherzustellen, wurde die Probenentnahme kapnometriebasiert vorgenommen. Der Kohlenstoffdioxid-Gehalt $\left(\mathrm{CO}_{2}\right.$-Gehalt $)$ der Exspirationsluft wurde durch einen zwischen Beatmungsschlauch und Beatmungsfilter eingebauten IRMA ${ }^{\mathrm{TM}}-$ Hauptstrom- $\mathrm{CO}_{2}$-Sensor der Firma PhaseIN (Danderyd, Schweden) ermittelt. Mit Hilfe des Kapnometriesignals wurde die endexpiratorische Phase $\left(\mathrm{CO}_{2}\right.$-Gehalt $>25$ $\mathrm{mmHg}$ ) bestimmt, während der die Atemluftprobe gewonnen wurde. Das Kapnometriesystem wurde mit einer externen Steuereinheit (ExSC) gekoppelt, welche je nach Signalhöhe des Sensors eine Einleitung der Probe in die Probenschleife ermöglicht. Die Probengewinnung wurde durch eine in das BR-MCC-IMS integrierte Pumpe unterstützt (siehe Abbildung 12). 


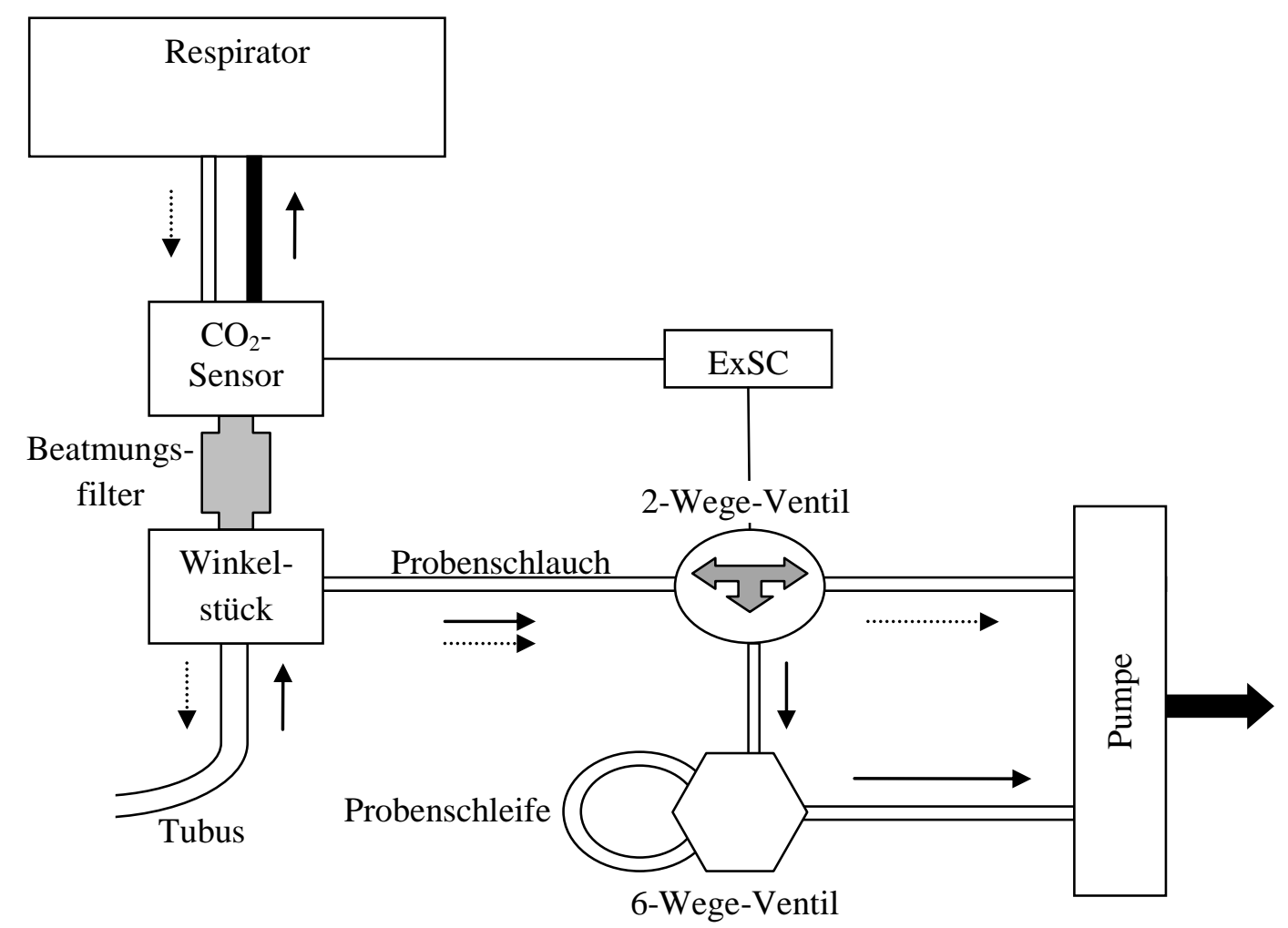

Abbildung 12. Schematische Darstellung der $\mathrm{CO}_{2}$-gesteuerten Probennahme. Der Fluss der Atemluft ist in der Inspiration mit gestrichelten und in der Exspiration mit durchgehenden Pfeilen gekennzeichnet. Die ExSC reguliert den unterstützenden Sog der Pumpe über das 2-Wege-Ventil auf der Basis der gemessenen $\mathrm{CO}_{2}$-Konzentration.

\subsection{DATENERFASSUNG UND VERARBEITUNG}

Die Probennahmesteuerung des BR-MCC-IMS sowie die Datenerfassung erfolgte mit Hilfe eines Notebooks (IBM, Lenovo R60) und einer im ISAS entwickelten Bedienungssoftware (qIMS v0.29). Die durch die Faraday-Platte des IMS erzeugten Messsignale lagen im NanoampereBereich und wurden mit Hilfe eines 1010-Volt/Ampere-Strom-Spannungsumwandlers (Entwicklung ISAS) verstärkt. Das verstärkte Signal wurde durch eine Analog-DigitalWandlerkarte (usbADC3, Entwicklung ISAS) digitalisiert und via USB-Anschluss übermittelt. Die Speicherung der Messdaten erfolgte als „Comma Separated Values“ - Files welche anschließend mit Hilfe einer Auswertungs- und Visualisierungssoftware (BB_IMSAnalyse v1.0, Entwicklung ISAS) ausgewertet wurden. 


\subsubsection{VISUALISIERUNG}

Jeder Datensatz beinhaltet die drei erfassten Parameter Ionenmobilität, Retentionszeit und Signalintensität. Die Visualisierungssoftware stellt die Ionenmobilität als inverse reduzierte Ionenmobilität $1 / \mathrm{K}_{0}\left[\mathrm{Vs} / \mathrm{cm}^{2}\right]$ dar. Diese Werte sind proportional zur tatsächlich gemessenen Driftzeit. Die Darstellung der Retentionszeit erfolgt in Sekunden und die Signalintensität in Volt. Hieraus resultiert eine zweidimensionale Darstellung der Daten (Bödeker et al. 2008 a) (siehe Abbildung 13).

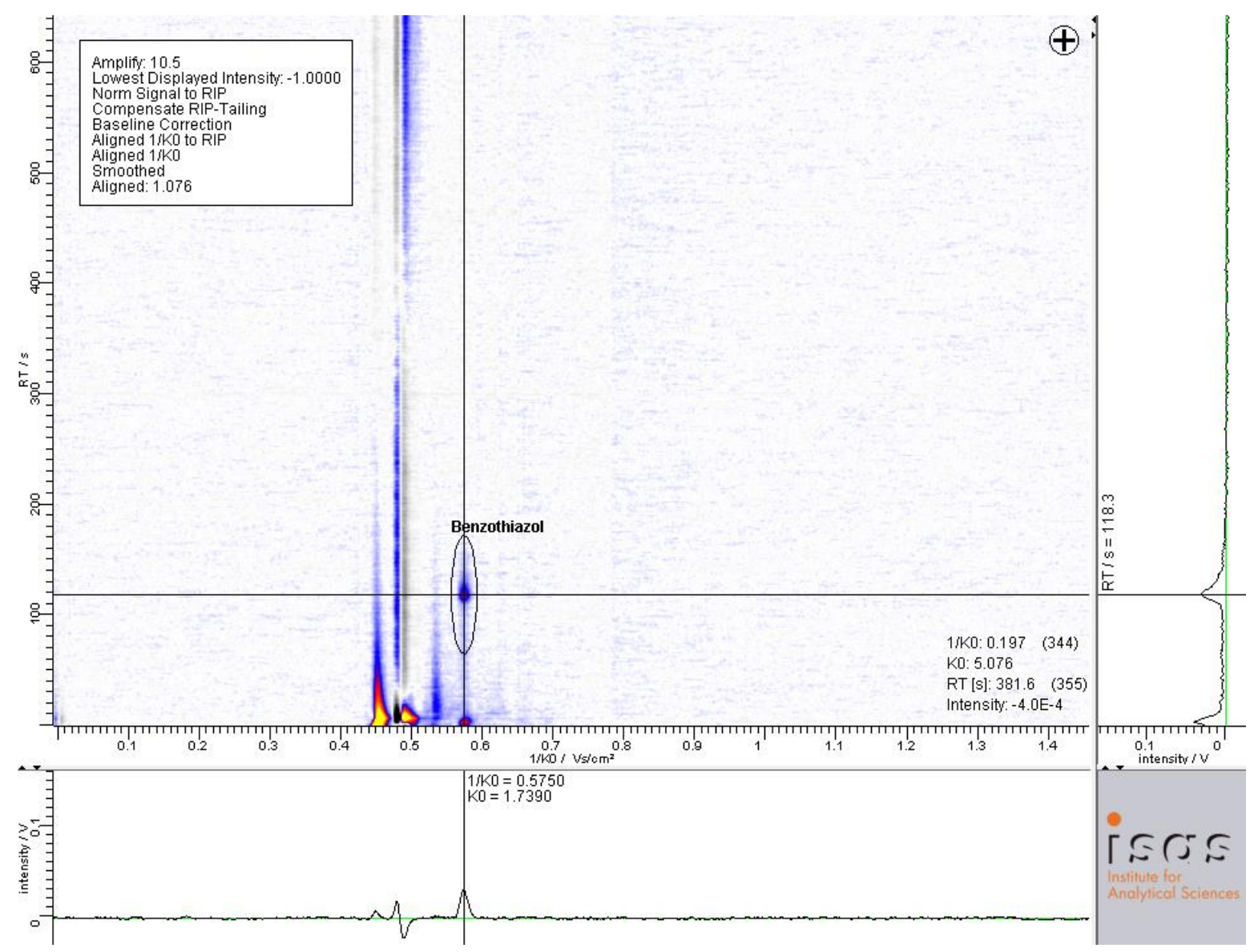

\section{Abbildung 13. Zweidimensionale Darstellung der Messergebnisse mittels Visualisierungssoftware} BB_IMSAnalyse 1.0. Die y-Achse zeigt die aus der Vortrennung durch die MCC resultierende Retentionszeit in Sekunden. Die X-Achse stellt die reduzierte Ionenmobilität in der Darstellung $1 / \mathrm{K}_{0}\left[\mathrm{Vs} / \mathrm{cm}^{2}\right]$ dar. Die Signalintensität in Volt wird zweifach in Bezug jeweils zur x- (unten) und y-Achse (rechts) dargestellt. Hier markiert für die Substanz Benzothiazol. Ebenso ist die relative Signalintensität aus der Farbe innerhalb der graphischen Darstellung abzulesen: gelb steht für die höchste Spannung, weiß steht für spannungsfrei. 


\subsubsection{NORMIERUNGSPROZESSE}

Um eine hohe Reliabilität und Validität der Daten zu gewährleisten, werden die Spektren verschiedenen Normierungsprozessen unterzogen.

Die Normierung der reduzierten Ionenmobilität erfolgt bereits bei der Datenerfassung durch die Bedienungssoftware qIMS. Hierfür wird die reduzierte Ionenmobilität der Reaktionsionen als konstant betrachtet. Die Software normiert den Reaktionsionen-Peak bei jeder Messung auf eine identische reduzierte Ionenmobilität. Hierdurch konnte in einer 1200 Messungen umfassenden Studie für verschiedene Substanzen eine präzisere Bestimmung der substanzspezifischen reduzierten Ionenmobilität gezeigt werden. Die Standardabweichung konnte für alle untersuchten Substanzen deutlich reduziert werden (Vautz et al. 2009).

Die Normierung der Signalintensität und der Retentionszeit erfolgt durch die Auswertungs- und Visualisierungssoftware BB_IMSAnalyse. Die Signalintensität eines gesamten Spektrums wird auf die Intensität des Reaktionsionen-Peaks von 1,0 Volt normiert. Für die Normierung der Retentionszeit wird das Signal von Benzothiazol verwendet. Diese Substanz ist als Kontamination in der verwendeten synthetischen Luft enthalten. Die mittlere Retentionszeit von Benzothiazol liegt bei den hier verwendeten Geräteeinstellungen bei 118,3 Sekunden. In diesem Retentionszeitbereich (Benzothiazol-Region) konnte in multiplen Messungen keine weitere Substanz nachgewiesen werden. Die Auswertungs- und Visualisierungssoftware ermittelt in der Benzothiazol-Region das Signalmaximum und setzt dieses mit der mittleren Retentionszeit für Benzothiazol von 118,3 Sekunden gleich (Perl et al. 2010).

Die Normierungsprozesse der reduzierten Ionenmobilität, Retentionszeit und Signalintensität werden im Folgenden zusammenfassend als Alignment bezeichnet. Das Alignment dient der Sicherstellung stabiler Messergebnisse und ersetzt wiederkehrende Kalibrationen. Über das Alignment hinaus werden die Datensätze automatisch weiteren Normierungsprozessen unterzogen, mit dem Ziel die Deutlichkeit der Substanz-Peaks zu erhöhen. Um Substanzen bereits bei geringer Menge und somit niedriger Signalintensität zu detektieren ist eine Erhöhung des Signal-Rausch-Verhältnis erforderlich. Dies geschieht durch Anwendung mathematischer Algorithmen (Bader et al. 2008). 


\subsubsection{AUSWERTUNG}

Durch das Programm BB_IMSAnalyse ist es möglich mehrere Spektren direkt miteinander zu vergleichen. Hierfür wird aus den zu untersuchenden Spektren ein als IMSSet bezeichneter Datensatz gebildet. Der Anwender legt für die Analyse Regionen innerhalb der Spektren fest, die miteinander verglichen werden. Die Software vergleicht diese Region in allen Spektren des Datensatzes binnen weniger Sekunden. Die Software ermittelt die maximale Signalintensität innerhalb der Region und liefert die zugehörige reduzierte Ionenmobilität und Retentionszeit. Die Ergebnisse der Vergleichsanalyse können visualisiert werden. Die Analyse zeigt ob und mit welcher Signalintensität identische Substanzen in der jeweiligen Proben vorhanden sind (Bödeker et al. 2008 b).

\subsection{KALIBRATIONSREIHEN}

Vor Beginn der Messungen am Patienten wurden für die eingesetzten Messtechniken (GC-MS und BR-MCC-IMS) jeweils Kalibrationsreihen durchgeführt. Hierfür wurden definierte Mengen Propofol in dem jeweiligen Untersuchungsmedium (Serum und Luft) analysiert.

\subsubsection{KALIBRATIONSREIHE GC-MS}

Zur Erstellung einer Kalibrationsreihe wurde je $1 \mathrm{~mL}$ natives Serum mit definierten Mengen Propofol $(2,4,5,6,8$ und $10 \mu \mathrm{g})$ sowie jeweils $5 \mu \mathrm{g}$ Thymol (Sigma-Aldrich, Seelze, Deutschland) versetzt und für 10 Sekunden geschüttelt. Das Thymol wurde auf Grund der ähnlichen Molekülstruktur und des mit Propofol vergleichbaren Lösungsverhaltens im Serum als interner Standard verwendet. Da sich menschliches Serum nicht zur direkten Injektion in einen GC-MS eignet, wurden dem Serum $3 \mathrm{~mL}$ Cyclohexan (HPLC grade, Fischer Scientific, Schwerte, Deutschland) als Lösungsmittel zugeführt. Die mit Cyclohexan versetzten Proben wurden für 30 Minuten bei Raumtemperatur mit einer Frequenz von 300/min geschüttelt. Anschließend wurde $1 \mu \mathrm{L}$ der Cyclohexanphase zur Analyse in den auf $250^{\circ} \mathrm{C}$ geheizten Injektor eines Gaschromatographen (6890N, Agilent Technologies, Santa Clara, Kalifornien, USA) appliziert. Es wurde eine HP-5MS-Säule (Agilent Technologies) mit einer Länge von $60 \mathrm{~m}$, einem Innendurchmesser von 0,25 mm und einer Filmdicke von 0,25 $\mu \mathrm{m}$ verwendet. Als Trägergas 
wurde Helium mit einem Fluss von $1 \mathrm{~mL} / \mathrm{min}$ eingesetzt. Die Ausgangstemperatur des Ofens von $35^{\circ} \mathrm{C}$ wurde nach 2 Minuten kontinuierlich um $7^{\circ} \mathrm{C} /$ min gesteigert, bis ein Maximum von $250^{\circ} \mathrm{C}$ erreicht wurde. Zur Detektion der aufgetrennten Probe wurde der Gaschromatograph mit einem Massenspektrometer der Baureihe Agilent Technologies 5973 mit Elektronenstoßionisation $(70 \mathrm{eV})$ gekoppelt. Als Messbereich für das Masse-Ladungs-Verhältnis wurde 33-450 [m/z] gewählt.

Die Auswertung der Massenspektren erfolgte computergestützt mittels AMDIS (Automated Mass Spectral Deconvolution and Identification System, Version 2.62, 2005) sowie der Spektrendatenbank des NIST (National Institute of Standards and Technology, Version 2.0, 2005).

Durch den im Massenspektrometer verwendeten Sekundärelektronenvervielfacher wurde der Totalionenstrom beider Substanzen ermittelt. Der TIC-Wert des internen Standards Thymol diente der Normierung des Propofol-Signals. Für die quantitative Bestimmung der PropofolSerumkonzentration $\left(\mathrm{C}_{\mathrm{PP}}\right)$ wurde die Peak-Fläche des TIC-Wertes berechnet und mit der definierten Propofol-Konzentration $[\mu \mathrm{g} / \mathrm{mL}]$ in Korrelation gesetzt.

Voraussetzung sowohl für die Normierung als auch die Quantifizierung mittels TIC-Wert ist eine alleinige Detektion hinsichtlich der Retentionszeit. Der Nachweis mehrerer Substanzen mit identischer Retentionszeit wird als Koelution bezeichnet. Hierdurch würden die TIC-Werte nicht mehr exakt die Konzentrationen der Substanzen von Interesse (Propofol und Thymol) wiederspiegeln.

\subsubsection{KALIBRATIONSREIHE BR-MCC-IMS}

Für die Bestimmung der Propofol-Atemluftkonzentration mittels BR-MCC-IMS wurde eine weitere Kalibrationsreihe durchgeführt. Die hierfür benötigten Gasgemische mit definierten Propofol-Konzentrationen $\left(\mathrm{C}_{\mathrm{GP}}\right)$ wurden mit Hilfe eines Kalibrationsgasgenerators (HovaCal 3834SP-VOC, Inspire Analytical Systems GmbH, Frankfurt am Main, Deutschland) erstellt. Die ursprünglich zur Kontrolle von Emissionsüberwachung entwickelte Technik ermöglicht eine 
kontrollierte Anreicherung von Luft mit Wasser, Säuren, Laugen und organischen Lösungen (Vautz und Schmäh 2009). Für die Kalibrationsreihe wurden Gasgemische mit PropofolKonzentrationen von 1, 3, 5, 7, 9, und 10 ppb erzeugt. Um eine hohe Vergleichbarkeit mit humaner Exspirationsluft zu ermöglichen, wurden Kalibrationsgase mit einer relativen Feuchte von $100 \%$ und einer Temperatur von $37^{\circ} \mathrm{C}$ verwendet. Diese Kalibrationsgase wurden in die Probenschleife eines MCC-IMS eingeleitet und analysiert. Für die verschiedenen Konzentrationen wurden je 4 Messungen unter identischen Bedingungen durchgeführt.

Für die Quantifizierung des Propofols wurde das Peak-Maximum bestimmt. Die Peak-Maxima wurden als Signalintensität in Volt [V] detektiert und mit der definierten PropofolKonzentration [ppb] in Korrelation gesetzt.

Aus den erhobenen Daten wurden der mittlere $1 / \mathrm{K}_{0}$-Wert und die mittlere Retentionszeit für Propofol bestimmt. Diese Werte lieferten für die Identifizierung von Propofol in den Exspirationsluft-Proben die zu erwartende Peak-Area.

\subsection{KLINISCHER STUDIENABSCHNITT}

Die in die Studie eingeschlossenen Patienten erhielten im Rahmen eines elektiv-operativen Eingriffs eine standardisierte totale intravenöse Anästhesie, deren Ablauf in 3.6.2 dargestellt wird. Das Messprotokoll wird unter 3.6.3 erläutert.

Alle Patienten wurden am Vortag der Narkose im Rahmen des Prämedikationsgespräches durch den behandelnden Anästhesisten aufgeklärt und gaben ihr mündliches und schriftliches Einverständnis zur Teilnahme an der Studie. 


\subsubsection{PATIENTENKOLLEKTIV}

Es wurden 13 Patienten in die Studie eingeschlossen. Alle Patienten wurden in der Hals-NasenOhrenklinik der Universitätsmedizin Göttingen behandelt und mussten sich einem elektiven chirurgischen Eingriff unterziehen. Nachfolgend sind die Kriterien zur Studienteilnahme aufgeführt:

\section{Einschlusskriterien:}

- Elektiver chirurgischer Eingriff in Vollnarkose

- Geplante Propofol-Narkose

- Lebensalter mindestens 18 Jahre

- Vorliegende Einwilligung nach Aufklärung des Patienten.

\section{Ausschlusskriterien:}

- Derzeitige Teilnahme an einer klinischen Prüfung mit einer Prüfmedikation oder anderem Prüfprodukt

- Moribunde Patienten

- Nachweis einer HIV-/Hepatitis-Infektion

- Relative oder absolute Kontraindikation für Propofol.

\subsubsection{NARKOSE-MANAGEMENT}

Die Narkoseeinleitung erfolgte nach ausreichender Präoxygenierung standardisiert durch die intravenöse Gabe von 2 mg/kg Körpergewicht Propofol (Disoprivan 1\%, Astra Zeneca, Wedel, Deutschland) und 0,5 $\mu \mathrm{g} / \mathrm{kg}$ Körpergewicht Remifentanyl (Ultiva, GlaxoSmithKline GmbH \& Co KG, München). Zur Erleichterung der trachealen Intubation wurde das Muskelrelaxans Cisatracurium (Nimbex, GlaxoSmithKline GmbH \& Co KG, München) in einer Dosis von 0,1 
mg/kg verabreicht. Die Aufrechterhaltung der Narkose resultierte aus der kontinuierlichen Applikation von Propofol und Remifentanyl nach klinischem Bedarf. Die Patienten wurden während der Narkose mit einer handelsüblichen Beatmungsmaschine (Cato, Dräger, Lübeck) ventiliert. Der eingestellte AirFlow (Frischgasfluss) mit einer inspiratorischen Sauerstoff Fraktion von 0,5 überschritt das Atemminutenvolumen, um eine Rückatmung zu verhindern.

\subsubsection{MESSPROTOKOLL}

Nach erfolgreicher Narkoseeinleitung wurden die Probanden wie unter 3.3 beschrieben an das BR-MCC-IMS angeschlossen. Zuvor wurden Null-Messungen (sogenannte „Feuchte Null in positiver Polarität“, FN+) durchgeführt. Diese dienten der Überprüfung des Systems auf Kontaminationen und der Reinigung der Probenschleife und lieferten für die Auswertung eine Null-Referenz. Es erfolgte die Anlage eines zweiten venösen Zugangs zum Zweck der Blutentnahme zur Bestimmung der Propofol-Serumkonzentration, welcher kontralateral des Medikamente zuführenden Zugangs platziert wurde. Die Probenentnahme der Exspirationsluft $(\mathrm{EX}+)$ erfolgte unter Steuerung mittels Hauptstrom-Kapnographie. Die Bestimmung der exspiratorischen Propofol-Konzentration $\left(\mathrm{C}_{\mathrm{AP}}\right)$ erfolgte basierend auf den Ergebnissen der Kalibrationsreihe BR-MCC-IMS. Innerhalb der Peak-Area wurde das Peak-Maximum bestimmt. Die Signalintensität diente der Berechnung der Propofol-Konzentration in ppb.

Abbildung 14 gibt einen Überblick über den zeitlichen Ablauf der Messung. Die Anzahl der Probenentnahmen war abhängig von der Narkosedauer. Zwischen den einzelnen Messungen wurden erneut Null-Messungen durchgeführt. 


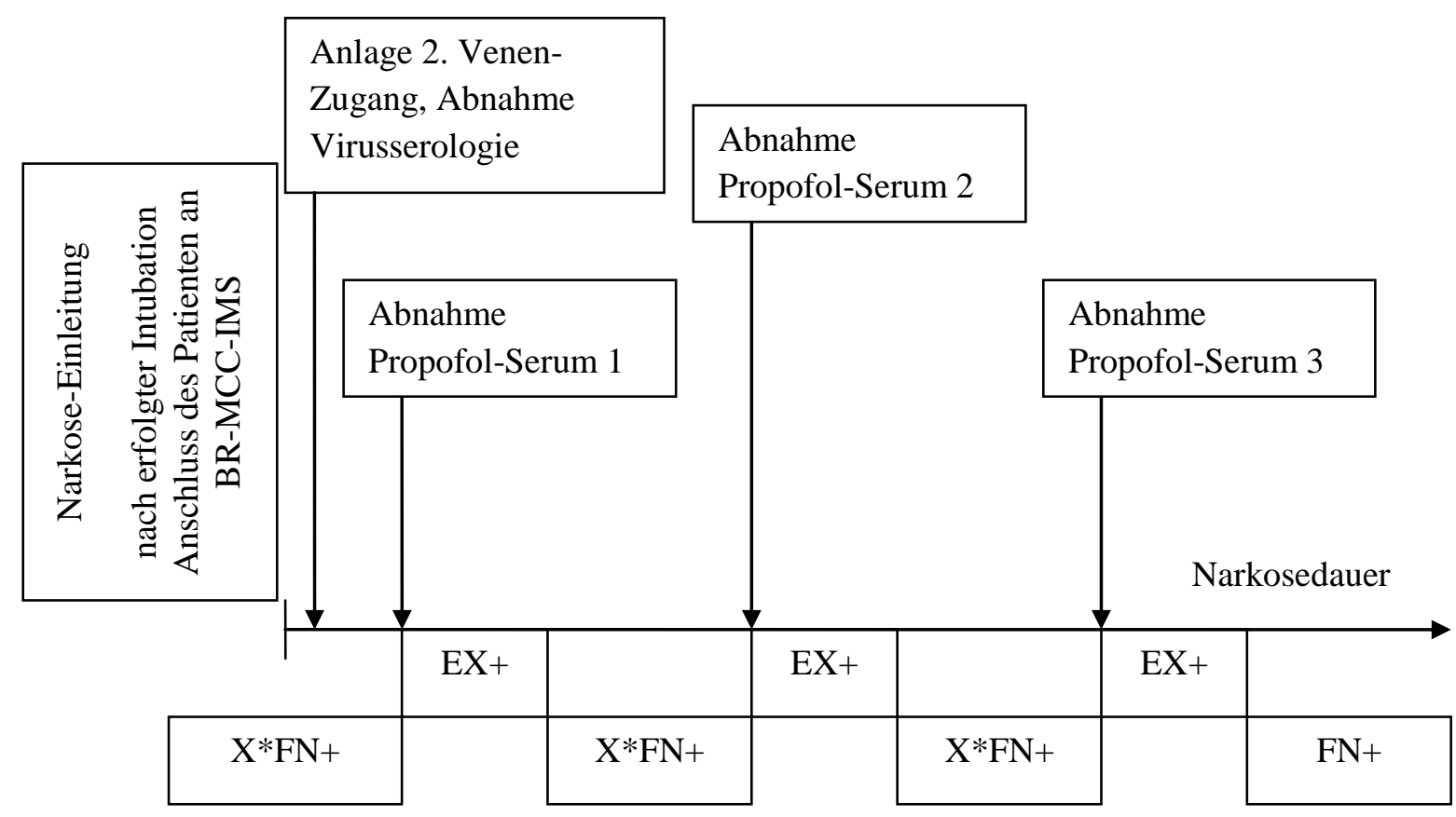

Abbildung 14. Schematische Darstellung Messablauf.

Zeitgleich zur Atemluft-Probenentnahme wurde eine Blutprobe zur Bestimmung der PropofolSerumkonzentration gewonnen. Hierzu wurden Serum-S-Monovetten ${ }^{\circledR}$ der Firma Sarstedt (Nümbrecht) mit einem Volumen von 5,5 mL verwendet. Diese wurde für 30 Minuten ruhen gelassen, um eine vollständige Blutgerinnung zu gewährleisten. Anschließend wurden die Proben zentrifugiert (Labofuge 400R, Heraeus Instruments $\mathrm{GmbH}$, Hanau; Einstellung: 20 Minuten, $1300 \mathrm{~g}, 6^{\circ} \mathrm{C}$ ) und der Überstand abpipettiert. Das gewonnene Serum wurde bei $-21^{\circ} \mathrm{C}$ tiefgefroren und nach Abschluss der Messreihe zur Konzentrationsanalyse mittels GC-MS ins ISAS überführt. Die GC-MS-Analyse der aus dem Patientenkollektiv gewonnenen Serumproben erfolgte analog des beschriebenen Vorgehens zur Erstellung der Kalibrationsreihe. Die hierbei ermittelten Peak-Flächen wurden für die Bestimmung der Serumkonzentration in die aus der Kalibrationsreihe resultierende Formel eingesetzt. 


\subsection{STATISTIK}

Die Daten werden, wenn nicht anderes gekennzeichnet, als Median (Minimum $\leftrightarrow$ Maximum) präsentiert.

Die Auswertung der Kalibrationsreihen erfolgte durch Regressionsanalysen 1. Art. Zur Ermittlung der Präzision der Kalibrationsreihen wurden die absolute und relative Standardabweichung bestimmt.

Zur Bestimmung der Sensitivität der Kalibrationsreihe BR-MCC-IMS wurde die Nachweisgrenze (LOD, limit of detection) sowie die Quantifizierungsgrenze (LOQ, limit of quantification) bestimmt. Hierzu wurde das Signal-Rausch-Verhältnis multipler Null-Messungen an Patienten in der Peak-Area gemittelt und die Standardabweichung berechnet. Die Grenzen wurden berechnet aus der mittleren Signalintensität in der Peak-Area plus der dreifachen Standardabweichung (LOD) beziehungsweise der zehnfachen Standardabweichung (LOQ) (MacDougall und Crummett 1980).

Die aus der Exspirationsluft gewonnenen BR-MCC-IMS-Daten $\left(\mathrm{C}_{\mathrm{AP}}\right)$ wurden mit der mittels GCMS kalkulierten Serumkonzentration $\left(\mathrm{C}_{\mathrm{PP}}\right)$ durch eine Regressionsanalyse 2. Art verglichen.

Da die Propofol-Konzentrationen in Exspirationsluft $[\mathrm{ppb}]$ und Serum $[\mu \mathrm{g} / \mathrm{mL}]$ unter Verwendung unterschiedlicher Einheiten erfasst wurden, erfolgte eine Normierung der Messwerte (Mayevsky et al. 2004). Hierfür wurde der jeweilige Maximalwert beider Messmethoden gleich 100\% gesetzt und die übrigen Werte in Relation hierzu. Mit dem Ziel des Methodenvergleichs erfolgte die Auswertung der Daten mittels Passing-Bablok-Regression (Passing und Bablok 1983) und Bland-Altman-Diagramm (Bland und Altman 1986). Aus der Regression nach Passing und Bablok resultiert die Steigung $\beta$ (Slope) sowie der Achsenabschnitt $\alpha$ (Intercept). Das Bland-Altman-Diagramm liefert die mittlere systematische Messabweichung (Bias). 
Die statistische Auswertung erfolgte unter Verwendung von Statistica für Windows Version 8.0 (StatSoft, Inc., Tulsa, Oklahoma, USA) und eines Tools für Microsoft Office Excel 2007 (http://www.acomed-statistik.de/passing-bablok-regression.html, Downloaddatum 19.12.2010) 


\section{ERGEBNISSE}

\subsection{KALIBRATIONSREIHEN}

Zunächst erfolgt die Darstellung der Ergebnisse aus den präklinischen Kalibrationsreihen. Die Untersuchungen bestanden aus je 6 verschiedenen definierten Konzentrationen. Für die definierten Propofol-Konzentrationen in Serum und Gasphase wurde mittels Regressionsanalyse 1. Art das jeweilige Bestimmtheitsmaß $\left(\mathrm{r}^{2}\right)$ der angewendeten Methode ermittelt. Die Präzision der Kalibrationsreihen wurde durch die absolute und relative Standardabweichung ermittelt.

\subsubsection{KALIBRATIONSREIHE GC-MS}

In allen aufgezeichneten Spektren der Kalibrationsreihe wurden Thymol (m/z 135 und 150) und Propofol (m/z 163 und 178) nachgewiesen. Die Detektion erfolgte mit Retentionszeiten von 21,5 Minuten für Thymol und 22,9 Minuten für Propofol (siehe Abbildung 15). Da es in dem Retentionszeitbereich von Thymol und Propofol $\mathrm{zu}$ keiner Koelution mit anderen Seruminhaltstoffen kam, wurde die Peak-Fläche des TIC zur Quantifizierung von Propofol genutzt.

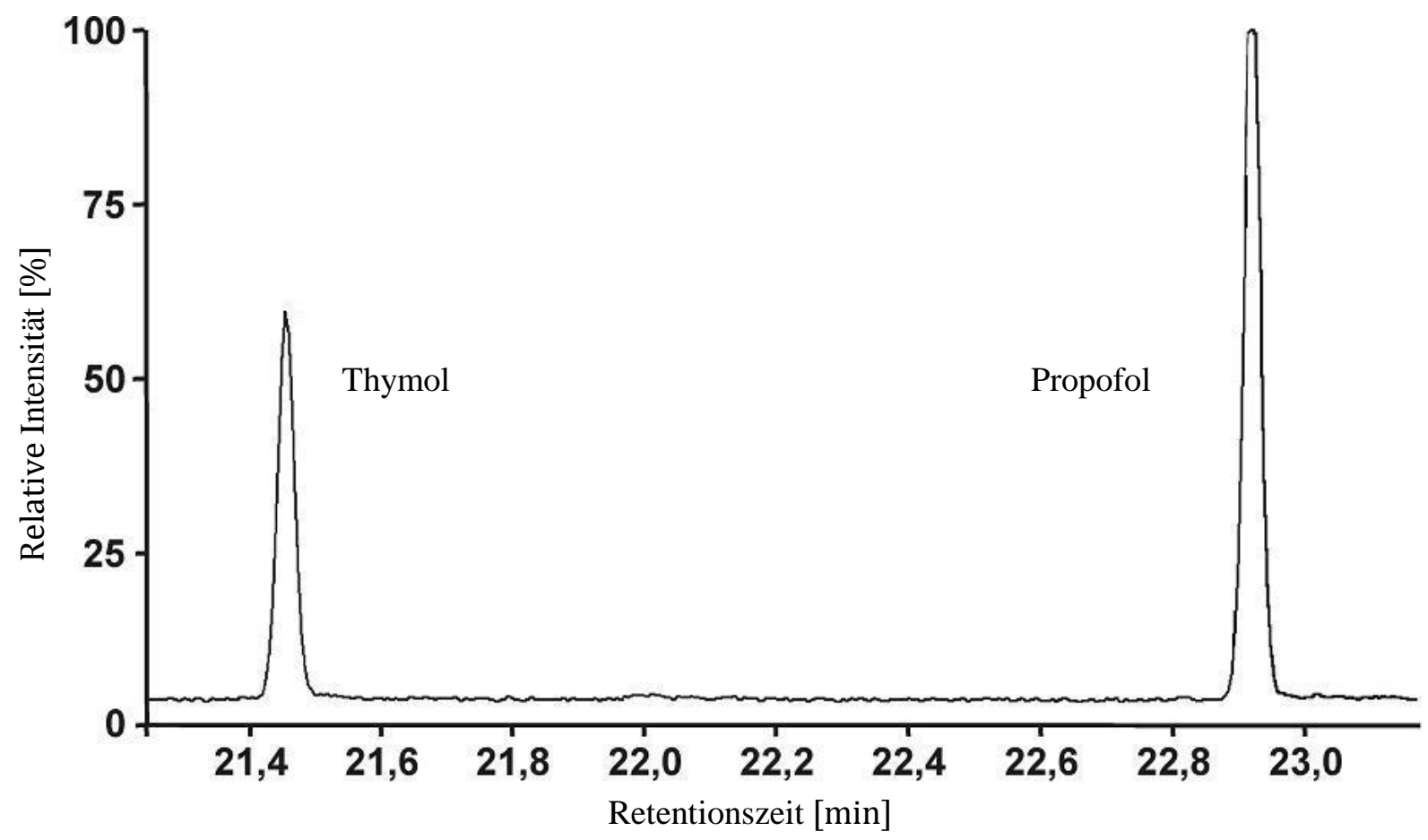

Abbildung 15. Gaschromatogramm der Kalibrationsreihe GC-MS. 
Die Ergebnisse der Kalibrationsreihe GC-MS ergaben eine lineare Korrelation zwischen den definierten Propofol-Serumkonzentrationen $\left(\mathrm{C}_{\mathrm{PP}}\right)[\mu \mathrm{g} / \mathrm{mL}]$ und der aus der GC-MS-Analyse stammenden Peak-Fläche mit einem Bestimmtheitsmaß r² von 0,9343 (siehe Abbildung 16).

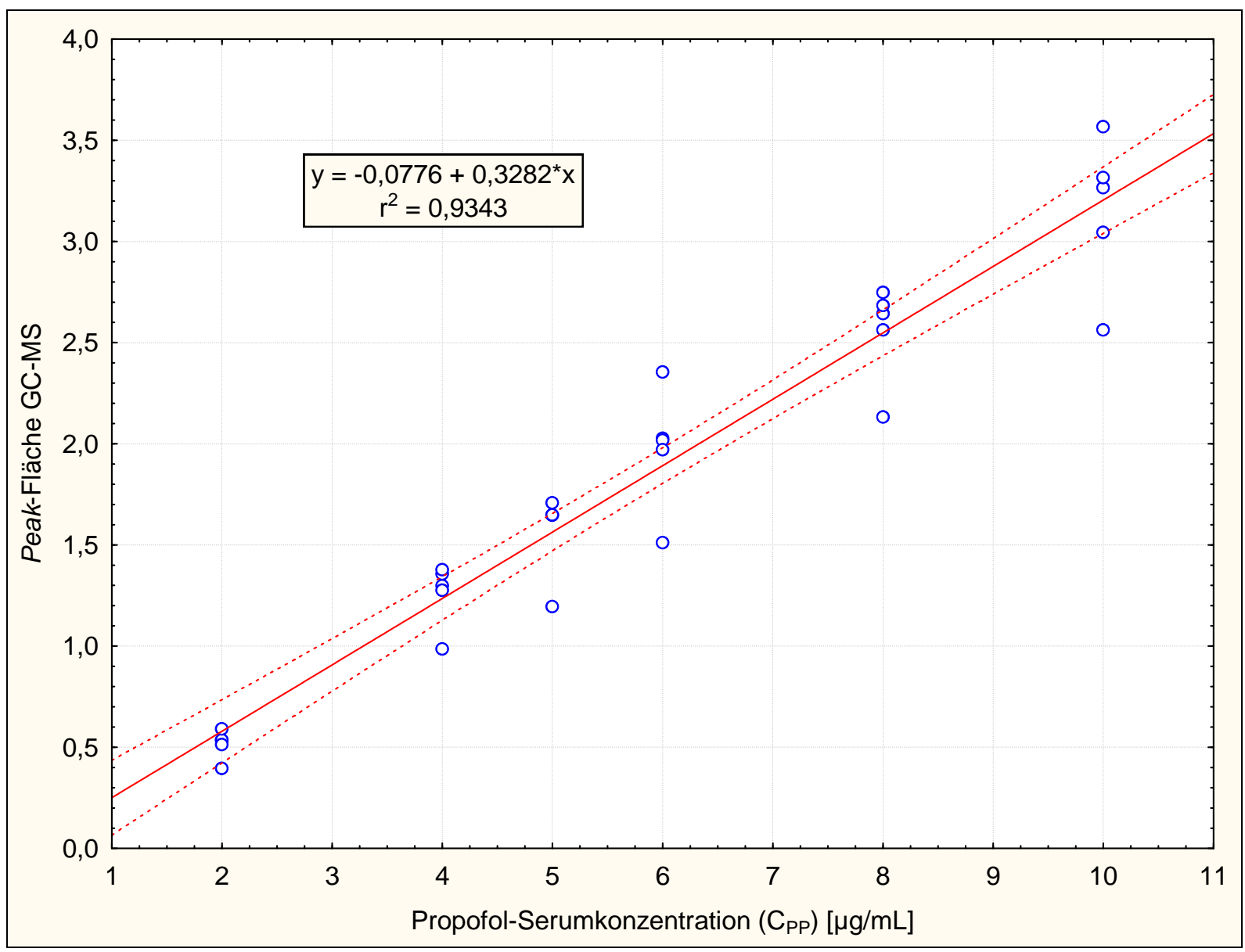

Abbildung 16. Regressionsanalyse 1. Art der Kalibrationsreihe GC-MS. lineare Regression zwischen Peak-Fläche im GC-MS Spektrum und definierter Propofol-Serumkonzentration $\left(\mathrm{C}_{\mathrm{PP}}\right)[\mu \mathrm{g} / \mathrm{mL}]$; durchgezogene Linie = Regressionsgerade, gestrichelte Linie $=95 \%$ Konfidenzintervall, Bestimmtheitsmaß $\left(r^{2}\right)=0,9343$.

Für die definierten Propofol-Serumkonzentrationen zwischen 2 und $10 \mu \mathrm{g} / \mathrm{mL}$ wurden gemittelte Peak-Flächen zwischen 0,51 und 3,15 gemessen. Zur Beurteilung der Messqualität der Kalibrationsreihe GC-MS wurde für jede der sechs definierten Konzentrationen die absolute und relative Standardabweichung bestimmt (siehe Tabelle 6). Für die Kalibrationsreihe GC-MS wurde eine mittlere relative Standardabweichung von 12,2\% ermittelt. 


\begin{tabular}{c|ccc}
\hline $\begin{array}{c}\text { Propofol-Serumkonzentration } \\
{[\mu \mathrm{g} / \mathrm{mL}]}\end{array}$ & $\varnothing$ Peak-Fläche GC-MS & SD & RSD [\%] \\
\hline 2 & 0,51 & 0,07 & 14,05 \\
\hline 4 & 1,26 & 0,16 & 12,54 \\
5 & 1,57 & 0,21 & 13,42 \\
8 & 1,98 & 0,30 & 15,24 \\
10 & 2,55 & 0,25 & 9,60 \\
\hline
\end{tabular}

Tabelle 6. Ergebnisse der Kalibrationsreihe GC-MS. Propofol-Serumkonzentration $[\mu \mathrm{g} / \mathrm{mL}]$, $\varnothing$ Peak-Fläche die mittels GC-MS detektiert wurde, absolute Standardabweichung (SD) und relative Standardabweichung in Prozent (RSD [\%]).

\subsubsection{KALIBRATIONSREIHE BR-MCC-IMS}

Die Ergebnisse der Kalibrationsreihe BR-MCC-IMS ergaben eine lineare Korrelation zwischen den definierten Propofol-Konzentrationen im Gasgemisch $\left(\mathrm{C}_{\mathrm{GP}}\right)$ [ppb] und der aus der BR-MCCIMS-Analyse stammenden Signalintensität mit einem Bestimmtheitsmaß $r^{2}$ von 0,984 (Abbildung 17). 


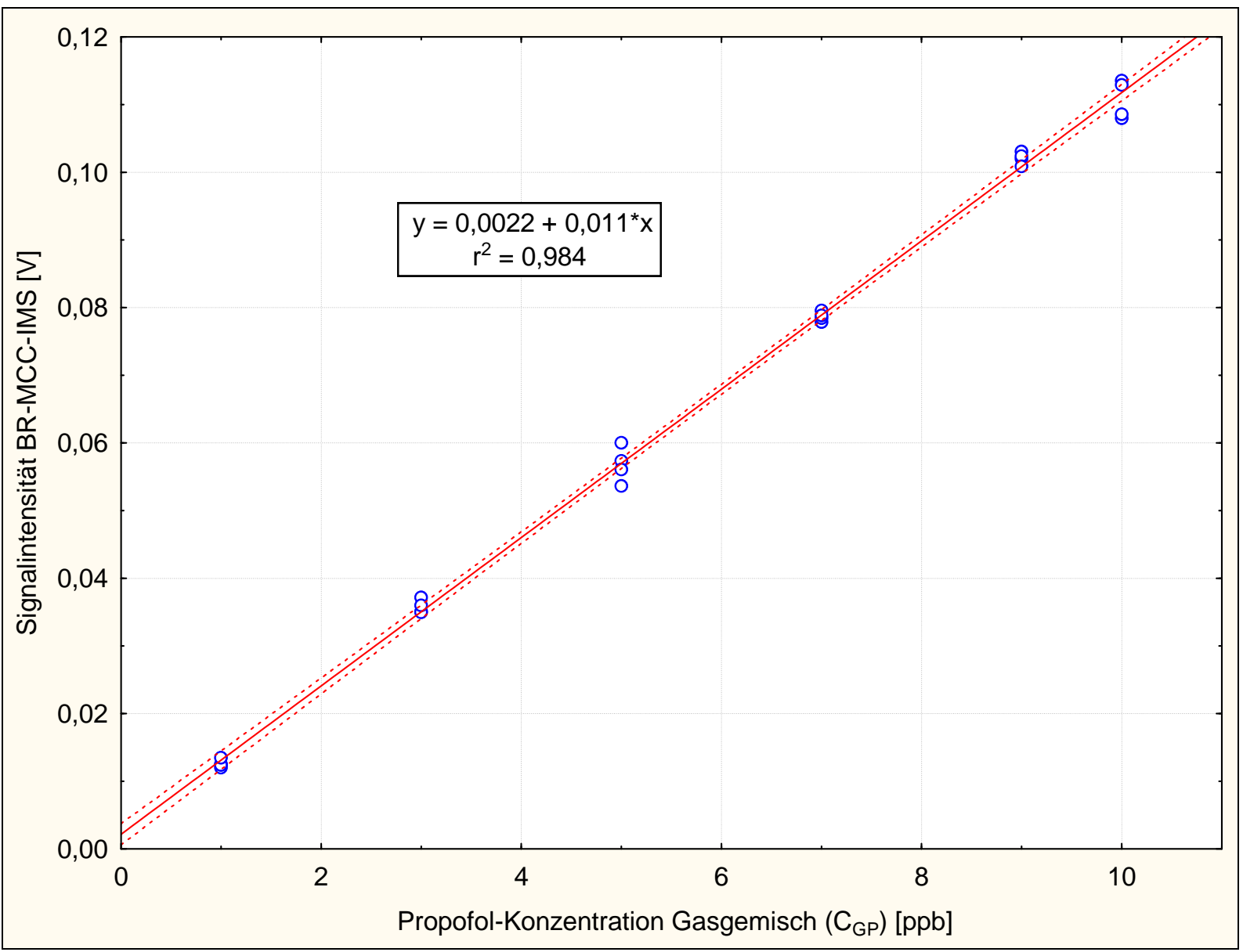

Abbildung 17. Regressionsanalyse 1. Art der Kalibrationsreihe BR-MCC-IMS. Lineare Regression zwischen definierter Propofol-Konzentration Gasgemisch ( $\mathrm{C}_{\mathrm{GP}}$ ) [ppb] und Signalintensität BR-MCC-IMS [V]; durchgezogene Linie $=$ Regressionsgerade, gestrichelte Linie $=95 \%$ Konfidenzintervall, Bestimmtheitsmaß $\left(\mathrm{r}^{2}\right)=0,984$.

Für die definierten Propofol-Konzentrationen zwischen 1 und 10 ppb wurden gemittelte IMSSignale zwischen 0,013 und 0,111 Volt gemessen. Zur Beurteilung der Messqualität der Kalibrationsreihe BR-MCC-IMS wurde für jede der sechs definierten Propofol-Konzentrationen die absolute und relative Standardabweichung bestimmt (siehe Tabelle 7). Für die Kalibrationsreihe BR-MCC-IMS wurde eine mittlere relative Standardabweichung von 2,5\% ermittelt. 


\begin{tabular}{c|ccc}
\hline $\begin{array}{c}\text { Propofol-Konzentration } \\
\text { Gasgemisch }\left(C_{G P}\right)[p p b]\end{array}$ & $\begin{array}{c}\text { Ø Signalintensität BR- } \\
\text { MCC-IMS }[V]\end{array}$ & RSD [\%] \\
\hline 1 & 0,013 & 0,0005 & 4,3 \\
3 & 0,036 & 0,0010 & 2,8 \\
5 & 0,057 & 0,0023 & 4,1 \\
7 & 0,079 & 0,0006 & 0,8 \\
9 & 0,102 & 0,0007 & 0,8 \\
10 & 0,111 & 0,0025 & 2,2 \\
\hline
\end{tabular}

Tabelle 7. Ergebnisse der Kalibrationsreihe BR-MCC-IMS. Propofol-Konzentration Gasgemisch ( $\left.\mathrm{C}_{\mathrm{GP}}\right)$ [ppb] , Signalintensität BR-MCC-IMS [V], absolute Standardabweichung (SD) und relative Standardabweichung in Prozent (RSD [\%]).

Die Nachweisgrenze (limit of detection, LOD) lag bei 0,7 ppb, eine Quantifizierung (limit of quantification, LOQ) war möglich ab 1,5 ppb.

Basierend auf den Peak-Maxima erfolgte die Bestimmung der mittleren Retentionszeit und der reduzierten Mobilität des ionisierten Propofols. Der mittlere $1 / \mathrm{K}_{0}$-Wert für Propofol liegt bei 0,674 Vs/cm² mit einer Standardabweichung von +/- 0,0009 Vs/cm² (RSD 0,001\%). Das Signal wurde bei einer mittleren Retentionszeit von 474,5 Sekunden aufgezeichnet (SD +/- 4,7 s, RSD 0,01\%). Tabelle 8 zeigt die gemessenen Signale der Kalibrationsreihe BR-MCC-IMS. 


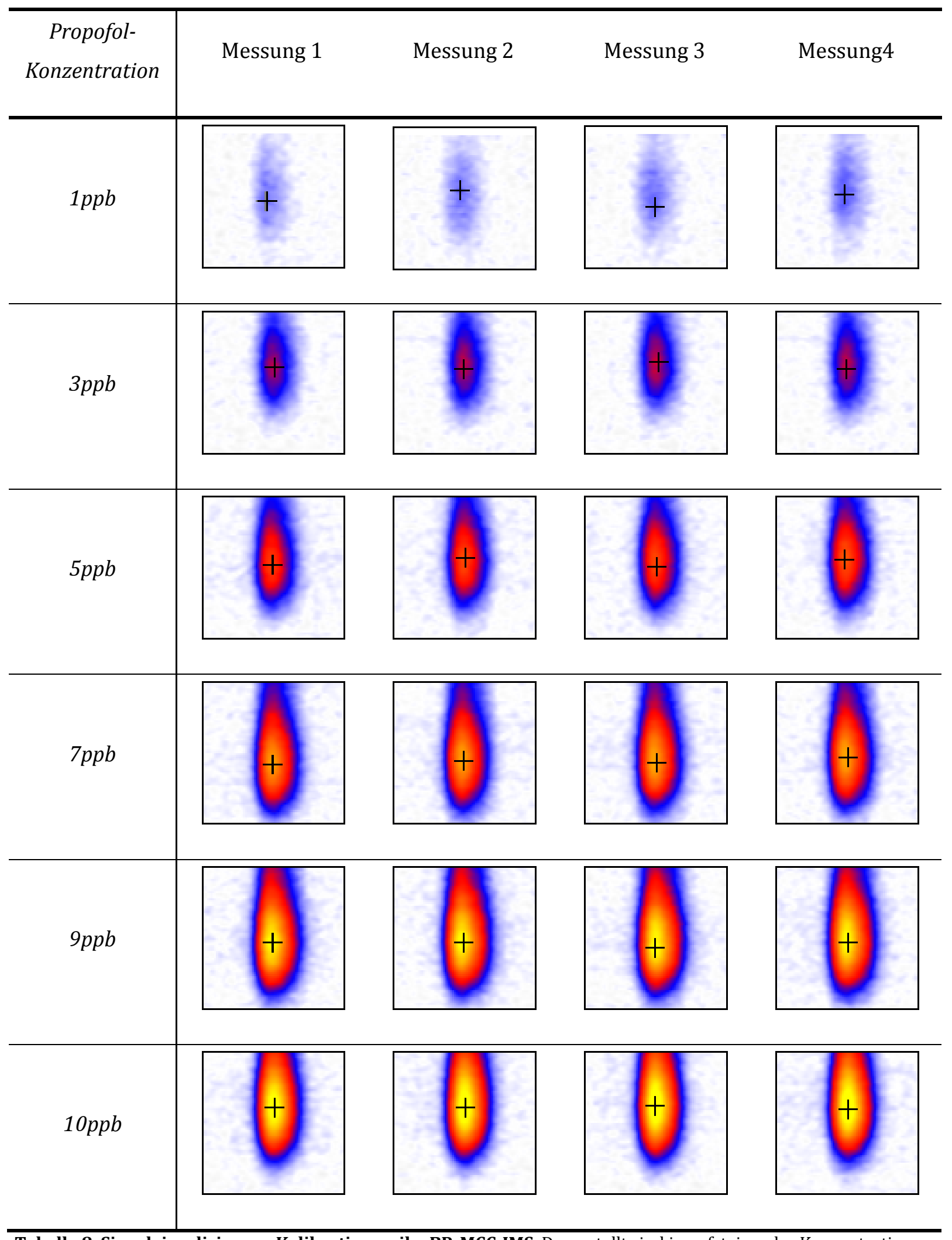

Tabelle 8. Signalvisualisierung Kalibrationsreihe BR-MCC-IMS. Dargestellt sind in aufsteigender Konzentration die gemessenen Signale. Das Kreuz zeigt den Schnittpunkt, welchen die gemittelte Retentionszeit und die reduzierte Ionenmobilität bilden. 
Aus den Ergebnissen der Kalibrationsreihe BR-MCC-IMS wurde für die klinische Untersuchung die Peak-Area für Propofol ermittelt. Für die Bestimmung wurde die 20-fache Standardabweichung zu Grunde gelegt. Dies ergab für die Retentionszeit eine Abweichung von gerundet +/- 80 Sekunden und für die inverse reduzierte Ionenmobilität $1 / \mathrm{K}_{0}$ von $0,018 \mathrm{Vs} / \mathrm{cm}^{2}$. Es resultiert eine ellipsenförmige Peak-Area für Propofol mit einem Mittelpunkt beschrieben durch eine reduzierte Ionenmobilität von $0,674 \mathrm{Vs} / \mathrm{cm}^{2}$ und eine Retentionszeit von 474,5 Sekunden (siehe Abbildung 18).

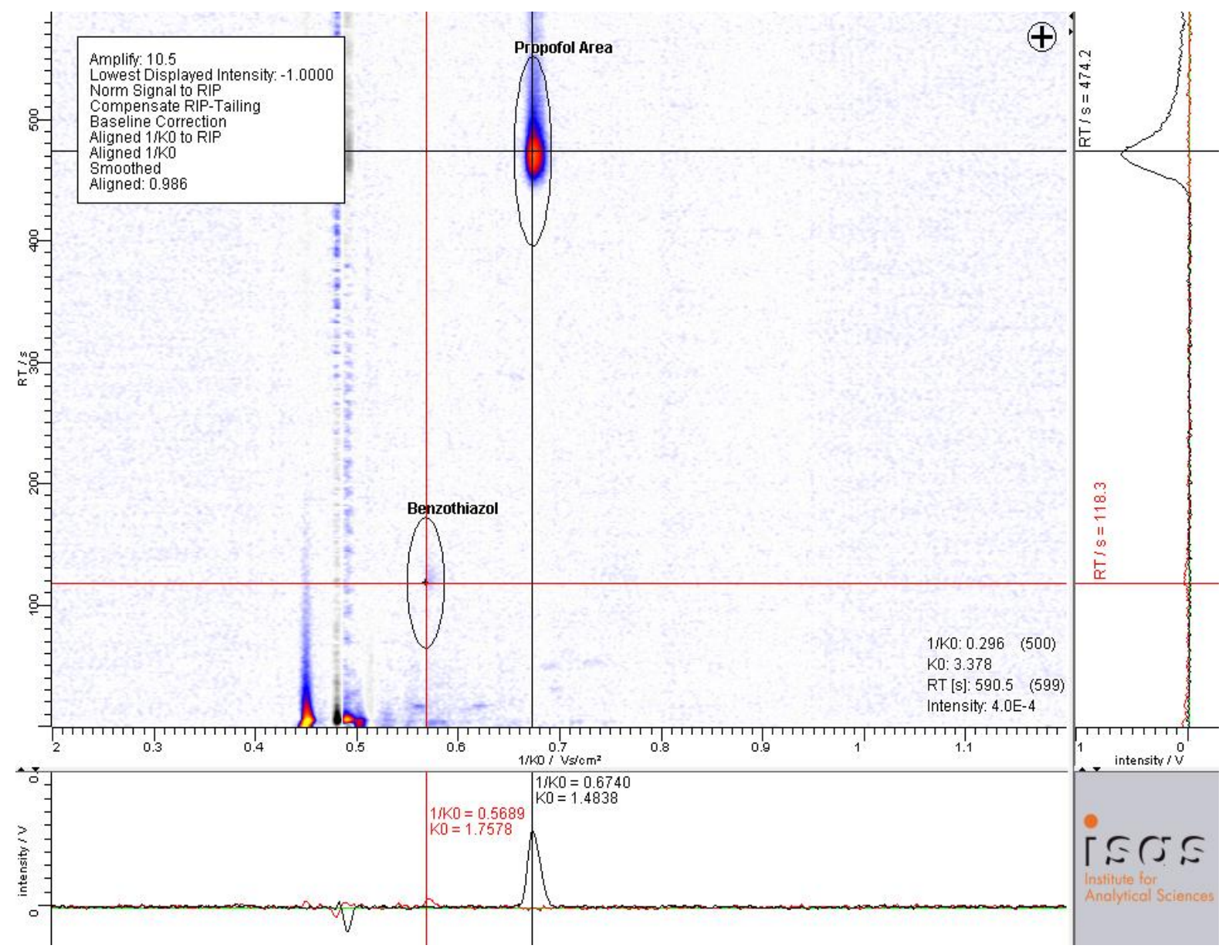

Abbildung 18. BR-MCC-IMS Spektrum Propofol-Area. 


\subsection{KLINISCHE UNTERSUCHUNG DER PLASMATISCHEN UND EXSPIRATORISCHEN PROPOFOL-KONZENTRATION BEI TIVA-PATIENTEN}

Die Tabellen 9 und 10 skizzieren das Patientenkollektiv. Tabelle 9 zeigt die demographische Zusammensetzung unter Berücksichtigung des Body-Mass-Index (BMI) und der ASAKlassifikation (ASA, American Society of Anesthesiologists). Tabelle 10 enthält die Diagnosen inklusive geplanter Eingriffe aller Patienten.

\begin{tabular}{l|ccc}
\hline \multicolumn{1}{c|}{$\begin{array}{c}n=13 \\
\quad+=4 \hat{\jmath}=9\end{array}$} & Median & Minimum & Maximum \\
\hline Alter & 45 & 18 & 68 \\
Gewicht $[\mathrm{kg}]$ & 76 & 58 & 107 \\
Größe $[\mathrm{cm}]$ & 173 & 160 & 38,8 \\
BMI & 24,6 & 19,6 & 3 \\
ASA-Score & 2 & 1 & \\
\hline
\end{tabular}

Tabelle 9. Zusammensetzung des Patientenkollektivs. 


\begin{tabular}{|c|c|c|c|c|}
\hline $\begin{array}{l}\text { Pat.- } \\
\text { ID }\end{array}$ & Alter & Geschlecht & Diagnose & Operation \\
\hline 1 & 40 & $\mathrm{M}$ & Otosklerose & Tympanoskopie, Tympanoplastik \\
\hline 2 & 69 & M & Tonsillen-/Zungengrund-CA & Panendoskopie, Laserablation \\
\hline 3 & 21 & $\mathrm{~W}$ & Chronische Sinusitis & Pansinus-Operation \\
\hline 4 & 53 & M & Zungengrund-CA & Panendoskopie, Laserablation \\
\hline 5 & 68 & M & $\begin{array}{l}\text { Muschelhyperplasie, chronische } \\
\text { Sinusitis }\end{array}$ & $\begin{array}{l}\text { Septumkorrektur, Pansinus- } \\
\text { Operation }\end{array}$ \\
\hline 6 & 61 & M & $\begin{array}{l}\text { Nasenatmungsbehinderung, } \\
\text { chronische Sinusitis }\end{array}$ & $\begin{array}{l}\text { Septumplastik, Pansinus-Operation, } \\
\text { Conchotomie, Lymphknoten- } \\
\text { Exstirpation }\end{array}$ \\
\hline 7 & 43 & $\mathrm{~W}$ & Otosklerose & Stapesplastik \\
\hline 8 & 25 & M & $\begin{array}{l}\text { Septumquerstand, chronische } \\
\text { Sinusitis }\end{array}$ & Septumplastik, Conchotomie \\
\hline 9 & 18 & $\mathrm{~W}$ & Chronische Sinusitis & $\begin{array}{l}\text { Septumplastik, Pansinus-Operation, } \\
\text { Conchotomie }\end{array}$ \\
\hline 10 & 45 & M & Chronische Sinusitis & $\begin{array}{l}\text { Septumplastik, Pansinus-Operation, } \\
\text { Conchotomie }\end{array}$ \\
\hline 11 & 55 & $\mathrm{~W}$ & Otosklerose & Tympanoplastik, Mastoidektomie \\
\hline 12 & 45 & M & Cholesteatom & Tympanoplastik \\
\hline 13 & 45 & M & Chronische Sinusitis & $\begin{array}{l}\text { Septumplastik, Pansinus-Operation, } \\
\text { Conchotomie }\end{array}$ \\
\hline
\end{tabular}

Tabelle 10. Übersicht Patientenkollektiv mit Alter, Geschlecht, Diagnose und Operation. M=männlich, $\mathrm{W}=$ weiblich 
Die Narkoseeinleitung erfolgte durch Bolusapplikation von im Mittel 2,1 $(1 \leftrightarrow 3,4) \mathrm{mg} / \mathrm{kg}$ Propofol und $0,5(0,3 \leftrightarrow 0,7) \mathrm{mg} / \mathrm{kg}$ Rocuronium sowie einer kontinuierlichen Gabe von 0,5 $\mu \mathrm{g} / \mathrm{kg} / \mathrm{min}$ Remifentanyl. Zur Aufrechterhaltung der Narkose wurden im Mittel 3,9 (1↔7) $\mathrm{mg} / \mathrm{kg} / \mathrm{h}$ Propofol und standardisiert 0,5 $\mu \mathrm{g} / \mathrm{kg} / \mathrm{min}$ Remifentanyl appliziert. Die Probanden wurden mit einem Atemzugvolumen von im Mittel 6,9 $(4 \leftrightarrow 10) \mathrm{mL} / \mathrm{kg}$ und einer Atemfrequenz von im Mittel 11,5 (10↔14) /min ventiliert. Das Verhältnis von Inspiration zu Exspiration lag im Mittel bei 1:1,5.

Aus dem Patientenkollektiv (n=13) konnten 24 Datensätze, bestehend aus intravasaler Serumkonzentration und exspiratorischer Propofol-Konzentration, generiert werden. Die intravasalen Serumkonzentrationen erstreckten sich mit Werten zwischen 0,38 und 4,29 $\mu \mathrm{g} / \mathrm{mL}$ über den unteren bis mittleren therapeutischen Bereich. Die Messung der exspiratorischen Propofol-Konzentration mittels BR-MCC-IMS ergab Werte zwischen 5,08 und 15,54 ppb (siehe Tabelle 11, Spalte 1 und 2). 


\begin{tabular}{|c|c|c|c|}
\hline $\begin{array}{c}\text { Propofol-Serum } \\
{[\mu \mathrm{g} / \mathrm{mL}]}\end{array}$ & $\begin{array}{l}\text { Propofol- } \\
\text { Exspirationsluft [ppb] }\end{array}$ & $\begin{array}{c}\text { Propofol-Serum } \\
\text { normiert [\%] }\end{array}$ & $\begin{array}{c}\text { Propofol- } \\
\text { Exspirationsluft } \\
\text { normiert [\%] }\end{array}$ \\
\hline 2,35 & 11,38 & 54,70 & 73,21 \\
\hline 2,84 & 14,00 & 66,34 & 90,10 \\
\hline 4,29 & 12,41 & 100 & 79,86 \\
\hline 2,54 & 11,83 & 59,22 & 76,15 \\
\hline 3,38 & 14,20 & 78,84 & 91,40 \\
\hline 4,07 & 15,54 & 94,96 & 100 \\
\hline 2,59 & 11,55 & 60,33 & 74,34 \\
\hline 3,94 & 11,58 & 91,83 & 74,55 \\
\hline 2,14 & 12,63 & 49,91 & 81,25 \\
\hline 1,26 & 6,65 & 29,46 & 42,81 \\
\hline 1,32 & 5,70 & 30,84 & 36,68 \\
\hline 0,38 & 5,08 & 8,97 & 32,72 \\
\hline 1,45 & 7,54 & 33,74 & 48,53 \\
\hline 1,31 & 5,27 & 30,54 & 33,90 \\
\hline 1,16 & 6,87 & 26,99 & 44,20 \\
\hline 1,62 & 9,05 & 37,77 & 58,22 \\
\hline 2,31 & 10,39 & 53,94 & 66,87 \\
\hline 2,50 & 9,84 & 58,30 & 63,32 \\
\hline 2,30 & 9,05 & 53,57 & 58,27 \\
\hline 2,82 & 12,17 & 65,70 & 78,31 \\
\hline 2,08 & 10,25 & 48,59 & 65,95 \\
\hline 3,61 & 13,29 & 84,13 & 85,52 \\
\hline 2,91 & 9,17 & 67,95 & 59,04 \\
\hline 1,04 & 7,42 & 24,20 & 47,76 \\
\hline
\end{tabular}

Tabelle 11. Ergebnisse der Patientenmessungen. Die Spalten 1 und 2 zeigen die Propofol-Konzentration im Serum $[\mu \mathrm{g} / \mathrm{mL}]$ gemessen mittels GC-MS und in der Exspirationsluft [ppb] kalkuliert mittels BR-MCC-IMS. Die Spalten 3 und 4 zeigen die nach Mayevsky et al. (2004) normierten Messwerte. 
Die Ergebnisse der Regressionsanalyse 2. Art der Propofol-Konzentration in der Exspirationsluft (BR-MCC-IMS) und im Serum (GC-MS) zeigt Abbildung 19. Der Korrelationskoeffizient für die Propofol-Konzentrationen in der Exspirationsluft $\left(\mathrm{C}_{\mathrm{AP}}[\mathrm{ppb}]\right)$ und im Serum $\left(\mathrm{C}_{\mathrm{PP}}[\mu \mathrm{g} / \mathrm{mL}]\right)$ lag bei $\mathrm{r}=0,8550$.

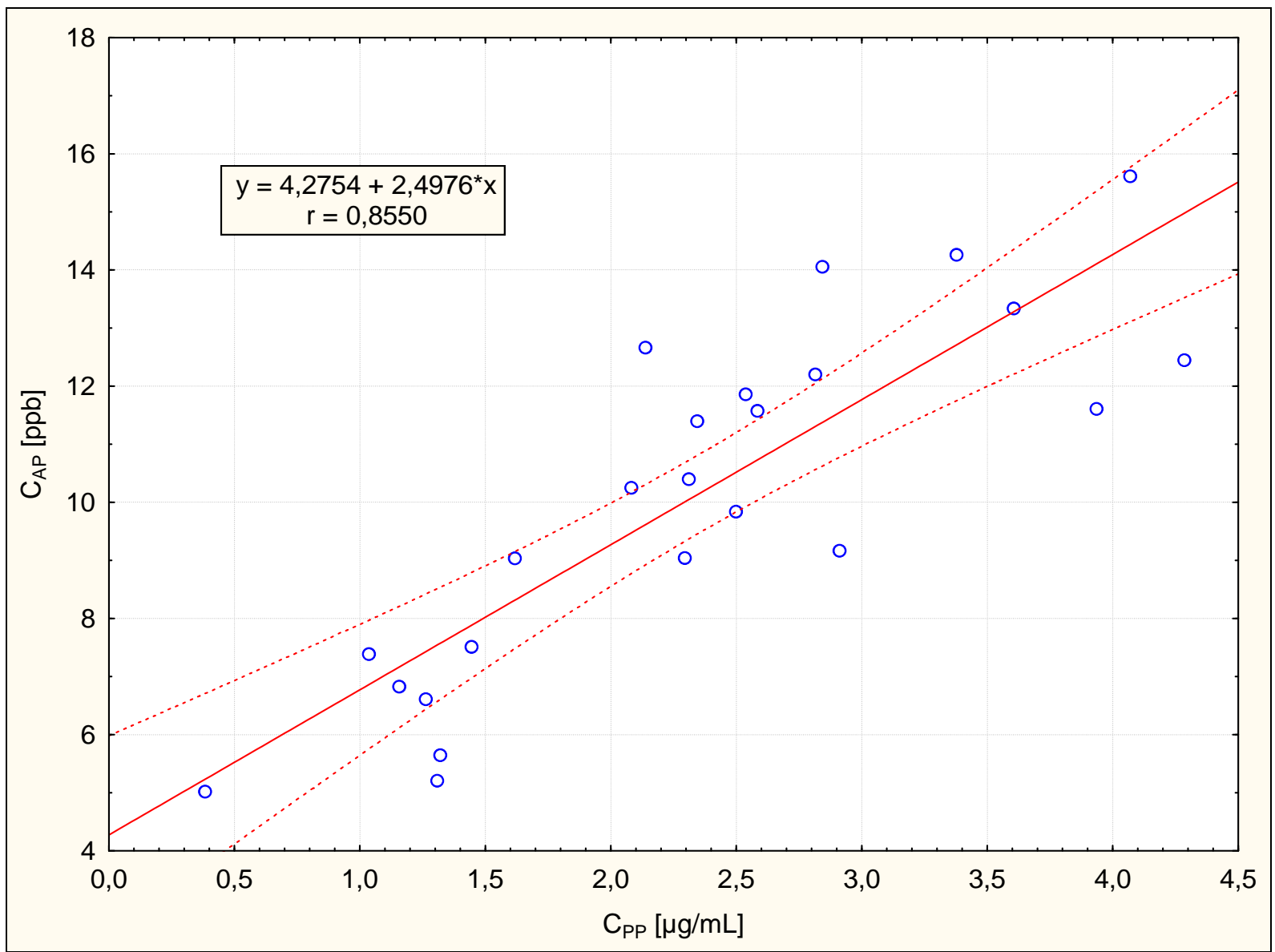

Abbildung 19. Regressionsanalyse 2. Art Patientenkollektiv. Lineare Regression zwischen PropofolKonzentration in der Exspirationsluft $\mathrm{C}_{\mathrm{AP}}[\mathrm{ppb}]$ gemessen durch BR-MCC-IMS und Propofol-Konzentration im Serum $\mathrm{C}_{\mathrm{PP}}[\mu \mathrm{g} / \mathrm{mL}]$ gemessen durch GC-MS; durchgezogene Linie $=$ Regressionsgerade, gestrichelte Linie $=95 \%-$ Konfidenzintervall. Korrelationskoeffizient $(r)=0,8550$.

Die Passing-Bablok-Regression der nach Mayevsky et al. (2004) normierten Messwerte (Tabelle 10) ergab eine Regressionsgrade mit einer Steigung (Slope) von $\beta=0,84$ (95\%Konfidenzintervall 0,65-1,06) und einem Achsenabschnitt (Intercept) von $\alpha=21,54$ (95\%Konfidenzintervall 10,15 - 31,34). Abbildung 20 zeigt die Passing-Bablok-Regression. 


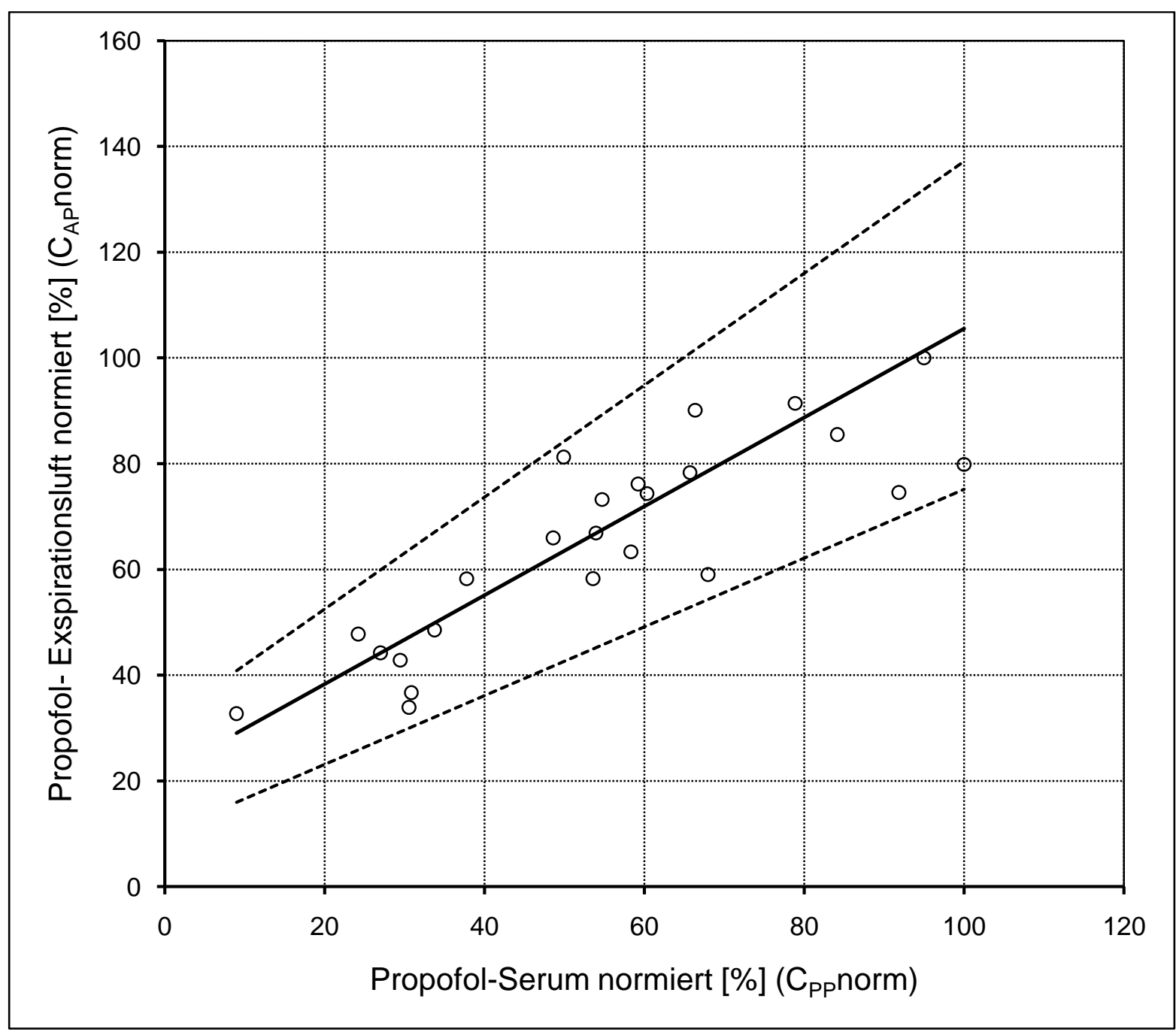

Abbildung 20. Passing-Bablok-Regression der nach Mayevsky et al. (2004) normierten Messwerte.

Durchgezogene $=$ Linie Passing-Bablok-Regressionsgrade zum Methodenvergleich, gestrichelte Linie $=95 \%$ Konfidenzintervall

Der Vergleich der nach Mayevsky et al. (2004) normierten Messwerte (Tabelle 10) ergab eine mittlere systematische Messabweichung (Bias) von -10,5\%. Die Standardabweichung lag bei +/12,3\%. Mit diesen Werten ist das 95\%-Konfidenzintervall (+/- 2SD) zwischen $+14,1 \%$ und 35,1\% definiert. Abbildung 21 zeigt das nach Mayevsky et al. (2004) modifizierte Bland-AltmanDiagramm. 


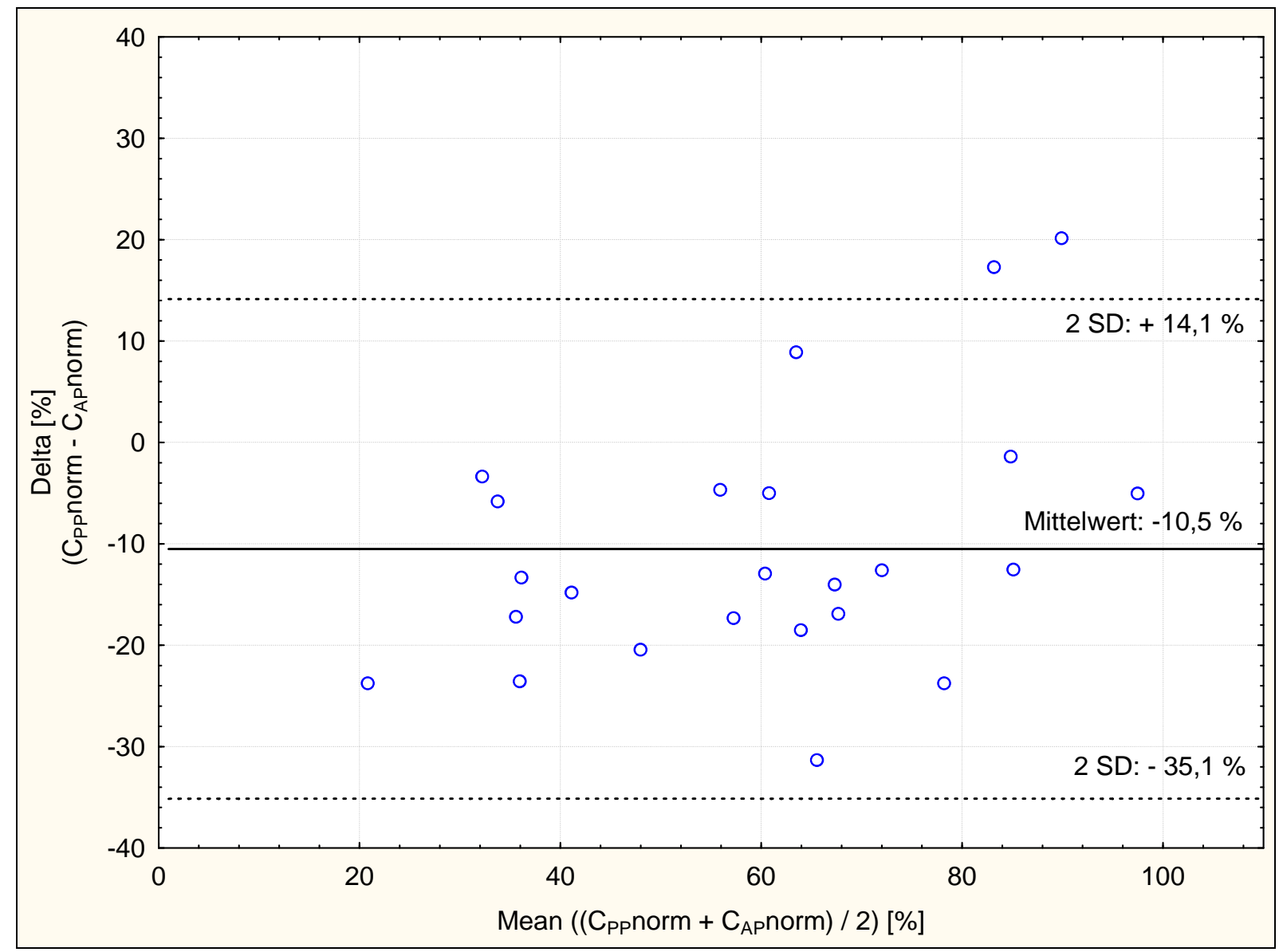

Abbildung 21. Bland-Altman-Diagramm Patientenkollektiv, modifiziert nach Mayevsky et al. (2004). Mean [\%] = Mittelwert zwischen normiertem [\%] $\mathrm{C}_{\mathrm{AP}}$ und $\mathrm{C}_{\mathrm{PP}}$. Delta [\%] = Differenz zwischen normiertem [\%] $\mathrm{C}_{\mathrm{PP}}$ und $\mathrm{C}_{\mathrm{AP}}$. Die durchgezogene Linie stellt die systematische Messabweichung (Bias), die gestrichelten Linien das 95\%Konfidenzintervall dar.

Tabelle 12 fasst die Ergebnisse der statischen Verfahren zusammen.

\begin{tabular}{c|ccc}
\hline Statistisches Verfahren & Kalibrationsreihe & Kalibrationsreihe & Methodenvergleich \\
& GC-MS & BR-MCC-IMS & (95\%-Konfidenzintervall) \\
\hline Regressionsanalyse & $\mathrm{r}^{2}=0,934$ & $\mathrm{r}^{2}=0,984$ & $\mathrm{r}=0,855$ \\
Passing-Bablok-Regression & & $\beta=0,84(0,65-1,06)$ \\
& & $\alpha=21,54(10,15-31,34)$ \\
Bland-Altman-Diagramm & & Bias $=-10,5 \%(-35,1-14,1)$ \\
\hline
\end{tabular}

Tabelle 12. Zusammenfassung der statistischen Verfahren. $r^{2}=$ Bestimmtheitsmaß, $r=$ Korrelationskoeffizient, $\beta=$ Steigung (Slope), $\alpha=$ Achsenabschnitt (Intercept), Bias = mittlere systematische Messabweichung. 


\section{DISKUSSION}

Die in dieser Studie gewonnenen Ergebnisse zeigen, dass durch den Einsatz der Ionenmobilitätsspektrometrie gekoppelt mit einer Multikapillarsäule die Identifizierung von Propofol in der Exspirationsluft von TIVA Patienten möglich ist. Die bei Patienten unter einer TIVA mit Propofol und Remifentanil gewonnenen Atemluftproben zeigten in der erwarteten Peak-Area für Propofol alle ein charakteristisches Signal.

Die Kalibrationsreihe BR-MCC-IMS zeigt eine hohe Korrelation $\left(\mathrm{r}^{2}=0,984\right)$ zwischen den definierten Propofol-Konzentrationen und der Signalintensität. Die Propofol-Konzentration in einem Gasgemisch $\left(\mathrm{C}_{\mathrm{GP}}\right)\left[\mathrm{ppb}_{\mathrm{v}}\right]$ und die gemessene Signalintensität BR-MCC-IMS (SI $\left.\mathrm{SR}_{\text {BRCC-IMS }}\right)$ [V] lassen sich nach Regressionsanalyse über folgenden mathematischen Zusammenhang ausdrücken:

$$
S I_{B R-M C C-I M S}=0,0022+0,011 * C_{G P}
$$

Eine hohe Vergleichbarkeit zwischen Kalibrationsgas und der humanen Exspirationsluft vorausgesetzt,

$$
C_{G P}=C_{A P}
$$

lässt sich Gleichung 10 zur Bestimmung der exspiratorischen Propofol-Konzentration $\left(\mathrm{C}_{\mathrm{AP}}\right)$ [ppb] wie folgt umformen:

$$
S I_{B R-M C C-I M S}=0,0022+0,011 * C_{A P}
$$


Somit lässt sich basierend auf der hohen Korrelation der Kalibrationsreihe $\left(\mathrm{r}^{2}=0,984\right)$ die Propofol-Konzentration der Exspirationsluft präzise aus der Signalintensität kalkulieren.

Die exspiratorische Propofol-Konzentration korreliert mit der aus der GC-MS-Analyse ermittelten venösen Serumkonzentration $(r=0,8550)$. Die Regressionsanalyse nach Passing und Bablok (1983) weist ebenfalls eine Korrelation der Messwerte nach. Die Steigung (Slope) der Regressionsgrade beträgt $\beta=0,84$ bei einem den Wert 1 einschließenden 95\%Konfidenzintervall zwischen 0,65 - 1,06. Hierdurch wird die Hypothese eines Zusammenhangs der Methoden bestätigt. Der Achsenabschnitt (Intercept) von $\alpha=21,54$ mit einem 95\%Konfidenzintervall von 10,15 - 31,34 zeigt das eine systematische Messabweichung vorliegt, da der Wert 0 nicht in dem Konfidenzintervall enthalten ist. Das Bland-Altman-Diagramm beziffert diese systematische Messabweichung (Bias) bei der Prognose der venösen aus der exspiratorischen Propofol-Konzentration mit einer tolerablen Abweichung von im Mittel $-10,5 \%$.

Die Studie demonstriert somit, dass mittels BR-MCC-IMS eine Bestimmung der exspiratorischen Propofol-Konzentration möglich ist. Ergebnisse dieser nicht-invasiven Methode korrelieren mit der Propofol-Konzentration in venösem Serum, was ein exspiratorisches Drug-Monitoring ermöglichen könnte.

\subsection{IDENTIFIZIERUNG VON PROPOFOL IN DER EXSPIRATIONSLUFT}

Der Nachweis von Propofol in der Exspirationsluft gelang bisher in verschiedenen Studien mit unterschiedlichen massenspektrometrischen Verfahren. Zur Anwendung kamen Protonentransferreaktions-Massenspektrometer (Harrison et al. 2003, Takita et al. 2007), Ionenmolekülreaktions-Massenspektrometer (Hornuss et al. 2007) und GaschromatographMassenspektrometer mit verschiedenen Präkonzentrationstechniken (Grossherr et al. 2006, Miekisch et al. 2008). Die Möglichkeit, Propofol in der Exspirationsluft nachzuweisen, beruht auf dem Verteilungsverhalten der Substanz zwischen Blut und Luft. Auf Grund der geringen Wasserlöslichkeit der Substanz erfolgt eine Anreicherung in der angrenzenden Luft. Dies wurde in verschiedenen Studien in headspace-Analysen belegt (Harrison et al. 2003, Hornuss et al. 2007, Miekisch et al. 2008). 
Die von den Autoren formulierte Schlussfolgerung, dass Propofol nach intravenöser Applikation in geringsten Mengen in der Exspirationsluft detektierbar sei, wird durch die Ergebnisse der vorliegenden Studie unterstützt.

\subsection{QUANTIFIZIERUNG VON PROPOFOL IN DER EXSPIRATIONSLUFT}

Um aus dieser Hypothese einen klinischen Nutzen zu ziehen, ist neben der Identifizierung auch die quantitative Bestimmung des Propofols notwendig. Die Ergebnisse der vorliegenden Studie zeigen, dass ausgehend von der hohen Korrelation $\left(\mathrm{r}^{2}=0,984\right)$ aus der Kalibrationsreihe BRMCC-IMS die Quantifizierung von Propofol in einem feuchten Gasgemisch präzise möglich ist. Die relative Standardabweichung der Methode ist mit im Mittel 2,5\% sehr gering. Die Vergleichbarkeit von Kalibrationsgas und Exspirationsluft vorausgesetzt, ist somit auch die Quantifizierung des in der Exspirationsluft nachgewiesenen Propofols möglich.

Um die Quantifizierung des Propofols an Hand der gemessenen Signalintensität zu standardisieren wurde der Reaktionsionen-Peak als kontinuierliche, interne Kalibrierung genutzt. Die gemessene Signalintensität des Analyten wurde auf eine definierte Intensität (1 Volt) der Reaktionsionen korrigiert. Das auf diese Weise am RIP normierte Signal wurde über die Kalibrationsreihe zur Kalkulation der Analytmenge genutzt. Diese Methodik bietet somit nach Kalibration die Möglichkeit einer präzisen Quantifizierung.

Die verschiedenen angewandten massenspektrometrischen Techniken sind bezüglich der Quantifizierung von Substanzen in zwei Gruppen zu betrachten. Zum einen die indirekte Massenspektrometrie (GC-MS) und zum anderen die direkte Massenspektrometrie (PTR-MS, IMR-MS).

Eine Konzentrationsbestimmung ist mittels GC-MS präzise durchführbar. Der Vorteil dieser zeitversetzten Methode besteht in der Möglichkeit, über einen in den inerten Transportbehälter zugeführten internen Standard eine relative Bezugsgröße zu ermitteln. Mit Hilfe von zuvor durchgeführten Kalibrationsreihen und der definierten Menge des internen Standards ist die Konzentrationsbestimmung in nmol/L möglich (Miekisch et al. 2008). Die relative 
Standardabweichung der Kalibrationsreihe wurde von den Autoren mit im Mittel 8,5\% angegeben $(n=6)$. Die Kalibrationsreihe BR-MCC-IMS aus der vorliegenden Studie zeigte mit einer deutlich geringeren relativen Standardabweichung von im Mittel 2,5\% ( $n=24)$ eine höhere Präzision.

In einer weiteren GC-MS-Studie zur Quantifizierung von Propofol in der Exspirationsluft von Säugetieren wurde kein interner Standard verwendet. Hier wurde bei einer durchgeführten Kalibrationsreihe $(n=21)$ eine relative Standardabweichung von im Mittel 12,1\% gemessen (Grossherr et al. 2006).

Eine potentielle Fehlerquelle bei der Quantifizierung von Substanzen mittels indirekter Massenspektrometrie stellt die Präkonzentration dar. Es werden Adsorbantien in Probenröhrchen (z.B. Tenax) oder auf Mikrofasern (SPME) verwendet, die zur Messung thermodesorbiert werden. Alle in der Probe enthaltenen Substanzen konkurrieren untereinander um die Adsorption. Je nach Zusammensetzung der Probe führt dies unter Umständen zu unterschiedlichen Adsorptionsverhältnissen der Substanzen. Die humane Exspirationsluft stellt ein in ihrer Zusammensetzung sehr variables Medium dar. Unterschiede sind nicht nur interindividuell, sondern durch Konzentrationsunterschiede auch intraindividuell zu erwarten.

Bei den direkten massenspektrometrischen Verfahren ist der Einsatz eines in seiner Menge definierten internen Standards nicht möglich, da die Probe unmittelbar nach Entnahme analysiert wird.

Die Forschungsgruppe um Hornuss verwendete 2007 im Sinne einer Standardisierung die cpsWerte der zur Ionisation eingesetzten Quecksilberionen. Die aus der IMR-MS-Analyse stammenden cps-Werte des Propofol-Signals wurden durch die der Quecksilberionen dividiert. Hieraus resultierte ein dimensionsloser Wert, der eine relative Bestimmung der PropofolKonzentration ermöglichte. Die nicht standardisierten cps-Werte zeigten deutliche interindividuelle Abweichungen bei erwarteten identischen Konzentrationen. Dies würde lediglich eine Beurteilung einer intraindividuellen Konzentrationsänderung erlauben, jedoch 
keine Quantifizierung ermöglichen. Mit Hilfe des Quotienten aus Propofol- und Quecksilberionen-Signal wurde dieses Problem gelöst (Hornuss et al. 2007). Eine Kalibration an definierten Propofol-Konzentrationen wurde durch die Forschungsgruppe um Hornuss nicht durchgeführt. Somit ist im beschriebenen Versuchsaufbau eine Quantifizierung des gemessenen exspiratorischen Propofols in einer gebräuchlichen SI-Einheit nicht möglich.

Bei PTR-MS-Analysen ist eine Berechnung der Konzentration in relative Mengenangaben [ppb ${ }_{v}$ ] aus den cps-Werten möglich. Hierzu werden die cps-Werte des Analyten mit denen der zur Ionisation eingesetzten Hydroniumionen in Beziehung gesetzt. Die Berechnung erfolgt mit Hilfe eines Korrekturfaktors, der die Parameter Temperatur, Druck, Reaktionskonstante, Fragmentierungsrate und einen Umrechnungsfaktor zwischen cps und $\mathrm{ppb}_{\mathrm{v}}$ beinhaltet. Die mathematisch ermittelten Werte können jedoch eine kalibrationsbedingte Abweichung von +/$30 \%$ aufweisen. Dies wird durch die Autoren auf eine problematische Herstellung des Kalibrationsgases zurückgeführt. Bei der Verdampfung des flüssigen Propofols in die Gasphase wurden Abweichungen von $+/-20 \%$ festgestellt (Takita et al. 2007). Die in der vorliegenden Arbeit ermittelte Kalibrationsreihe zeigt mit einer mittleren Standardabweichung von 2,5\% eine deutlich höhere Präzision.

\subsection{ERfassung Von Fragmenten und Metaboliten des Propofols}

Die Quantifizierung von Substanzen in der Exspirationsluft kann durch die Bildung von Fragmenten und Erfassung möglicher Metaboliten der Ausgangssubstanz erschwert werden. Die Metabolite werden in vivo gebildet. Die Fragmente entstehen während der Analyse innerhalb der Geräte. Je nach Methode werden Fragmente zusätzlich zum Ausgangs-Molekül oder ausschließlich detektiert. Eine Aussage über die Korrelation zwischen der exspiratorischen und plasmatischen Konzentration kann durch das Vorhandensein von Fragmenten und Metaboliten erschwert werden.

Im Fall des Propofols handelt es sich bei den Metaboliten um hypnotisch inaktive Substanzen, die vorwiegend in der Leber durch Glukuronidierung und Sulfatkonjukation entstehen (Ostwald 2004). Als volatile Metabolite konnten die Substanzen 2,6-Di-isopropyl-chinon und 2,6-Diisopropyl-hydrochinon in der humanen Exspirationsluft identifiziert werden (Harrison et al. 
2003). In der vorliegenden Arbeit wurde keine der Substanzen nachgewiesen. Denkbare Erklärungen hierfür sind eine Konzentration unterhalb der Nachweisgrenze beziehungsweise eine Retentionszeit außerhalb des untersuchten Zeitraums von 600 Sekunden. Eine längere Retentionszeit wäre durch die größere Molekülmasse beider Substanzen verglichen mit Propofol erklärbar.

Bei einigen der beschriebenen massenspektrometrischen Verfahren kommt es während der Ionisation der Proben zu einer Fragmentierung der Substanzen. Hierbei entsteht häufig ein Fragment mit einer Molekülmasse von 163 u. Dieses Fragment wurde sowohl in der vorliegenden Arbeit bei der Erstellung der Kalibrationsreihe GC-MS als auch von den Arbeitsgruppen Hornuss et al. (2007) und Miekisch et al. (2008) in der Exspirationsluft detektiert. Ob die während der Analyse entstehenden Fragmente ausschließlich aus Propofol oder auch aus dessen Metaboliten resultieren ist bisher nicht untersucht worden. Für die Kalibrationsreihe GC-MS ist dies auszuschließen, da in den nativen Serumproben nach Zugabe des Propofols kein Metabolismus zu erwarten ist.

Die Bedingungen innerhalb des Ionisationsraums und der Driftröhre eines IMS verhindern die Bildung von Fragmenten. Die Moleküle werden als Ganzes analysiert, was kombiniert mit der Vortrennung mittels MCC, eine quantitativen Mitbestimmung der Metabolite verhindert.

In den PTR-MS-Analysen von Harrison et al. (2003) wurden neben protoniertem Propofol (179 u) zwei Fragmente (95 u und 137 u) sowie die Metabolite des Propofols identifiziert. Die Entstehung der Fragmente war für die Fragestellung der Nachweisbarkeit der Substanz Propofol in der Atemluft nicht relevant, da keine Quantifizierung vorgenommen wurde. In einer weiteren PTR-MS-Analyse mit dem Ziel der Quantifizierung von Propofol konnte die Entstehung der Fragmente durch Veränderung der Driftspannung verhindert werden (Takita et al. 2007).

Hornuss et al. identifizierten 2007 mit einem IMR-MS zwei Peaks mit unterschiedlichen Massen als Propofol-Signale. Neben dem unfragmentierten ionisierten Propofol mit einer Masse von 178 u wurde ebenfalls das Fragment 163 u detektiert. Bei der Quantifizierung ergaben sich Unterschiede in der Korrelation zur Propofol-Konzentration im Plasma. Das Propofol-Fragment 
$163 \mathrm{u}$ weist insgesamt geringere cps-Werte auf und zeigt eine engere Korrelation mit der Plasmakonzentration (Hornuss et al. 2007).

Als ein Faktor, der die Menge des detektierbaren intakten Propofolmoleküls beeinflusst, konnte das Inhalationsnarkotikum Sevofluran identifiziert werden. Während der Ionisation reagierte intaktes Propofol mit Rückständen des Narkosegases. Eine Interaktion zwischen dieser Substanz und dem Propofol-Fragment konnte nicht beobachtet werden (Hornuss et al. 2007). Weitere Interaktionen von Propofol und anderen Substanzen in der Exspirationsluft oder dem Beatmungssystem sind nicht bekannt. Die Möglichkeit solcher Reaktionen zeigt jedoch auf, wie wichtig die separate Analyse der einzelnen Substanzen ist.

Bei der Verwendung eines GC-MS kommt es auf Grund der Elektronenstoß-Ionisation zu einer Fragmentierung des gesamten Propofols der Probe. Es resultiert ausschließlich ein Fragment mit einer Masse von $163 \mathrm{u}$ (Miekisch et al. 2008).

\subsection{KORRELATION ZWISCHEN EXSPIRATORISCHER UND INTRAVASALER PROPOFOL- KONZENTRATION}

Voraussetzung für ein exspiratorisches Drug-Monitoring ist eine Beziehung zwischen exspiratorischer und intravasaler Propofol-Konzentration. Durch Regressionsanalysen wurde die Korrelation für die verschiedenen Techniken untersucht. In den massenspektrometrischen Studien konnte eine Korrelation zwischen den beiden Konzentrationen nachgewiesen werden (Grossherr et al. 2006, Hornuss et al. 2007, Takita et al. 2007, Miekisch et al. 2008). Die Ergebnisse der vorliegenden Arbeit bestätigen eine solche Korrelation.

Neben den unterschiedlichen Techniken zur Atemgasanalyse bestehen zwischen den einzelnen Studien auch Unterschiede in dem zur intravasalen Konzentrationsbestimmung verwendeten Material (arteriell, gemischt-venös und venös/ Plasma, Vollblut und Serum). Im Folgenden werden Unterschiede und Gemeinsamkeiten der jeweiligen Ergebnisse dargestellt. 


\subsubsection{KORRELATION IM TIERMODELL}

An Hand zweier Tiermodelle wurde mittels Tenax-GC-MS eine Korrelation sowohl zwischen arteriellem wie auch venösem Plasma bezogen auf die exspiratorische Propofol-Konzentration nachgewiesen (Grossherr et al. 2006). Die gemessenen Konzentrationen in der Exspirationsluft lagen bei Schweinen ( 0 - 22 ppb) deutlich über denen von Ziegen (0 - 1,4 ppb). Für die Ziegen ergaben sich hieraus Korrelationen zwischen $r^{2}=0,760$ bis $0,979(\varnothing=0,887)$ für arterielles und 0,893 bis $0,985(\varnothing=0,930)$ für venöses Plasma. Bei der Untersuchung an Schweinen zeigten sich Werte zwischen $r^{2}=0,804$ und 0,895 $(\varnothing=0,858)$ für arterielles und 0,802 bis $0,906(\varnothing=0,857)$ für venöses Plasma. Die gemittelten Ergebnisse zeigen für das Tiermodell eine vergleichbare Korrelation sowohl für die arterielle wie auch für die venöse Plasmakonzentration verglichen mit der exspiratorischen Propofol-Konzentration.

\subsubsection{KORRELATION IN HUMANEN PATIENTENKOLLEKTIVEN}

In der vorliegenden Studie erfolgte der Vergleich der exspiratorischen Propofol-Konzentration mit der aus venösem Serum. Insgesamt wurden 24 Wertepaare in Regressionsanalysen eingeschlossen. Diese ergaben eine hohe Korrelation mit einem Korrelationskoeffizienten von $r=0,8550$ in der Regressionsanalyse 2.Art sowie einem $\beta=0,84$ in der Passing-BablokRegression. Ebenso wie im Tiermodell konnte somit ein enger Zusammenhang zwischen der exspiratorischen und venösen Propofol-Konzentration nachgewiesen werden.

Die Daten wurden des Weiteren einer Auswertung in einem Bland-Altman-Diagramm unterzogen. Dies ermöglicht eine Aussage bezüglich der systematischen Messabweichung, welche bei der Kalkulation des einen Parameters aus dem anderen auftritt. Die Ergebnisse dieser Studie zeigen, dass die Bestimmung der venösen Propofol-Konzentration mit einer Abweichung von $-10,5 \%$ aus der mittels BR-MCC-IMS ermittelten exspiratorischen Konzentration möglich ist.

Eine Bestimmung der systematischen Messabweichung wurde auch durch Takita et al. 2007 durchgeführt. In einem Patientenkollektiv bestehend aus 11 elektiv-chirurgischen Patienten 
wurden 24 exspiratorische Konzentrationen mittels PTR-MS bestimmt. Diese wurden ohne Angabe eines Korrelationskoeffizienten mit der Propofol-Konzentration in arteriellem Plasma verglichen. Die Analyse in einem Bland-Altman-Diagramm ergab eine systematische Messabweichung von 5,2\% (Takita et al. 2007). Auf Grund der von Takita et al. (2007) beschriebenen Problematik bei der Erstellung einer Kalibrationsreihe mit einer hohen Abweichung der verdampften Propofolmenge ist unter Umständen die systematische Messabweichung unpräzise. Daher ist kein Schluss über eine engere Korrelation zwischen arterieller beziehungsweise venöser versus der exspiratorischen Konzentration möglich.

Ein weiterer Vergleich zwischen arterieller und exspiratorischer Konzentration erfolgte in einer IMR-MS-Studie (Hornuss et al. 2007). Die Bestimmung der Blutkonzentration erfolgte in Vollblut-Proben. Der Blutkonzentration $[\mu \mathrm{g} / \mathrm{mL}]$ wurde das mittels Quecksilberionen korrigierte Propofol-Signal gegenübergestellt. Die Regressionsanalyse zeigte für die 49 Wertepaare einen Korrelationskoeffizienten von $r=0,85$.

Im Jahre 2008 untersuchten Miekisch et al. Blutproben aus verschiedenen Kreislaufsegmenten ( $n=16$, pro Patient eine Messung). Den Konzentrationen aus arteriellen, gemischt-venösen und venösen Vollblut-Proben wurden die Ergebnisse ihrer SPME-GC-MS-Analysen gegenübergestellt. Anders als in der vorliegenden Studie konnte keine Korrelation zwischen der venösen und exspiratorischen Konzentration gefunden werden (P-Wert >0,2). Dies gilt auch für die gemischtvenösen Proben (P-Wert > 0,7). Die Ergebnisse zeigten lediglich eine Korrelation ( $\left.\mathrm{r}^{2}=0,849\right)$ für die arteriellen Konzentrationen verglichen mit den Werten der Exspirationsluft (Miekisch et al. 2008).

Da in der vorliegenden Studie keine Bestimmung der arteriellen Konzentration erfolgte, ist ein Vergleich mit diesen Aussagen schwierig. Die Ergebnisse der vorliegenden Studie zeigen allerdings im Gegensatz zu der Arbeit von Miekisch et al. (2008) eine hohe Korrelation der Konzentrationen in venösem Serum und der Exspirationsluft. Diese Ergebnisse werden durch die Aussagen aus einem Tiermodell gestützt (Grossherr et al. 2006). 
Eine mögliche Ursache für die differierende Aussage bezüglich der Korrelation zwischen venöser und exspiratorischer Konzentration könnte die Methode der Konzentrationsbestimmung aus dem Medium Blut sein. Miekisch et al. untersuchten 2008 die Blutproben mittels highperformance liquid chromatography (HPLC). Dieses Verfahren wurde in weiteren Studien verwendet (Grossherr et al. 2006, Takita et al. 2007). Die Forschungsgruppe um Hornuss ermittelte die Propofol-Blutkonzentration durch liquid chromatography ion spray tandem mass spectrometry (Hornuss et al. 2007, Beaudry et al. 2005). In der vorliegenden Studie erfolgte die Konzentrationsbestimmung mittels GC-MS. Die hierfür durchgeführte Kalibrationsreihe zeigte eine hohe Korrelation der Ergebnisse mit einem Bestimmtheitsmaß von $r^{2}=0,9343$. Um die Ergebnisse folgender Studien besser vergleichen zu können erscheint eine Vereinheitlichung der Analyseverfahren zur intravasalen Konzentrationsbestimmung sinnvoll.

Ein weiterer Punkt, in dem sich die Studien unterscheiden, ist das zur Bestimmung der Blutkonzentration verwendete Material. Sowohl Vollblut (Horrnus et al. 2007, Miekisch et al. 2008), Plasma (Grossherr et al. 2006, Takita et al. 2007) als auch wie in der vorliegenden Arbeit Serum wurde verwendet. Ob das Untersuchungsmaterial Auswirkungen auf die Ergebnisse und eine mögliche Korrelation zur exspiratorischen Konzentration hat ist noch nicht ausreichend untersucht. Miekisch et al. untersuchten 2008 sowohl Vollblut (SPME-GC-MS) als auch Plasma (HPLC) von 7 Patienten. Sie fanden einen eindeutigen Zusammenhang beider Materialien, wobei die Propofol-Konzentration in Vollblut konstant höher als im Plasma war (Miekisch et al. 2008). In einer weiteren Studie wurde der Unterschied der Propofol-Konzentration in Vollblut und Plasma in verschieden Spezies (Mensch, Schwein, Schaf und Ziege) untersucht. Die Ergebnisse zeigten zum Teil eine deutliche Differenz zwischen und auch innerhalb der Spezies. Intraindividuell konnte jedoch nur ein leichter Unterschied registriert werden (Grossherr et al. 2007).

Dawidowicz und Kalitynski veröffentlichten 2005 Ergebnisse einer Studie, welche die Beeinflussung der freien Propofol-Konzentration in Plasma untersuchte. Diese zeigten dass das verwendete Antikoagulans bei der Gewinnung von Plasma-Proben keinen Einfluss auf die Menge des freien Propofols hat. Es konnte jedoch eine Veränderung im Zusammenhang mit Kühlung beziehungsweise längeren Gefrierung festgestellt werden (Dawidowicz und Kalitynski 2005). 
Insgesamt belegen die Studien, dass ein Zusammenhang zwischen der Propofol-Konzentration in Blut und Exspirationsluft vorliegt. Ob dies für Blut (Plasma, Serum oder Vollblut) aus allen Kreislaufsegmenten (arteriell, venös, gemischt-venös) zutrifft, sollte in weiteren Studien evaluiert werden, ebenso wie die Güte der Korrelation.

\subsection{Der ASPEKT Zeit in DER ATEMgaSANALYSE}

Die klinische Relevanz der quantitativen Bestimmung von Propofol in der Exspirationsluft ist abhängig von der schnellen Verfügbarkeit der Analyseergebnisse. Nur durch schnell vorliegende Ergebnisse ist eine Steuerung des für die Narkose gewünschten Wirkspiegels denkbar.

Für den Vergleich der verschiedenen atemgasanalytischen Verfahren bietet sich eine Unterteilung in Online-/Offline-Analysen an. Unter Online-Analysen sind solche Verfahren zu verstehen, bei denen Probennahme und Analyse räumlich nicht getrennt (bettseitig) und somit zeitlich kontinuierlich ablaufen können. Bei Offline-Analysen hingegen erfolgt nach der Probennahme ein Transport der Probe. Die eigentliche Analyse erfolgt räumlich getrennt und somit zeitversetzt.

Eine Sonderstellung innerhalb der Online-Analyse stellt die Real-time-Analyse dar. Real-timeAnalyse bedeutet bezogen auf die Atemgasanalyse eine kontinuierliche Konzentrationsbestimmung jedes Atemzugs mit multiplen Messungen sowohl während der Inals auch Exspiration. Voraussetzung hierfür sind ein geringes Probenvolumen, eine nur wenige Millisekunden dauernde Analyse und vor allem die Möglichkeit der Gemischanalyse ohne Vortrennung. Diese Voraussetzungen erfüllen lediglich die direkten massenspektrometrischen Verfahren wie PTR-MS (Harrison et al. 2003, Takita et al. 2007) oder IMR-MS (Hornuss et al. 2007). Auf Grund ihrer Ionisationsart können diese Verfahren ohne Vortrennung im SIM-Modus verwendet werden. Dadurch ist eine selektive Konzentrationsbestimmung einer Einzelsubstanz (Propofol) aus einem Gemisch (Atemluft) möglich.

Die Ionenmobilitätsspektrometrie stellt ein Online-Verfahren dar. Zeitlich unmittelbar nach Beendigung der Probennahme erfolgt die Analyse. Die Notwendigkeit einer Vortrennung und 
das benötigte Probenvolumen machen einen Einsatz zur Real-time-Analyse unmöglich. Für ein klinisch-relevantes Drug-Monitoring ist dies auch nicht zwingend erforderlich. Eine schnelle Online-Analyse der endtidalen Exspirationsluft wäre für diesen Einsatz ausreichend.

Unter den verwendeten Geräteeinstellungen wurde Propofol bei einer mittleren Retentionszeit von 474,5 Sekunden detektiert. Die Retentionszeit ist abhängig von Säulenlänge und Säulentemperatur sowie dem Trägergasfluss (Perl et al. 2010). Um eine Abschätzung des Einflusses der Säulentemperatur auf die Retentionszeit von Propofol zu ermöglichen, wurden im Institute for analytical sciences wiederholt Messungen bei verschiedenen Temperaturen durchgeführt. Hierbei konnte gezeigt werden, dass die Retentionszeit einer logarithmischen Funktion folgend mit steigender Temperatur deutlich abnimmt (siehe Abbildung 22).

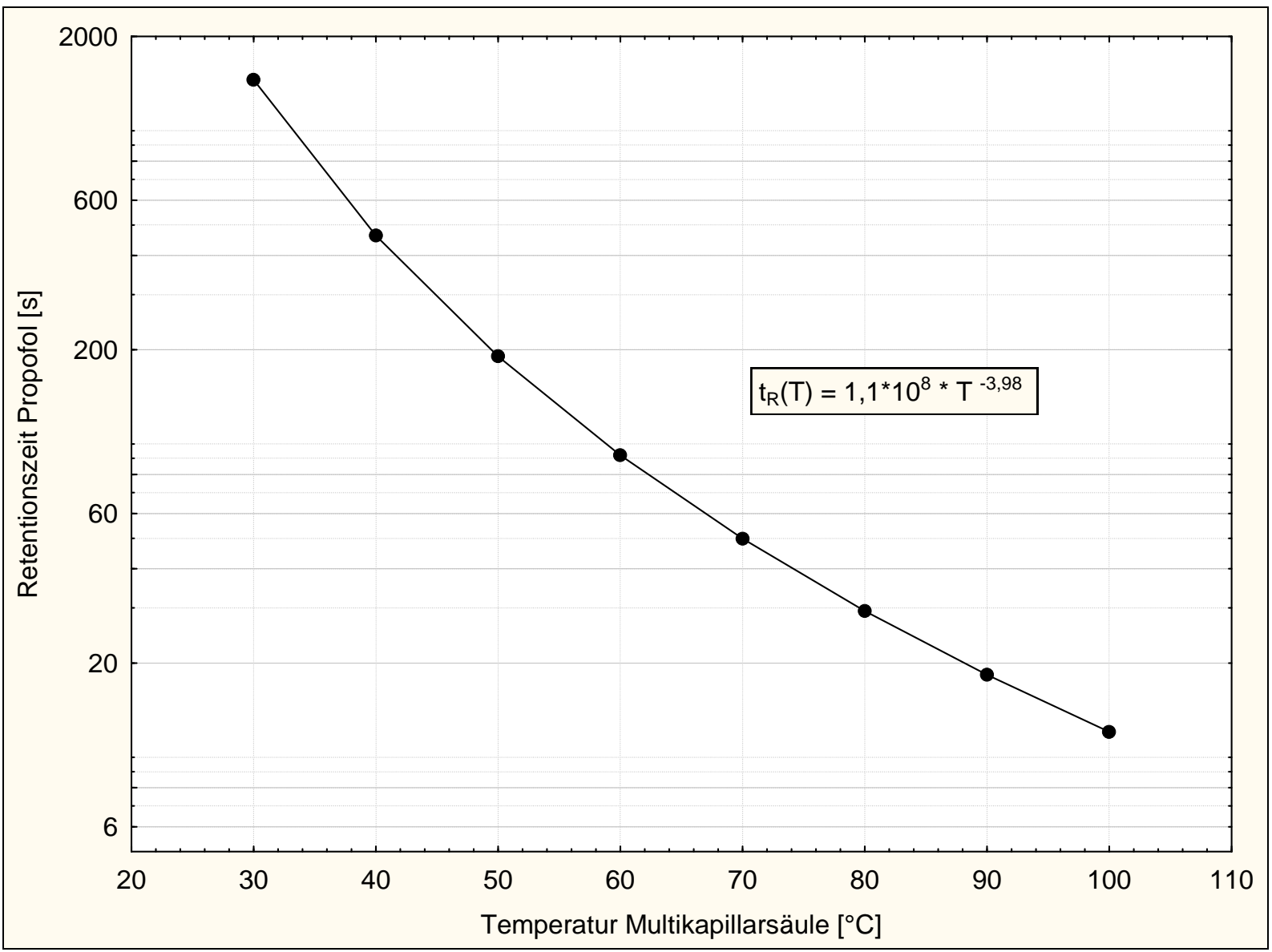

Abbildung 22. Logarithmische Darstellung des Einflusses der Säulentemperatur auf die Retentionszeit von Propofol. 
Eine Erhöhung der Säulentemperatur auf $100^{\circ} \mathrm{C}$ reduziert die Retentionszeit auf ungefähr 12 Sekunden. Durch Veränderungen der Säulenlänge beziehungsweise des Trägergasflusses könnte die Retentionszeit weiter verkürzt werde. Eine Halbierung der Säulenlänge verglichen mit der im Prototypen BR-MCC-IMS auf $10 \mathrm{~cm}$ würde eine Detektion von Propofol bereits nach weniger als 10 Sekunden ermöglichen.

Eine aus der Reduktion der Retentionszeit möglicherweise resultierende Koelution mit anderen Bestandteilen der Exspirationsluft könnte die Quantifizierung von Propofol erschweren. Unter den verwendeten Geräteeinstellungen wurden in den Patientenproben neben Propofol ausschließlich Substanzen mit einer Retentionszeit kleiner 120 Sekunden detektiert. Da sich die Retentionszeit aller Substanzen verringern würde, wäre eine Koelution mit diesen Substanzen nicht zu erwarten. Somit wäre eine schnelle Online-Analyse ( $<60$ Sekunden) und Quantifizierung mittels MCC-IMS möglich.

Bei den von den Arbeitsgruppen um Grossherr und Miekisch verwendeten Verfahren handelt es sich um Offline-Analysen. Die Kombination aus Gaschromatograph und Massenspektrometer ist nicht transportabel und bettseitig einsetzbar. Dies macht einen Transport der Probe notwendig. Diese Methoden sind demnach für eine zeitnahe Bestimmung der intravasalen PropofolKonzentration ungeeignet. 


\subsection{LIMITATIONEN}

Für einen klinischen Einsatz der Ionenmobilitätsspektrometrie bestehen gegenwärtig noch Limitationen. Im Folgenden werden diese unterteilt in technische, pharmakologische und pathophysiologische Limitationen erläutert.

\subsubsection{TECHNISCHE LIMITATIONEN}

\subsubsection{Probennahmetechnik}

Die höchste Präzision für eine Ermittlung der intravasalen Konzentration von Propofol über die Messung der exspiratorischen Konzentration ist bei der Analyse von endexspiratorischen Proben zu erwarten. Hierfür ist eine präzise, schnelle und reproduzierbare Bestimmung der endexspiratorischen Phase eines Atemzykluses erforderlich. Dies gilt insbesondere für die Online-/Offline-Analysen, da der Zeitpunkt der Probennahme in dieser Phase erfolgt. Durch die kontinuierliche Bestimmung der Propofol-Konzentration sind die Real-time-Verfahren nicht zwingend auf eine Bestimmung der endexspiratorischen Phase angewiesen. Erfolgen die Messung mit einer ausreichend hohen Frequenz, entspricht die höchste gemessene Konzentration der in der endexspiratorischen Phase. Die hier in der Arbeit diskutierten Realtime-Verfahren (Hornuss et al. 2007, Takita et al. 2007) bestimmten die endexspiratorische Phase zusätzlich und synchronisierten ihre Messwerte daran.

Eine Möglichkeit zur Ermittlung der endexspiratorischen Phase ist die Bestimmung des $\mathrm{CO}_{2}$ Gehalts der Atemluft. In der vorliegenden Arbeit erfolgte dies wie in weiteren Studien (Grossherr et al. 2006, Miekisch et al. 2008) nach dem von Schubert et al. (2001) beschriebenen Verfahren mittels Hauptstromsensor.

Alternativ zu den Hauptstromsensoren ist auch die Entnahme der Atemluft zur Bestimmung des $\mathrm{CO}_{2}$-Gehalts in einem separaten Detektor möglich. Ein solches sidestream-Verfahren wurde von Hornuss et al. (2007) angewandt. Parallel zur Probennahme für die IMR-MS-Analyse erfolgte eine Entnahme weiterer Exspirationsluft. Diese wurde über eine eigene Probenleitung einem 
zweiten Massenspektrometer zugeführt, in welchem die $\mathrm{CO}_{2}$-Konzentration mit einer Frequenz von 100 ms bestimmt wurde. Das Signal wurde simultan zu dem des IMR-MS aufgezeichnet. Die letzte aus der real-time-Analyse resultierende Propofol-Konzentration vor Abfall des $\mathrm{CO}_{2}$ Gehalts wurde als endexspiratorisch definiert (Hornuss et al. 2007).

Eine Bestimmung der endexspiratorischen Phase ist nicht nur durch Bestimmung des $\mathrm{CO}_{2}$ Gehaltes sondern auch durch Messung der Temperatur denkbar. Mit Hilfe von sensiblen DigitalThermometern kann die Temperatur innerhalb des Beatmungssystems kontinuierlich gemessen werden (Takita et al. 2007).

Das Institute for analytical scienses und das Zentrum für Anaesthesiologie, Rettungs- und Intensivmedizin der Universitätsmedizin Göttingen verglichen mit dem Ziel einer Optimierung der Probennahme verschiedene Techniken. Untersucht wurde die Bestimmung der endexspiratorischen Phase unter maschineller Beatmung durch Feuchte- beziehungsweise Kohlenstoffdioxidgehalt sowie Fluss und Volumen der Exspirationsluft. Bei allen untersuchten Verfahren handelt es sich um Hauptstromsensoren. Die Ergebnisse zeigen dass die Bestimmung der endexspiratorischen Phase mittels Feuchte-, $\mathrm{CO}_{2}$ - und Volumensensoren möglich ist, jedoch nicht durch Messung des Flusses. Für eine Steuerung der Probennahme eignen sich in erster Linie die $\mathrm{CO}_{2^{-}}$und Volumensensoren. Allerdings sind auch diese Verfahren nicht ohne Limitation. Für die Steuerung mittels Volumensensoren ist eine patientenindividuelle Kalibrierung erforderlich, da das Atemzugvolumen physiologisch signifikant unterschiedlich ist. Der untersuchte $\mathrm{CO}_{2}$-Sensor weist eine zeitliche Verzögerung von $300 \mathrm{~ms}$ auf. Hierdurch ist bei einer hohen Atemfrequenz und einhergehender Verkürzung der endexspiratorischen Phase eine exakte Abgrenzung zur Frühphase der Inspiration nicht sicher gegeben (Vautz et al. 2010).

Der in der vorliegenden Arbeit verwendete $\mathrm{CO}_{2}$-Sensor ist identisch mit dem aus der Untersuchung von Vautz et al. (2010). Die Beatmungsparameter der vorliegenden Untersuchung mit einer mittleren Atemfrequenz von 12 pro Minute und einem Inspiration/ExspirationVerhältnis von im Mittel 1:1,5 machen eine fehlerhafte Probennahme unwahrscheinlich. Sollte es doch zu minimalen Beimengungen von Inspirationsluft in den Proben gekommen sein, wäre dies bei allen Probanden gleichermaßen aufgetreten. Hierdurch wäre die Problematik für die vorliegenden Ergebnisse zu vernachlässigen. 
Die relative Kürze eines Atemzykluses, besonders der endexspiratorischen Phase, machen präzise und schnelle Analysen zur Bestimmung der endexspiratorischen Phase notwendig. Eine Behebung dieser Problematik könnte die Anwendbarkeit und Qualität der Atemgasanalytik nochmals steigern. Dies gilt vor allem für die Online-/Offline-Verfahren, bei denen die Probennahme ausschließlich in der endexspiratorischen Phase erfolgt. Das bestgeeignete Verfahren hierfür wäre ein $\mathrm{CO}_{2}$-Hauptstrom-Sensor, der eine zeitliche Verzögerung von maximal $50 \mathrm{~ms}$ aufweisen würde (Vautz et al. 2010). Ein wie durch Hornuss et al. (2007) verwendetes sidestream-Verfahren eignet sich auf Grund der relativ langen Detektionszeit (Verweildauer in Probenleitung und Analyse im MS) nicht zum Steuern einer Probennahme für Online-Verfahren wie der Ionenmobilitätsspektrometrie. Das beschriebene sidestream-Verfahren ist verglichen mit einem Hauptstromsensor darüber hinaus auch kostenintensiv und mit einem hohen technischen Aufwand verbunden.

\subsubsection{Rückatmung von Propofol}

In einer Real-time-Analyse wurde Propofol nicht nur in der Exspirations- sondern auch in der Inspirationsluft nachgewiesen (Takita et al. 2007). Der Nachweis von Propofol in der Inspirationsluft könnte darauf hinweisen, dass es während der Inspiration zu einer Rückatmung des bereits abgeatmeten Propofols gekommen ist. Die in der Anästhesie gebräuchlichen Respiratoren basieren auf einem Kreissystem, welches dies ermöglichen kann (siehe Abbildung 23). Hierdurch wäre eine fehlerhafte Analyse der endexspiratorischen Konzentration durch Kumulation anzunehmen. Um dies zu verhindern, wurde in der vorliegenden Arbeit ein Beatmungsmodus verwendet, dessen AirFlow größer als das Atemminutenvolumen war. Dadurch wurde sichergestellt, dass keine Exspirationsluft erneut in den Inspirationsschenkel gelang. Um falsch hohe Konzentrationsbestimmungen in der Exspirationsluft zu vermeiden sollte die Ionenmobilitätsspektrometrie nur unter solchen Bedingungen eingesetzt werden. Es resultiert ein höherer Verbrauch an medizinischem Sauerstoff. 


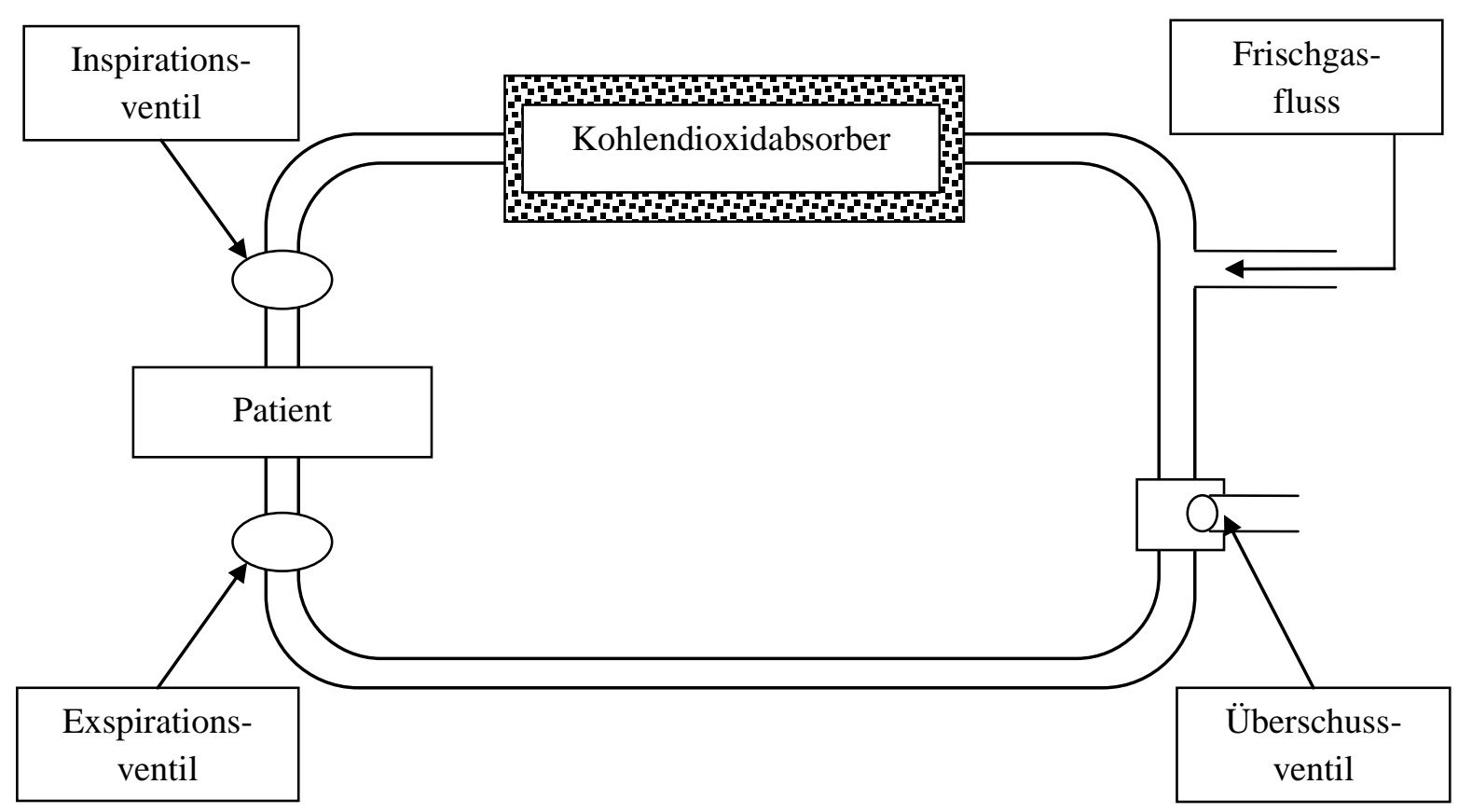

Abbildung 23. Schematische Darstellung eines in der Anästhesiologie gebräuchlichen Kreissystems für Respiratoren. (vgl. Simon 2004, S. 413) Ein Frischgasfluss (AirFlow) größer dem Atemminutenvolumen sorgt für ein Entweichen der Exspirationsluft über das Überschussventil. Eine Rückatmung der propofolhaltigen Exspirationsluft wird demnach verhindert.

\subsubsection{Dimerbildung bei hohen Analyt-Konzentrationen}

Ein mögliches Problem der Analyse mittels Ionenmobilitätsspektrometrie stellt die Bildung von Dimeren dar. Diese können bei hohen Konzentrationen der Analytmoleküle entstehen. Eine Konzentrationsbestimmung bei Vorliegen von Dimeren würde eine Erweiterung der Kalibrationsreihe erforderlich machen. Im aktuellen Patientenkollektiv und den untersuchten klinisch relevanten Atemluftkonzentrationen konnte keine Dimer-Bildung festgestellt werden. Diese ist auch in anderen Kollektiven nicht zu erwarten, da die hierfür erforderliche exspiratorische Konzentration vermutlich deutlich außerhalb des therapeutischen Bereichs liegt und nur bei einer massiven Überdosierung auftreten würde.

\subsubsection{PHARMAKOKINETISCHE LIMITATIONEN}

Wie in der Einleitung beschrieben unterliegt Propofol der Verteilung nach einem 3Kompartiment-Modell. Bis zum Erreichen einer annähernd stabilen Verteilung (steady-state) der 
Substanz in die drei Kompartimente ist eine Konzentrationsbestimmung nicht sinnvoll. Erst im steady-state erlaubt die Bestimmung der intravasalen Konzentration eine Aussage über die Konzentration und somit die Wirkung am Zielorgan ZNS. Während der Distributionsphase ist dies nicht möglich. Die hohe Konzentration im zentralen Kompartiment würde falsch hohe Werte für die peripheren Kompartimente ergeben.

Die Forschungsgruppe Takita et al. zeigte 2007 durch Real-time-Analysen den Verlauf der exspiratorischen Konzentration in der Distributionsphase nach Bolusapplikation. Der exspiratorische Nachweis von Propofol erfolgte im Mittel 42 Sekunden nach Bolusapplikation. Bei alleiniger Bolusgabe wurde das Maximum des nachweisbaren exspiratorischen Propofols nach im Mittel 333 Sekunden detektiert. In dieser dynamischen Phase ist der Einsatz der Atemgasanalytik im Sinne einer Narkosesteuerung limitiert. Dies berücksichtigend wurden in der vorliegenden Studie ausschließlich Messungen bei anzunehmendem steady-state durchgeführt. Die Probennahme erfolgte daher frühestens 15 Minuten nach Narkoseeinleitung. In einer jüngeren Studie (Grossherr et al. 2009) zeigte sich in einem Kollektiv bestehend aus 12 kardiochirurgischen Patienten, dass sich kein Gleichgewicht innerhalb der ersten 20 Minuten nach Narkoseeinleitung einstellt. Die Autoren beschreiben allerdings auch das Fehlen eines Gleichgewichts in anderen Phasen der Narkose.

Ein genaues Verständnis der Pharmakokinetik von Propofol ist Voraussetzung für die Interpretation der Ergebnisse aus atemgasanalytischen Verfahren. Für eine mögliche klinische Anwendung ist $\mathrm{zu}$ beachten, dass die Dauer der Distributionsphase patientenindividuell variieren kann. Der Einfluss individueller Faktoren wie die Höhe des Körperfettanteils oder das Vorliegen einer Leberinsuffizienz sollte in nachfolgenden Studien gezielt untersucht werden.

Eine weitere Limitation ergibt sich möglicherweise aus der Plasmaproteinbindung von Propofol. Ausschließlich das freie, nichtproteingebundene Propofol ist eliminierbar und kann somit in der Exspirationsluft detektiert werden. Sowohl in der vorliegenden Arbeit wie auch in den Studien anderer Autoren wird die exspiratorische allerdings mit der intravasale Gesamtkonzentration bestehend aus freiem und proteingebundenem Propofol verglichen. Dawidowicz et al. konnten in verschiedenen Studien zeigen, dass das Verhältnis von freiem und proteingebundenem Propofol nicht konstant ist. Beeinflusst wird dieses Verhältnis durch verschiedene Faktoren. Zunächst ist die Proteinbindung abhängig von der intravasalen Gesamtkonzentration. Bei niedrigen Konzentrationen zeigt sich prozentual eine deutlich geringere Proteinbindung als bei 
hohen Konzentrationen. Dieses Phänomen ist darüber hinaus auch temperaturabhängig. Der prozentuale Anteil des freien Propofols bei identisch niedriger Gesamtkonzentration liegt bei einer Temperatur von $40^{\circ} \mathrm{C}$ um etwa $5 \%$ über der bei $10^{\circ} \mathrm{C}$. Bei zunehmender Gesamtkonzentration kommt es zu einer Umkehr dieses Phänomens (Dawidowicz et al. 2008). Des Weiteren konnte gezeigt werden, das einige Infusionslösungen einen Einfluss auf die Menge des freien Propofols haben. Eine signifikante Abnahme des freien Propofols wurde bei der Verwendung von Hydroxyethylstärke (HAES) sowie fünfprozentiger Glucose-Lösung beobachtet. Keinen Einfluss auf das Verhältnis zwischen freiem und proteingebundenem Propofol haben Ringer- und Vollelektrolyt-Lösungen (Dawidowicz und Kalitynski 2005).

\subsubsection{PATHOPHYSIOLOGISCHE LIMITATIONEN}

Grundlage für eine Korrelation zwischen exspiratorischer und intravasaler PropofolKonzentration ist ein physiologisches Ventilations-Perfusions-Verhältnis. Besonders deutlich konnte dies in einem lungenchirurgischen Kollektiv gezeigt werden (Miekisch et al. 2008). Ein aus der Operation (Lungenlappen- bzw. Lungenflügelresektion) bei Einlungenventilation resultierender Rechts-Links-Shunt ging mit signifikant geringeren exspiratorischen bei gleichen arteriellen Konzentrationen einher.

Da es verschiedene Ursachen für eine pathologische Abweichung des Ventilations-PerfusionsVerhältnisses gibt, sollten nachfolgende Studien Patienten mit solchen Kriterien einschließen. Hierunter fallen Erkrankungen der Lunge aber auch Patienten mit anatomischen Anomalien (z.B. intrakardialer Shunt). Mit dem Ziel der generellen Machbarkeit sind in die vorliegende Studie als Probanden bewusst ausschließlich lungengesunde Patienten eingeschlossen worden.

Die Atemgasanalytik erfasst mit dem exspiratorischen Propofol lediglich einen der möglichen Eliminationswege. Die weitere Elimination erfolgt renal und biliär nach hepatischer aber auch extrahepatischer Biotransformation. Ob und wie weit pathophysiologische Störungen in diesen Systemen die exspiratorische Konzentration beeinflussen ist bislang ungeklärt. Ebenso ungeklärt ist, ob sich pathologische Veränderungen des Plasmaproteinspiegels negativ auswirken. 


\section{ZUSAMMENFASSUNG}

Das Injektionshypnotikum Propofol wird häufig im Rahmen der total intravenösen Anästhesie eingesetzt. Bei der Verwendung der Substanz können Komplikationen sowohl bei einer zu geringen als auch zu hohen Dosierung auftreten. Bei Fehlen einer Spiegel-Kontrolle erfolgt die Applikation bis heute klinisch und an Vitalparametern orientiert.

Eine neue Option für eine Dosis-Kontrolle wurde durch den massenspektrometrischen Nachweis von zuvor intravenös appliziertem Propofol in der humanen Exspirationsluft eröffnet. In verschiedenen Studien wurden die Quantifizierbarkeit der Substanz und eine mögliche Korrelation zur intravasalen Propofol-Konzentration untersucht. Unter Verwendung unterschiedlicher massenspektrometrischer Verfahren wurden diesbezüglich vielversprechende Ergebnisse erzielt, ohne dass sich bis heute ein Verfahren etablieren konnte.

Die vorliegende Studie untersucht die Möglichkeit des Nachweises und der Quantifizierung des Injektionshypnotikums Propofol in der humanen Exspirationsluft mittels Ionenmobilitätsspektrometrie.

Die Ionenmobilitätsspektrometrie ist ein etabliertes Verfahren innerhalb der analytischen Chemie. Bis zum heutigen Zeitpunkt erfolgt der Einsatz jedoch primär zu nicht medizinischen Zwecken wie beispielsweise der Sprengstoffdetektion. In der Ionenmobilitätsspektrometrie werden volatile Analyten zunächst ionisiert und anschließend in einem homogenen elektrischen Feld durch einen Driftgasfluss ihrer Mobilität nach aufgetrennt. Neben der analytenspezifischen Ionenmobilität wird eine Signalintensität detektiert. In dem gewählten Versuchsaufbau wurde das Ionenmobilitätsspektrometer mit einer Multikapillarsäule zur gaschromatograpischen Auftrennung der komplexen Matrix humaner Exspirationsluft gekoppelt. Aus der Auftrennung resultiert die Retentionszeit der Analyten. 
In einer zunächst durchgeführten Kalibrationsreihe wurde die Nachweisbarkeit von Propofol in einem der humanen Exspirationsluft nachempfundenen Gasgemisch belegt. Die Identifizierung der Substanz erfolgte anhand von Retentionszeit und Ionenmobilität. Zur Quantifizierung wurde die detektierte Signalintensität verwendet. Die Quantifizierung der Substanz gelang mit einer sehr hohen Genauigkeit $\left(\mathrm{r}^{2}=0,984\right)$.

Für die klinischen Untersuchungen wurden Messungen in einem chirurgischen Patientenkollektiv durchgeführt. Alle Probanden erhielten im Rahmen ihrer elektiven Operation eine total intravenöse Anästhesie, bei welcher Propofol als Hypnotikum eingesetzt wurde. Die Ergebnisse zeigen, dass auch in der humanen Exspirationsluft Propofol nachgewiesen und quantifiziert werden kann. Die gemessenen exspiratorischen Propofol-Konzentrationen zeigten eine enge Korrelation zu den synchron ermittelten Konzentrationen in venösem Serum (Korrelationskoeffizient $r=0,855$; Steigung $\beta=0,84$ aus Methodenvergleich nach Passing und Bablok 1983)). Durch die Ionenmobilitätsspektrometrie kann die Propofol-Konzentration im Serum mit einer mittleren Abweichung von -10,5\% kalkuliert werden. Die Messunsicherheit der Methode liegt bei 24,6\%.

Die Dauer bis zum Vorliegen der Ergebnisse ist für einen klinischen Einsatz nach der Genauigkeit der Ergebnisse der wichtigste Faktor. In dem gewählten Versuchsaufbau beträgt diese im Mittel 474,5 Sekunden, kann jedoch durch einfache technische Veränderungen auf deutlich unter 1 Minute reduziert werden, was den klinischen Einsatz als Online-Verfahren ermöglichen würde.

Ein Vorteil der Ionenmobilitätsspektrometrie gegenüber den massenspektrometrischen Verfahren ist der vergleichsweise geringe technische Aufwand der Messmethode. Insgesamt bestehen aber auch für die Ionenmobilitätsspektrometrie noch einige Limitationen für einen klinischen Einsatz. Diese sind zum Teil technischer Natur wie beispielsweise die exakte Bestimmung der endexspiratorischen Phase zur Probengewinnung. Weitere Limitationen begründen sich durch die Pharmakokinetik der Substanz selbst beziehungsweise durch Pathologien der Probanden. 
Insgesamt erscheint der Einsatz der Ionenmobilitätsspektrometrie im Sinne einer DosisKontrolle von Propofol denkbar. Das Verfahren liefert valide Ergebnisse mit einer hohen Präzision und ist als Online-Analyse einsetzbar. Verglichen mit massenspektrometrischen Verfahren benötigt die Ionenmobilitätsspektrometrie einen geringeren technischen Aufwand. Die pharmakokinetischen und pathophysiologischen Limitationen bestehen für alle Verfahren gleichermaßen und bedürfen weitergehender Untersuchungen. 


\section{ABKÜRZUNGSVERZEICHNIS}

$1 / \mathrm{K}_{0} \quad$ inverse reduzierte Ionenmobilität

$\alpha$

A

$\mathrm{AH}^{+}$

AMDIS

ASA

$\beta$

BMI

BR-MCC-IMS

C

$\mathrm{C}_{1}$

$\mathrm{C}_{\mathrm{AP}}$

$\mathrm{C}_{\mathrm{GP}}$

$\mathrm{C}_{\mathrm{PP}}$

CAS

CPS

$E_{d}$

$\mathrm{EX}+$

ExSC

FN+
Achsenabschnitt (Intercept)

Analytmolekül

Analytion

Automated Mass Spectral Deconvolution and Identification System

American Society of Anesthesiologists

Steigung (Slope)

Body-Mass-Index

Breath-Multikapillar-Ionenmobilitätsspektrometer

Kompartiment

Konzentration in einer Lösung

Propofol Konzentration Exspirationsluft

Propofol Konzentration Gasgemisch

Propofol Konzentration Serum

Chemical Abstracts Service

counts per second, auftreffende Ionen pro Sekunde

elektrisches Feld (Driftstrecke)

Exspirationsluftprobe in positiver Polarität

Externe Steuereinheit

Feuchte Null in positiver Polarität

Korrekturfaktor (nach Revercomb und Mason 1975) 
GC

GC-MS

HAES

HPLC

HS

$I_{(t)}$

IMR-MS

IMS

ISAS

i.v.

$\mathrm{K}_{0}$

$\mathrm{k}_{\mathrm{B}}$

$\mathrm{k}_{\mathrm{h}}$

$\mathrm{k}_{\mathrm{xy}}$

K

$l_{d}$

LOD

LOQ

$\mathrm{m}$

M

$\mathrm{M}_{\mathrm{m}}$

MAC

MCC

MCC-IMS

MS
Gaschromatograph

Gaschromatograph-Massenspektrometer

Hydroxyethylstärke

high-performance liquid chromatography

headspace, Dampfraum

Medikamentenzufuhr pro Zeit

Ionenmolekülreaktions-Massenspektrometer

Ionenmobilitätsspektrometer

Institute for Analytical Sciences

intravenös

reduzierte Ionenmobilität

Boltzmann-Konstante

Henry-Konstante

Transferkonstante zwischen den Kompartimenten X und Y

Ionenmobilität

Länge (Driftstrecke)

limit of detection, Nachweisgrenze

limit of quantification, Quantifizierungsgrenze

Ionenmasse

männlich

Masse der neutralen Driftgasmoleküle

minimal alveolar concentration, minimale alveolare Konzentration

Multi-Capillary-Column, Multikapillarsäule

Multikapillarsäulen-Ionenmobilitätsspektrometer

Massenspektrometer 


$\begin{array}{ll}\mathrm{n} & \text { Patientenkollektiv } \\ \mathrm{N} & \text { Molekülzahl } \\ \mathrm{NIST} & \text { National Institute of Standards and Technology }\end{array}$

$\Omega_{\mathrm{d}}\left(\mathrm{T}_{\text {eff }}\right) \quad$ temperaturabhängiger Stoßquerschnitt

$p_{\text {partial }} \quad$ Partialdruck

$\mathrm{p} \quad$ Druck

$\mathrm{p}_{0} \quad$ Druck unter Standardbedingungen

$\mathrm{pK}_{\mathrm{s}} \quad$ Dissoziationskonstante

ppb $\quad$ parts per billion $=10^{-9}=$ Teile pro Milliarde

ppt $\quad$ parts per trillion $=10^{-12}=$ Teile pro Billion

PTR-MS Protonentransferreaktions-Massenspektrometer

q $\quad$ Ladung

r Korrelationskoeffizient

$r^{2} \quad$ Bestimmtheitsmaß

REF Referenz

RIP Reaktionsionenpeak

RSD relative Standardabweichung

SD Standardabweichung

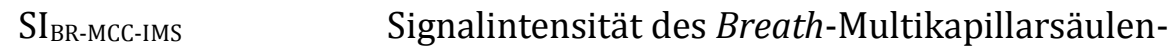
Ionenmobilitätsspektrometer

SIM single/selected ion monitoring

SPME solid phase microextraction, Festphasenmikroextraktion 


$\begin{array}{ll}\mathrm{t}_{\mathrm{d}} & \text { Driftzeit } \\ \mathrm{T} & \text { Temperatur } \\ \mathrm{T}_{0} & \text { Temperatur unter Standardbedingungen } \\ \mathrm{T}_{\mathrm{eff}} & \text { Temperatur des Driftgases } \\ \mathrm{TCI} & \text { target-controlled infusion, computergesteuerte Perfusoren } \\ \mathrm{TIC} & \text { total ion current, Totalionenstrom } \\ \mathrm{TIVA} & \text { total intravenöse Anästhesie } \\ \mathrm{UAW} & \\ \mathrm{V} & \text { unerwünschte Arzneimittelwirkung } \\ \mathrm{V} & \text { Driftgeschwindigkeit } \\ \text { VOC } & \text { volatile organic compounds, flüchtige organische Verbindungen } \\ \text { ZNS } & \text { zentrales Nervensystem } \\ & \end{array}$




\section{LITERATURVERZEICHNIS}

Amorim LCA, Cardeal ZdeL (2007): Breath air analysis and its use as a biomarker in biological monitoring of occupational and environmental exposure to chemical agents. J Chromatogr B 853 , $1-9$

Avidan MS, Zhang L, Burnside BA, Finkel KJ, Searleman AC, Selvidge JA, Saager L, Turner MS, Rao S, Bottros M, Hantler C, Jacobsohn E, Evers AS (2008): Anesthesia Awareness and the Bispectral Index. N Engl J Med $\underline{358}$ 1097-1108

Bader S, Urfer W, Baumbach JI (2008): Preprocessing of ion mobility spectra by lognormal detailing and wavelet transform. Int J Ion Mobil Spec 11, 43-49

Baumbach JI (2008): Ion mobility spectrometry in scientific literature and in the International Journal for Ion Mobility Spectrometry (1998-2007). Int J Ion Mobil Spec 11, 3-11

Baumbach JI, Eiceman GA (1999): Ion Mobility Spectrometry: Arriving On Site and Moving Beyond a Low Profile. Appl Spectrosc 53, 338A-355A

Baumbach JI, Eiceman GA, Klockow D, Sielemann $\quad$ S, Irmer AV (1997): Exploration of a Multicapillary Column for Use in Elevated Speed Gas Chromatography. Int J Env Anal Chem $\underline{66}, 225-239$

Baumbach JI, Sielemann S, Pilzecker P (2000): Coupling of Multi-Capillary Columns with two Different Types of Ion Mobility Spectrometer. Int J Ion Mobil Spec 3, 28-37

Beaudry F, Guenette SA, Winterborn A, Marier JF, Vachon P (2005): Development of a rapid and sensitive LC-ESI/MS/MS assay for the quantification of propofol using a simple off-line dansyl chloride derivatization reaction to enhance signal intensity. J Pharm Biomed Anal $\underline{39}, 411-417$ 
Bland JM, Altman DG (1986): Statistical methods for assessing agreement between two methods of clinical measurement. Lancet, 1986, II, 307-310

Bödeker B, Vautz W, Baumbach JI (2008 a): Visualisation of MCC/IMS-data. Int J Ion Mobil Spec $\underline{11}, 77-81$

Bödeker B, Vautz W, Baumbach JI (2008 b): Peak comparison in MCC/IMS-data - searching for potential biomarkers in human breath data. Int J Ion Mobil Spec $11,89-93$

Bruhn J, Myles PS, Sneyd R, Struys MMRF (2006): Depth of anaesthesia monitoring: what's available, what's validated and what's next? Br J Anaesth 97, 85-94

Budzikiewicz H: Massenspektrometrie - Eine Einführung, 4. Auflage Wiley-VCH, Weinheim 1998

Buszewski B, Kesy M, Ligor T, Amann A (2007): Human exhaled air analytics: biomarkers of diseases. Biomed Chromatogr 21, 553-566

Chamoun NG (2009): Annual Report 08, www.aspectmedical.com, download am 24.08.2009

Datenbank der United States National Library of Medicine, http://chem.sis.nlm.nih.gov/chemidplus/chemidlite.jsp

Dawidowicz AL, Kalitynski R (2005): Effects of intraoperative fluid infusions, sample storage time, and sample handling on unbound propofol assay in human blood plasma. J Pharm Biomed Anal 37 , 1167-1171

Dawidowicz AL, Fornal E, Mardarowicz M, Fijalkowska A (2000): The Role of Human Lungs in the Biotransformation of Propofol. Anesthesiology 93, 992-997 
Dawidowicz AL, Kobielski M, Pieniadz J (2008): Anomalous relationship between free drug fraction and its total concentration in drug-protein systems I. Investigation of propofol binding in model HSA solution. Eur J Pharm Sci $\underline{34}$, 30-36

Di Francesco F, Fuocob R, Trivellaa MG, Ceccarinib A (2005): Breath analysis: trends in techniques and clinical applications. Microchem J $\underline{79}, 405-410$

Domino KB, Posner KL, Caplan RA, Cheney FW (1999): Awareness during Anesthesia: A Closed Claims Analysis. Anesthesiology $\underline{90}$ 1053-1061

Duarte LTD, Saraiva RA (2009): When the Bispectral Index (Bis) can Give False Results. Rev Bras Anestesiol 59, 99-109

Ebert TJ (2005): Sympathetic and hemodynamic effects of moderate and deep sedation with propofol in humans. Anesthesiology 103, 20-24

Eiceman GA, Karpas Z: Ion mobility spectrometry, 2. Auflage CRC Press, London 2005

Enlund M (2008): TCI: Target Controlled Infusion, or Totally Confused Infusion? Call for an Optimised Population Based Pharmacokinetic Model for Propofol. Ups J Med Sci 113, 161-170

Excel-Tool Passing-Bablok-Regression der Firma acomed-statsik: http://www.acomedstatistik.de/passing-bablok-regression.html, Downloaddatum 19.12.2010)

Gey M: Instrumentelle Analytik und Bioanalytik, 2. Auflage, Springer-Verlag, Berlin, Heidelberg 2008 
Grossherr M, Hengstenberg A, Meier T, Dibbelt L, Gerlach K, Gehring H (2006): Discontinuous Monitoring of Propofol Concentrations in Expired Alveolar Gas and in Arterial and Venous Plasma during Artificial Ventilation. Anesthesiology 104, 786-790

Grossherr M, Spies E, Scheel A, Hengstenberg A, Gehring H, Dibbelt L (2007): Differences of Propofol Concentrations in Mammalian Whole Blood an in Corresponding Plasma Samples Analyzed by High Performance Liquid Chromatography. Clin Lab $\underline{53}$, 315-319.

Grossherr M, Hengstenberg A, Meier T, Dibbelt L, Igl BW, Ziegler A, Schmucker P, Gehring H (2009): Propofol concentration in exhaled air and arterial plasma in mechanically ventilated patients undergoing cardiac surgery. Br J Anaesth $\underline{102}$, 608-613

Hansel A, Jordan A, Holzinger R, Prazeller P, Vogel W, Lindinger W (1995): Proton transfer reaction mass spectrometry: on-line trace gas analysis at the ppb level. Int J Mass Spectrom $\underline{149 / 150}, 609-619$

Harrison GR, Critchley ADJ, Mayhew CA, Thompson JM (2003): Real-time breath monitoring of propofol and its volatile metabolites during surgery using a novel mass spectrometric technique: a feasibility study. Br J Anaesth 91, 797-799

Hill HH Jr, Siems WF, St. Louis RH, McMinn DG (1990): Ionmobility spectrometry. Anal Chem $\underline{62}$ 1201-1209

Hornuss C, Praun S, Villinger J, Dornauer A, Moehnle P, Dolch M, Weninger E, Chouker A, Fei C, Briegel J, Thiel M, Schelling G (2007): Real-time Monitoring of Propofol in Expired Air in Humans Undergoing Total Intravenous Anesthesia. Anesthesiology, 106, 665-674

Karasek FW, Keller RA (1972): Gas chromatograph/plasma chromatograph interface and its performance in the detection of musk ambrette. J Chromatogr Sci 10, 626-628 
Kay B, Rolly G (1977): ICI 35868, a new intravenous induction agent. Acta Anaesthesiol Belg $\underline{28}$ 303

Kharitonov SA, Barnes PJ (2001): Exhaled Markers of Pulmonary Disease. Am J Respir Crit Care Med $\underline{163}, 1693-1722$

Leslie K, Clavisi O, Hargrove J (2008): Target-controlled infusion versus manually-controlled infusion of propofol for general anaesthesia or sedation in adults. Cochrane Database Syst Rev 16, CD006059

MacDougall D, Crummett WB (1980): Guidelines for data acquisition and data quality evaluation in environmental chemistry. Anal Chem $\underline{52}, 2242-2249$

Marsh B, White M, Morton N, Kenny GN (1991): Pharmacokinetic model driven infusion of propofol in children. Br J Anaesth $\underline{67}, 41-48$

Mayevsky A, Manor T, Pevzner E, Deutsch A, Etziony R, Dekel N, Jaronkin A (2004): Tissue spectroscope: a novel in vivo approach to real time monitoring of tissue vitality J Biomed Opt $\underline{9}$ 1028-1045

Miekisch W, Schubert JK, Noeldge-Schomburg GFE (2004): Diagnostic potential of breath analysis-focus on volatile organic compounds. Clin Chim Acta 347, 25-39

Miekisch W, Fuchs P, Kamysek S, Neumann C, Schubert JK (2008): Assessment of propofol concentrations in human breath and blood by means of HS-SPME-GC-MS. Clini Chim Acta $\underline{395}$ 32-37 
Ostwald P: Hypnotika: Barbiturate, Propofol, Etomidate; in: Die Anästhesiologie; hrsg. v. Rossaint R, Werner C, Zwißler B unter Mitarbeit namhafter Autoren; Springer-Verlag, Berlin 2004, 211-222

Passing H, Bablok W (1983) A new biometrical procedure for testing the equality of measurements from two different analytical methods. Application of linear regression procedures for method comparison studies in clinical chemistry, Part I. J Clin Chem Clin Biochem $\underline{21}, 709-720$

Perl T, Bödeker B, Jünger M, Nolte J, Vautz W (2010): Alignment of Retention Time obtained from Multi-Capillary Column Gas-Chromatography. (Anal Bioanal Chem, im Druck)

Revercomb HE, Mason EA (1975): Theory of plasma chromatography/gaseous electrophoresis A Review. Anal Chem $\underline{47}$, 970-982

Roehl RE (1991): Environmental and Precess applications for Ion Mobility Spectrometry. Appl Spectrosc Rev 26, 1-57

Ruzsanyi V, Baumbach JI, Sielemann S, Litterst P, Westhoff M, Freitag L (2005): Detection of human metabolites using multi-capillary columns coupled to ion mobility spectrometers. J Chromatogr A 1084, 145-151

Schnider TW, Minto CF, Shafer SL, Gambus PL, Andresen C, Goodale DB, Youngs EJ (1999): The Influence of Age on Propofol Pharmacodynamics. Anesthesiology 90 1502-1516

Schubert JK, Spittler KH, Braun G, Geiger K, Guttmann J (2001): $\mathrm{CO}_{2}$-controlled sampling of alveolar gas in mechanically ventilated patients. J Appl Physiol 90, 486-492 
Schüttler J, Schwilden H: Pharmakologische Grundlagen; in: Die Anästhesiologie; hrsg. v. Rossaint R, Werner C, Zwißler B unter Mitarbeit namhafter Autoren; Springer-Verlag, Berlin 2004, 194-210

Sielemann S (1999): Detektion flüchtiger organischer Verbindungen mittels Ionenmobilitätsspektrometrie und deren Kopplung mit Multi-Kapillar-Gas-Chromatographie, Chem. Diss. Dortmund (Fachbereich Chemie der Universität Dortmund) 1999

Simon HB: Anästhesiesysteme und Beatmungsgeräte; in: Die Anästhesiologie; hrsg. v. Rossaint R, Werner C, Zwißler B unter Mitarbeit namhafter Autoren; Springer-Verlag, Berlin 2004, 411-421

Stach J, Baumbach JI (2002): Ion Mobility Spectrometry - Basic Elements and Applications. Int J Ion Mobil Spec, $\underline{5}, 1-21$

Struys MMRF, De Smet T, Depoorter B, Versichelen LFM, Mortier EP, Dumortier FJE, Shafer SL, Rolly G (2000): Comparison of Plasma Compartment versus Two Methods for Effect Compartment-controlled Targetcontrolled Infusion for Propofol. Anesthesiology 92, 399-406

Takita A, Masui K, Kazama T (2007): On-line Monitoring of End-tidal Propofol Concentration in Anesthetized Patients. Anesthesiology, 106, 659-664

Vautz W, Baumbach JI (2008): Exemplar application of multi-capillary column ion mobility spectrometry for biological and medical purpose. Int J Ion Mobil Spec 11, 35-41

Vautz W, Schmäh M (2009): HovaCAL ${ }^{\circledR}$ - a generator for multi-component humid calibration gases. Int J Ion Mobil Spec $\underline{12}, 139-147$

Vautz W, Bödeker B, Baumbach JI, Bader S, Westhoff M, Perl T (2009): An implementable approach to obtain reproducible reduced ion mobility. Int J Ion Mobil Spec $\underline{12}$ 47-57 
Vautz W, Baumbach JI, Westhoff M, Züchner K, Carstens ETH, Perl T (2010): Breath Sampling Control for Medical Application. Int J Ion Mobil Spec 13, 41-46

Westhoff M, Litterst P, Freitag L, Baumbach JI (2007): Ion mobility spectrometry in the diagnosis of sarcoidosis: results of a feasibility study. J Physiol Pharmacol, $\underline{58}$, 739-751 


\section{DANKSAGUNG}

Für die Ermöglichung zunächst meiner Dissertation und darüber hinaus der weiteren Mitarbeit an wissenschaftlichen Projekten danke ich meinem Doktorvater Prof. Dr. med. Michael Quintel.

In tiefster Dankbarkeit verbunden bin ich meinen wissenschaftlichen Betreuern Dr. med. Thorsten Perl sowie Dr. rer. nat. Wolfgang Vautz. Beiden ist es stets gelungen mir Möglichkeiten aufzuzeigen, mich aufs Neue zu motivieren, das Ziel als großes Ganzes nicht aus den Augen zu verlieren und neben diesem eigentlichen Ziel auch die verdiente Bühne zu betreten, das Erreichte zu präsentieren, mit Druck aber ohne Zwang. Neben dieser wissenschaftlichen Unterstützung habe ich auch menschlich von der Zusammenarbeit profitieren dürfen.

Meinen Dank möchte ich auch an verschiedene Mitarbeiter der an dem Projekt beteiligten Institutionen Ausdruck verleihen, die alle an dem Gelingen beteiligt gewesen sind. Dies sind für das Institute for Analytical Sciences Priv.-Doz. Dr. Jörg-Ingo Baumbach, Dr. Jürgen Nolte, Dr. Melanie Jünger und Luzie Seifert. Aus dem Zentrum für Anaesthesiologie, Rettungs- und Intensivmedizin der Universitätsmedizin Göttingen gilt mein Dank Claudia Ottersbach und Andrea Kernchen, sowie meinen Mitstreitern Tobias Gehrig, Lena Hofmann und Siobhán Ulbricht.

Ein besonderer Dank gilt all den Menschen aus meinem persönlichen Umfeld die mich in den vergangenen drei Jahren während der Erstellung dieser Promotion auf unterschiedlichste Weise unterstützt haben. Ohne ein Leben daneben wäre das Alles nicht möglich gewesen. 


\section{LEBENSLAUF}

Mein Name ist Eike Tillmann Habakuk Carstens, geboren wurde ich am 04.Februar 1980 in Braunschweig als zweites Kind meiner Eltern Trientje Carstens (geborene Hagen, Krankenschwester) und Gerhard Carstens (Apotheker). Ich habe einen älteren Bruder, Mimke Jan Hieronymus Carstens (21. Januar 1978).

Meine schulische Laufbahn begann ich 1986 an der Grundschule Hämelerwald mit anschließendem zweijährigem Besuch der Orientierungsstufe Lehrte Ost (1990-1992). Von 1992 an war ich Schüler des Gymnasium Lehrte, an dem ich im Jahre 2000 meine Abiturprüfung erfolgreich mit einer Abschlussnote von 2,4 ablegen konnte.

Im Sommer 2000 begann ich mit der Ableistung meines zivilen Ersatzdienstes auf der Rettungsdienstwache Lehrte des Deutschen Roten Kreuzes. Während der elfmonatigen Dienstzeit wurde ich zum Rettungssanitäter ausgebildet.

Im Jahr 2001 nahm ich ein Studium der Fächer Germanistik und Philosophie an der Leibnitz Universität Hannover auf. In dieser Zeit arbeitete ich als Regieassistent am Staatstheater Hannover. Das Studium und auch die Tätigkeit am Theater beendete ich jedoch bereits nach einem Jahr der Orientierungsphase, an deren Ende der Berufswunsch Mediziner stand.

Ab dem Sommer 2002 bewarb ich mich über die Zentrale Vergabestelle für Studienplätze um einen Studienplatz der Humanmedizin. Seit dieser Zeit weitete sich meine Tätigkeit im Rettungsdienst, die ich nach Beendigung des Ersatzdienstes weitergeführt hatte, auf eine Vollzeittätigkeit aus. Im September 2003 legte ich an der Rettungsdienstschule Ronnenberg der Johanniter meine staatliche Prüfung zum Rettungsassistenten mit der Note 2 ab.

Zum Sommersemester 2004 erhielt ich einen Studienplatz der Humanmedizin an der GeorgAugust Universität Göttingen. Den ersten Abschnitt der ärztlichen Prüfung absolvierte ich nach Beendigung des Wintersemesters 2005/2006 mit der Note 3,5. Derzeit bereite ich mich auf den bevorstehenden zweiten Abschnitt der ärztlichen Prüfung nach Regelstudienzeit im Anschluss an das Wintersemester 2009/2010 vor.

Während meines Studiums der Humanmedizin arbeitete ich weiterhin als Teilzeitkraft im Rettungsdienst. Ich famulierte in verschiedenen Fachgebieten (Anästhesiologie und Urologie an der Universitätsmedizin Göttingen, Innere Medizin am Nordstadtkrankenhaus Hannover, Praxis für Radiologie in Göttingen). Mein Praktisches Jahr absolvierte ich am Helios-Albert-Schweitzer 
Krankenhaus Northeim (Viszeral- und Unfallchirurgie), dem Zentrum für Anaesthesiologie, Rettungs- und Intensivmedizin der Universitätsmedizin Göttingen und im evangelischen Krankenhaus Weende (Innere Medizin).

Seit Januar 2007 habe ich mich wissenschaftlich in der Forschungsgruppe Atemgasanalyse im Zentrum für Anaesthesiologie, Rettungs- und Intensivmedizin (Direktor Prof. Dr. med. M. Quintel) engagiert. Unter der Leitung von Herrn Dr. med. Thorsten Perl konnte ich in dieser Arbeitsgruppe die Datenerhebung zu meiner Dissertationsschrift durchführen. Das Zentrum ermöglichte mir die Ergebnisse auf verschiedenen Kongressen und Symposien vorzustellen. Neben der Datenerhebung für meine Dissertationsschrift war ich wissenschaftlich tätig im Bereich der experimentellen Pneumoniediagnostik sowie der protektiven Beatmung.

\section{Vorträge}

Breath 2009 - International Conference on Breath and Breath Odor Research, 26.-30.April 2009, Dortmund

Poster: Propofol measurment in expiered air using Multi-Capillary Column Ion Mobility Spectrometry (MCC-IMS); 28.April

Vortrag: Propofol measurment in expiered air using Multi-Capillary Column Ion Mobility Spectrometry (MCC-IMS); 29.April invited speaker

ISIMS $2009-18^{\text {th }}$ International Conference on Ion Mobility Spectrometry, 25.-31.Juli 2009, Thun, Schweiz

Vortrag: Propofol measurment in expired air using Multi-Capillary Column Ion Mobility Spectrometry (MCC-IMS); 27. Juli accepted speaker

BS-Analytik Symposium: Metabolite in der Exspirationsluft, 22.September 2009, Dortmund

Vortrag: Bestimmung der Serum-Propofolkonzentration durch Atemgasanalyse mittels IMS - online Narkosemonitoring; invited speaker

\section{$\underline{\text { Publikationen }}$}

Perl T, Carstens E, Hirn A, Quintel M, Vautz W, Nolte J, Jünger M (2009): Determination of serum propofol concentrations by breath analysis using ion mobility spectrometry $\mathrm{Br} \mathrm{J}$ Anaesth $\underline{103}, 822-827$

Carstens E, Hirn A, Quintel M, Nolte J, Jünger M, Perl T, Vautz W (2010): On-Line Determination of Serum Propofol Concentrations by Expired Air Analysis Int J Ion Mobil Spec $13,37-40$

Vautz W, Baumbach JI, Westhoff M, Züchner K, Carstens ETH, Perl T (2010): Breath Sampling Control for Medical Application Int J Ion Mobil Spec 13, 41-46 